\author{
UNIVERSIDADE DE SÃO PAULO \\ INSTITUTO DE FÍSICA DE SÃO CARLOS \\ INSTITUTO DE QUÍMICA DE SÃO CARLOS \\ ESCOLA DE ENGENHARIA DE SÃO CARLOS
}

ROGER GOMES FERNANDES

INFLUÊNCIA DE PbF 2 NAS PROPRIEDADES FÍSICAS E ESTRUTURAIS DE VIDROS BORATOS CONTENDO ÓXIDO DE METAIS PESADOS 

ROGER GOMES FERNANDES

\section{INFLUÊNCIA DE PbF 2 NAS PROPRIEDADES FÍSICAS E ESTRUTURAIS DE VIDROS BORATOS CONTENDO ÓXIDO DE METAIS PESADOS}

Dissertação apresentada ao Programa de PósGraduação Interunidades em Ciência e Engenharia de Materiais, da Universidade de São Paulo, para obtenção do título de Mestre em Ciência e Engenharia de Materiais.

Área de Concentração: Desenvolvimento, Caracterização e Aplicação dos Materiais.

Orientador: Prof. ${ }^{\text {a }}$ Dra Andréa Simone Stucchi de Camargo Alvarez Bernardez

São Carlos 
AUTORIZO A REPRODUÇÃO E DIVULGAÇÃO TOTAL OU PARCIAL DESTE TRABALHO, POR QUALQUER MEIO CONVENCIONAL OU ELETRÔNICO, PARA FINS DE ESTUDO E PESQUISA, DESDE QUE CITADA A FONTE.

Ficha catalográfica preparada pela Seção de Atendimento ao Usuário do Serviço de Biblioteca EESC/USP

\begin{tabular}{|c|c|}
\hline \multirow[t]{3}{*}{ F363i } & $\begin{array}{l}\text { Fernandes, Roger Gomes } \\
\quad \text { Influência de } \mathrm{PbF}_{2} \text { nas propriedades físicas e } \\
\text { estruturais de vidros boratos contendo óxidos de metais } \\
\text { pesados. / Roger Gomes Fernandes ; orientadora Andréa } \\
\text { Simone Stucchi de Camargo Alavrez Bernardez. São Carlos, } \\
2012 \text {. }\end{array}$ \\
\hline & $\begin{array}{l}\text { Dissertação (Mestrado) - Programa de Pós-Graduação } \\
\text { Interunidades em Ciências e Engenharia de Materiais e } \\
\text { Área de Concentração em Desenvolvimento, Caracterização e } \\
\text { Aplicação de Materiais -- Escola de Engenharia de São } \\
\text { Carlos da Universidade de São Paulo, 2012. }\end{array}$ \\
\hline & $\begin{array}{l}\text { 1. Vidros Oxifluoroboratos de chumbo. 2. RMN estado } \\
\text { sólido. 3. Vidros óxidos de metais pesados. I. Título. }\end{array}$ \\
\hline
\end{tabular}


Este exemplar foi revisado e alterado em relação ao original seguindo as orientações da comissão julgadora, sob a exclusiva responsabilidade do autor.

São Carlos, 22 de Agosto de 2012. 

Dedico este trabalho a minha sobrinha Alice, futura cientista que através da curiosidade e pela emoção de novas descobertas buscará no oceano cada gota necessária para construir seu conhecimento. 



\section{AGRADECIMENTOS}

Agradeço especialmente a minha orientadora, Prof. Dr ${ }^{\mathrm{a}}$. Andrea Simone Stucchi de Camargo Alvarez Bernardez pela ajuda na elaboração desta dissertação, pelas discussões para o enriquecimento do trabalho, seu grande incentivo no decorrer do projeto e por sua amizade e companheirismo por todo o período do meu mestrado.

A CNPq pelo apoio financeiro.

Ao Prof. Dr Hellmut Eckert que me proporcionou os conhecimentos básicos necessário para compreender os conceitos físicos de Ressonância Magnética Nuclear envolvida neste projeto, bem como a realização de um estágio de curta duração na Westfälishe Wilhelm Universität Münster, em Muenster, Alemanha.

Ao pós doutorando Jinjun Ren, da Westfälishe Wilhelm Universität Münster, por auxiliar-me em todos os experimentos de RMN contidos neste trabalho.

As pessoas responsáveis pelo funcionamento do laboratório Crescimento de cristais e Materiais Cerâmicos (CCMC) que deram suporte estrutural e técnico, no qual pude aprender e desenvolver parte do meu projeto de mestrado.

Aos meus pais, irmãos e parentes pelo esforço, dedicação e compreensão em todos os momentos desta e de outras caminhadas.

A minha namorada Rafaela Sanfelice pelo intenso apoio, paciência e principalmente pelos momentos felizes que me proporcionou ao seu lado.

Ao meu grupo de pesquisas, em especial os meus amigos de laboratório, Thiago Branquinho e Moema Botelho pela amizade, companheirismo, auxílio, sugestões e questionamentos no desenvolver deste projeto.

Aos meus amigos de Ituverava e Alfenas, que são pessoas muito especiais para mim, porque me fazem rir, me divertem, ajudaram e apoiaram em muitos dos momentos difíceis da minha vida.

A Maria Antonieta pelas conversar, sugestões, incentivos, orientações e pelos cafezinhos durante esse período.

Finalmente, quero reservar esse espaço para agradecer as pessoas que de alguma maneira participaram e ajudaram a desenvolver esta dissertação. 

"Construímos muros demais e pontes de menos" 



\section{RESUMO}

FERNANDES, R. G. Influência do $\mathbf{P b F}_{2}$ nas propriedades físicas e estruturais de vidros boratos contendo óxidos de metais pesados. (2012). 88p. Dissertação (Mestrado em Ciência e Engenharia de Materiais) - Instituto de Física de São Carlos, Instituto de Química de São Carlos, Escola de Engenharia de São Carlos, Universidade de São Paulo, São Paulo, 2012.

Vidros nas composições $26,66 \mathrm{~B}_{2} \mathrm{O}_{3}-16 \mathrm{GeO}_{2}-4 \mathrm{Bi}_{2} \mathrm{O}_{3}-(53,33-\mathrm{x}) \mathrm{PbO}-\mathrm{xPbF}_{2}$ com x até $30 \%$ mol foram sintetizados e caracterizados com respeito as suas propriedades térmicas e espectroscópicas. A substituição de $\mathrm{PbO}$ por $\mathrm{PbF}_{2}$ desloca a janela de transmissão óptica no ultravioleta para maiores energia. Os espectros Raman e Infravermelho foram interpretados em conjunto, e a partir desta análise identificou-se a ocorrência de uma leve conversão de unidades $\mathrm{BO}_{3}$ a unidades $\mathrm{BO}_{4}$, concomitante com o aumento da concentração de $\mathrm{PbF}_{2}$. Utilizando RMN de alta resolução em sólidos dos núcleos ${ }^{11} \mathrm{~B}$ e ${ }^{19} \mathrm{~F}$, e diferentes técnicas de dupla ressonância ${ }^{11} \mathrm{~B} /{ }^{19} \mathrm{~F}$ (REDOR, CPMAS e 2D-CPMAS), foi possível realizar uma análise estrutural quantitativa desses materiais. A fração encontrada de unidades estruturais $\mathrm{BO}_{4}$ é moderadamente maior comparada com vidros que apresentam a mesma razão de $\mathrm{PbO} / \mathrm{B}_{2} \mathrm{O}_{3}$, quando $\mathrm{PbF}_{2}$ é acrescido no sistema, sugerindo a participação de $\mathrm{PbF}_{2}$ no processo de transformação da rede. Essa sugestão é confirmada a partir dos espectros de RMN de ${ }^{19} \mathrm{~F}$. A maior parte dos íons fluoretos encontra-se na sua forma iônica, mas aproximadamente $20 \%$ atua como modificador de rede, resultando na formação de unidades $\mathrm{BO}_{3 / 2} \mathrm{~F}^{-}$. Essas unidades foram identificadas por experimentos REDOR ${ }^{19} \mathrm{~F}\left\{{ }^{11} \mathrm{~B}\right\}$ e CPMAS ${ }^{11} \mathrm{~B}\left\{{ }^{19} \mathrm{~F}\right\}$. Esses resultados fornecem as primeiras evidências das ligações $\mathrm{B}-\mathrm{F}$ em sistemas vítreos modificados por $\mathrm{PbF}_{2}$. Além disso, verifica-se que a maioria dos íons fluoretos é encontrada em um ambiente dominado por chumbo. As medidas de segundo momento dipolar homonuclear ${ }^{19} \mathrm{~F}-{ }^{19} \mathrm{~F}$ a partir de experimentos por espectroscopia de decaimento de eco de spin são quantitativamente consistentes com um modelo no qual esses íons estão aleatoriamente distribuídos no interior de um subdomínio constituído de $\mathrm{PbO}, \mathrm{Bi}_{2} \mathrm{O}_{3}$ and $\mathrm{PbF}_{2}$. Este modelo, que implica na coordenação dos átomos de flúor às espécies formadoras da rede borato em adição ao surgimento de íons de flúor, com certo grau de agregação, é consistente com todas as observações experimentais.

Palavras-chave: Vidros oxifluoroboratos de chumbo. RMN estado sólido. Vidros óxidos de metais pesados. 



\begin{abstract}
FERNANDES, R. G. Influence of $\mathbf{P b F}_{\mathbf{2}}$ in physical and structural properties in heavy metal oxides borate glasses. (2012). 88 p. Dissertação (Mestrado em Ciência e Engenharia de Materiais) - Instituto de Física de São Carlos, Instituto de Química de São Carlos, Escola de Engenharia de São Carlos, Universidade de São Paulo, São Paulo, 2012.
\end{abstract}

A series of heavy metal oxide (HMOG) glasses with composition 26,66 $\mathrm{B}_{2} \mathrm{O}_{3}-16 \mathrm{GeO}_{2}-$ $4 \mathrm{Bi}_{2} \mathrm{O}_{3}-(53,33-\mathrm{x}) \mathrm{PbO}-\mathrm{xPbF}_{2}$ with $\mathrm{x}$ until $40 \% \mathrm{~mol}$, has been prepared and characterized with respect to their bulk (glass transition and crystallization temperature, densities, molar volumes) and spectroscopic properties. Homogeneous glasses are formed up to $\mathrm{x}=30$, while crystallization of $\mathrm{B}-\mathrm{PbF}_{2}$ takes place at higher contents. Substitution of $\mathrm{PbO}$ by $\mathrm{PbF}_{2}$ shifts the optical band gap towards higher energies, thereby extending the UV transmission window significantly towards higher frequencies. Raman and infrared absorption spectra can be interpreted in conjunction with published reference data. Using ${ }^{11} \mathrm{~B}$ and ${ }^{19} \mathrm{~F}$ high-resolution solid state NMR as well as ${ }^{11} \mathrm{~B} /{ }^{19} \mathrm{~F}$ double resonance methodologies, we developed a quantitative structural description of this material. The fraction of four-coordinated boron is found to be moderately higher compared to that in glasses with the same $\mathrm{PbO} / \mathrm{B}_{2} \mathrm{O}_{3}$ ratios, suggesting some participation of $\mathrm{PbF}_{2}$ in the network transformation process. This suggestion is confirmed by the ${ }^{19} \mathrm{~F}$ NMR spectra. While the majority of the fluoride ions is present as ionic fluoride, approximately $20 \%$ of the fluorine inventory acts as a network modifier, resulting in the formation of four-coordinate $\mathrm{BO}_{3 / 2} \mathrm{~F}^{-}$units. These units can be identified by ${ }^{19} \mathrm{~F}\left\{{ }^{11} \mathrm{~B}\right\}$ rotational echo double resonance and ${ }^{11} \mathrm{~B}\left\{{ }^{19} \mathrm{~F}\right\}$ cross-polarization magic angle spinning (CPMAS) data. These results provide the first unambiguous evidence of B-F bonding in a $\mathrm{PbF}_{2}$-modified glass system. The majority of the fluoride ions are found in a lead-dominated environment. ${ }^{19} \mathrm{~F}-{ }^{19} \mathrm{~F}$ homonuclear dipolar second moments measured by spin echo decay spectroscopy are quantitatively consistent with a model in which these ions are randomly distributed within the network modifier subdomain consisting of $\mathrm{PbO}, \mathrm{Bi}_{2} \mathrm{O}_{3}$ and $\mathrm{PbF}_{2}$. This model, which implies both the features of atomic scale mixing with the network former borate species and some degree of fluoride ion clustering is consistent with all of the experimental data obtained on these glasses.

Keywords: Lead oxyfluoroborate glasses. Solid state NMR. Heavy metal oxide glasses 



\section{LISTA DE FIGURAS}

Figura 1- Representação bidimensional: (a) Arranjo cristalino simétrico e periódico do $\mathrm{SiO}_{2}$; (b) Representação da rede do vidro do mesmo composto, na qual fica caracterizada a ausência de simetria e periodicidade.

Figura 2-Variação do volume específico com a temperatura de um líquido durante o resfriamento

Figura 3- Representação esquemática de diferentes unidades estruturais presentes em vidros boratos 22

Figura 4- Esquema de um alfabeto dipolar para um sistema de dois spins com spin nuclear $1 \frac{1}{2}$ idêntico.

Figura 5- Níveis Zeeman de um núcleo quadrupolar $(\mathrm{I}=3 / 2)$ e seus respectivos desdobramentos

Figura 6- Rotação da amostra na condição de ângulo mágico sob ação de um campo magnético $\mathrm{B}_{0}$ 38

Figura 7- Descrição da sequência de pulso utilizada por um experimento REDOR 40

Figura 8- Vetor modelo e sequência de pulso spin echo. 43

Figura 9- Fotografias das amostras sintetizadas após corte e polimento 51

Figura 10- Difratogramas de raios $X$ em pó dos vidros estudados. 52

Figura 11- a) Espectros de absorção no IV de todas amostras estudadas e b) Comparação entre os espectros no IV para as amostras BPBG, BPBG15 e BPBG30.

Figura 12- (a) Espectros de espalhamento micro-Raman obtido para todos os vidros (b) Espectro micro-Raman para a amostra BPBG e suas deconvoluções em múltiplas Gaussianas.

Figura 13- Variação da temperatura de transição vítrea com o aumento de $\mathrm{PbF}_{2}$ (esquerda) e estabilidade térmica dos vidros frente à cristalização (direita) para os vidros BPBG, BPBG15 e BPBG30.

Figura 14- Densidade (esquerda) e volume molar (direita) dos vidros BPBG, BPBG15 e BPBG30 58

Figura 15- Espectros de absorbância na região do UV-Visível-NIR em função da concentração de $\mathrm{PbF}_{2}$

Figura 16- Espectros de RMN ${ }^{11}$ B PS - MAS das amostras BPBG, BPBG15 e BPBG30 ..... 60 
Figura 17- Dados de REDOR ${ }^{11} \mathrm{~B}\left\{{ }^{19} \mathrm{~F}\right\}$ dos vidros estudados. (a) Forma de linha do ${ }^{11} \mathrm{~B}$ para o vidro BPBG30 na ausência e na presença da defasagem dipolar (b) Curvas REDOR indicando a diferença de sinal $\Delta \mathrm{S} / \mathrm{S}_{\mathrm{o}}$ como uma função da evolução temporal dipolar de $\mathrm{NT}_{\mathrm{r}}$. (c) e (d) Curvas REDOR indicando a diferença de sinal $\Delta \mathrm{S} / \mathrm{S}_{\mathrm{o}}$ como uma função da evolução temporal dipolar de $\mathrm{NT}_{\mathrm{r}}$ para as espécies $\mathrm{BO}_{4}$ e $\mathrm{BO}_{3}$ respectivamente. 1 BPBG15, 2 BPBG30, 3 BPBG40.

Figura 18- Espectros de $\mathrm{RMN}{ }^{19} \mathrm{~F}$ PS - MAS dos vidros contendo $\mathrm{PbF}_{2}$ e deconvolução proposta em três novos picos

Figura 19- Dados REDOR ${ }^{19} \mathrm{~F}\left\{{ }^{11} \mathrm{~B}\right\}$ (verde) e sinal referência (azul) observados para um tempo de reacoplamento dipolar fixado em $400 \mu$ s (superior). Curva REDOR para as diferentes espécies observadas nos espectros de RMN ${ }^{19}$ F PS - MAS (inferior).

Figura 20- Dados RMN CPMAS ${ }^{19} \mathrm{~F}\left\{{ }^{11} \mathrm{~B}\right\}$ em função do tempo de contato para as amostras (a) e (b). Na ordem de amplitudes cada vez maiores os tempos de contatos são 20, 50, 80, 100, 200, 500, 2000, 5000, 8000 and $10000 \mu \mathrm{s}$ .66

Figura 21- Desvio químico do ${ }^{11} \mathrm{~B}$ observado para as espécies $\mathrm{BO}_{4}$ nos espectros $\mathrm{RMN}$ CPMAS ${ }^{19} \mathrm{~F}\left\{{ }^{11} \mathrm{~B}\right\}$ como função do tempo de contato para as amostras No.1 (BPBG15) e No2 (BPBG30).

Figura 22- Dados CPMAS 2-D ${ }^{11} \mathrm{~B}\left\{{ }^{19} \mathrm{~F}\right\}$ observado para vidros BPBG30 usando tempo de contato de $50 \mu \mathrm{s}$ (esquerda), $200 \mu \mathrm{s}$ (meio), $5 \mathrm{~ms}$ (direta). .68

Figura 23- Amplitude do sinal ${ }^{19} \mathrm{~F}$ observado em função do tempo de acoplamento dipolar nos experimentos de ecos de spin em rotor sincronizado, para as diferentes espécies fluoretos nos vidros estudados.

Figura 24- Amplitude ${ }^{19} \mathrm{~F}$ Hahn spin echo sob condições estáticas dos vidros BPBGF15 e BPBGF30 em função do tempo de acoplamento dipolar. 


\section{LISTA DE TABELAS}

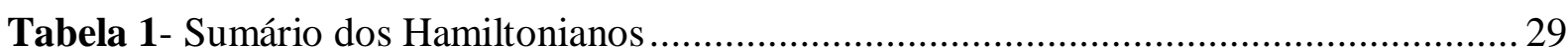

Tabela 2- Precursores utilizados na síntese das amostras ................................................. 45

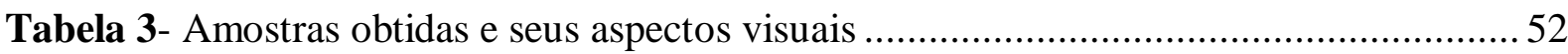

Tabela 4- Atribuição das bandas de absorção no IV para o vidro BPBG …......................... 54

Tabela 5- Número de ondas e atribuições às bandas observadas nos espectros Raman ......... 56

Tabela 6- Propriedades físicas dos vidros estudados. * Amostra parcialmente cristalina ...... 58

Tabela 7- Janela de transmissão óptica dos vidros BPBG, BPBG15, BPBG30 e composições

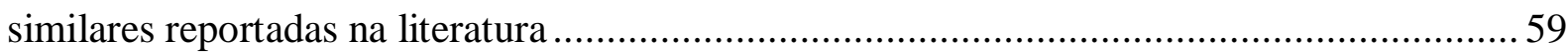

Tabela 8- Parâmetros do ${ }^{11} \mathrm{~B}$ obtidos a partir dos espectros dos quatro vidros estudados ...... 61

Tabela 9- Deconvolução dos espectros de RMN ${ }^{19} \mathrm{~F}$ PS - MAS dos vidros contendo flúor .. 64

Tabela 10- Valores de $\mathrm{M}_{2}\left({ }^{19} \mathrm{~F}-{ }^{19} \mathrm{~F}\right.$ ) previsto (em unidades de $10^{6} \operatorname{rad}^{2} \mathrm{~s}^{2}$ ) para diferentes cenários de íons fluoretos e comparação com os dados experimentais (erro estimado $\mp 10 \%$ ). 



\section{SUMÁRIO}

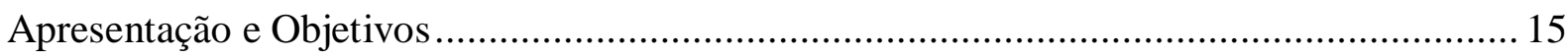

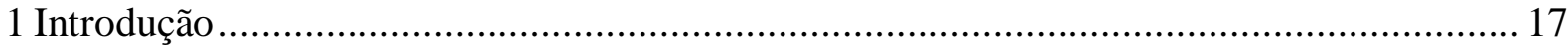

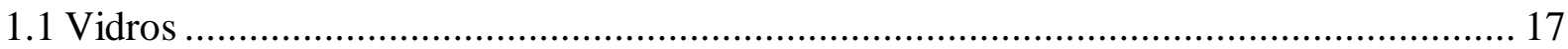

1.1.1 Definição e Teoria de Formação Vítrea ............................................................... 17

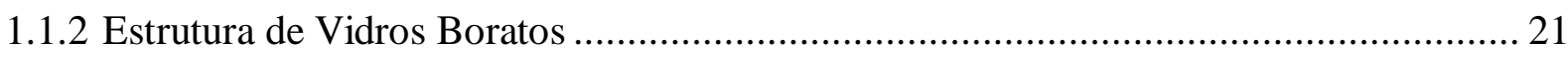

1.1.3 Vidros Óxidos de Metais Pesados (HMOG) ............................................................ 22

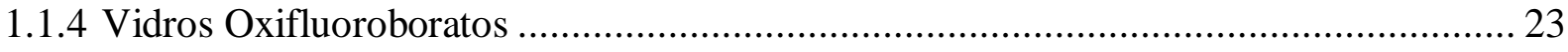

1.2 Teoria Básica de Ressonância Magnética Nuclear (RMN) ......................................... 24

1.2.1 Mecânica Quântica do Momento angular ................................................................ 24

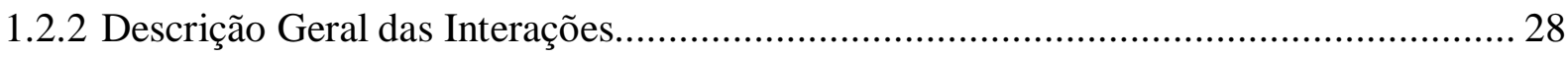

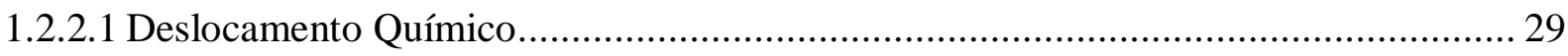

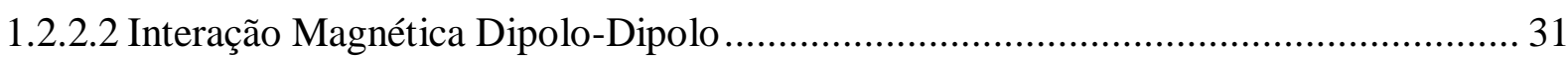

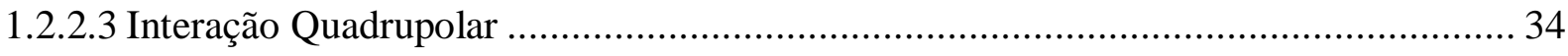

1.3 Técnicas de RMN de alta resolução .................................................................. 37

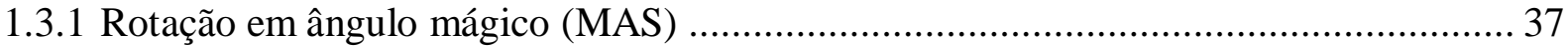

1.3.2 Eco rotacional de dupla ressonância (REDOR - Rotacional Echo Doble Ressonance) 38 1.3.3 Polarização Cruzada (CP) e correlação heteronuclear em 2D da polarização cruzada

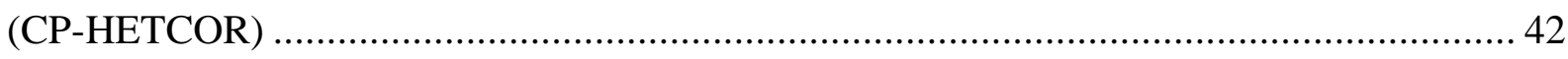

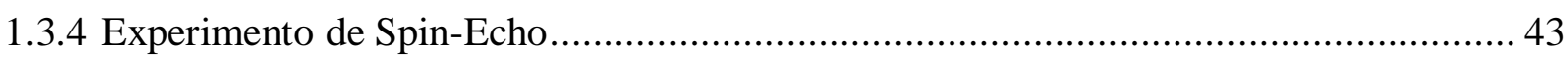

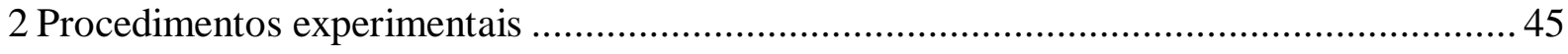

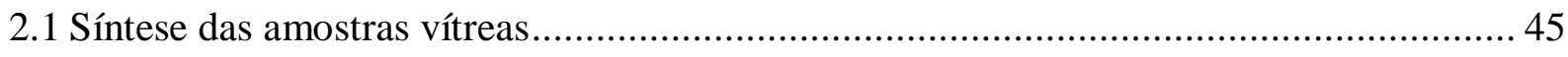

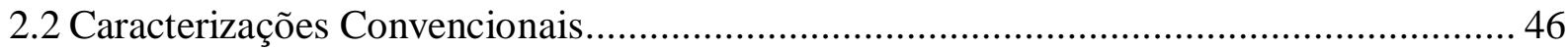

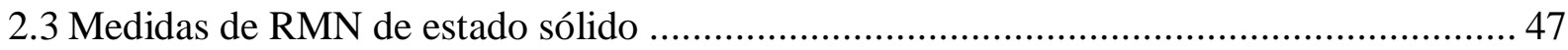

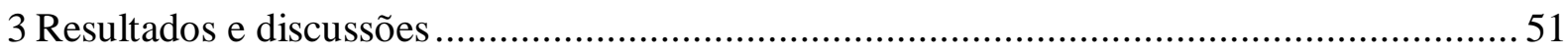

3.1 Influência do $\mathrm{PbF}_{2}$ nas propriedades físicas dos vidros estudados ............................... 51

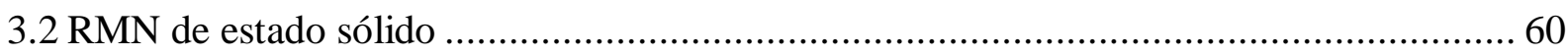

3.2.1 RMN de alta resolução em sólidos - REDOR ${ }^{11} \mathrm{~B}\left\{{ }^{19} \mathrm{~F}\right\}$ e ${ }^{11} \mathrm{~B}$ Pulso Simples (PS) - MAS60

3.2.2 RMN de Alta resolução em sólidos - REDOR ${ }^{19} \mathrm{~F}\left\{{ }^{11} \mathrm{~B}\right\}$ e ${ }^{19} \mathrm{~F}$ Pulso Simples (PS) - MAS63

3.2.3 Polarização Cruzada ${ }^{11} \mathrm{~B}\left\{{ }^{19} \mathrm{~F}\right\}$ e Correlação em $2 \mathrm{D}$ da Polarização Cruzada ${ }^{19} \mathrm{~F}\left\{{ }^{11} \mathrm{~B}\right\} . .65$

3.2.4 Espectroscopia por decaimento de eco de spin e efeitos de agregação de íons $\mathrm{F}^{-}$.......... 68

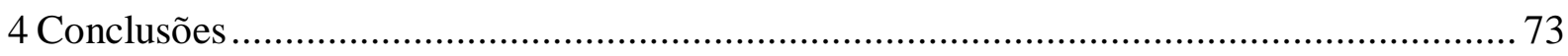




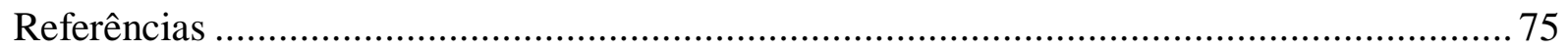




\section{Apresentação e Objetivos}

Embora o vidro seja um dos materiais mais antigos preparados pelo homem, no século XX ele ressurgiu como um material possuindo fantásticas propriedades tecnológicas. Porém, algumas propriedades particulares em vidros precisam ainda ser desenvolvidas e para tanto se faz necessário desenvolver novas composições vítreas que também satisfaçam às novas demandas tecnológicas.

Os vidros apresentam considerável flexibilidade na sua síntese e também a habilidade de incorporar maiores concentrações de íons dopantes opticamente ativos comparado a materiais cristalinos. Na pesquisa de novas e eficientes combinações matriz-íon que sejam menos sensíveis ao efeito da supressão luminescente, estudos detalhados sobre as características estruturais, ópticas e espectroscópicas desses materiais são indispensáveis.

Dentre os vidros mais estudados, os de óxido de metais pesados (HMOG do inglês "Heavy Metal Oxide Glasses") têm sido amplamente investigados nos últimos anos devido ao seu reconhecido potencial para aplicações em fotônica e optoeletrônica. Em particular, vidros HMOG contendo $\mathrm{Bi}_{2} \mathrm{O}_{3}$ e $\mathrm{PbO}$ apresentam várias propriedades físicas de interesse, tais como, elevado índice de refração, extensa janela de transmissão compreendida entre as regiões do visível e do infravermelho, baixa energia de fônons e grande estabilidade vítrea. [1-4]. A presença do formador vítreo $\mathrm{B}_{2} \mathrm{O}_{3}$ garante uma ampla região de formação vítrea proporcionando a incorporação de outros constituintes (por exemplo, $\mathrm{GeO}_{2}$ ), e permitindo assim obter combinações de propriedades físicas que visam uma ampla demanda de aplicações. A incorporação de íons fluoretos nestes vidros é de interesse, pois permite deslocar a janela de transmissão óptica para maiores energias tornando-os bons hospedeiros para íons terras raras trivalente $\left(\mathrm{TR}^{3+}\right)$ com aplicações em lasers de estado sólido [5-9]. Além disso, vidros fluoroboratos de chumbo têm gerado grande interesse como materiais condutores iônicos rápidos, nos quais o flúor é o principal portador de carga [10-13]. Estes vidros apresentam também fenômeno de cristalização induzida abaixo da temperatura de transição vítrea $\left(\mathrm{T}_{\mathrm{g}}\right)$ quando um campo elétrico externo é aplicado [12]. Em particular, a modificação estrutural das redes boratos na presença de $\mathrm{PbF}_{2}$ é um assunto muito interessante do ponto de vista acadêmico. Fundamentado em um número de evidências indiretas, foi sugerido que a rede borato é modificada pelo elemento flúor, resultando na formação de ligações B-F, entretanto, nenhuma prova definitiva foi fornecida [10-16]. Até então, a 
principal evidência desta ligação foi observada em espectros de XPS no sistema binário $\mathrm{PbF}_{2}$ $\mathrm{B}_{2} \mathrm{O}_{3}$ e $\mathrm{PbO}-\mathrm{PbF}_{2}-\mathrm{B}_{2} \mathrm{O}_{3}[17,36]$.

A espectroscopia de Ressonância Magnética Nuclear (RMN) de alta resolução em sólidos provê ferramentas ideais para abordar tais questões estruturais [18,19]. Alguns estudos de RMN de estado sólido a cerca da modificação estrutural da rede borato na presença de fluoretos alcalinos foram relatados [20-21], porém nenhum estudo sobre a modificação estrutural da rede borato na presença de $\mathrm{PbF}_{2}$ ainda foi apresentado. Assim, no presente trabalho apresentamos o primeiro estudo de RMN de alta resolução em estado sólido em sistemas vítreos boratos modificados pela presença de $\mathrm{PbF}_{2}$ através de experimentos $\mathrm{RMN}$ de simples e dupla ressonância dos núcleos ${ }^{11} \mathrm{~B}$ e ${ }^{19} \mathrm{~F}$, em uma série de vidros HMOG.

Os objetivos gerais deste trabalho podem ser resumidos da seguinte forma:

1. Determinar o domínio vítreo e obter amostras para o sistema $26,66 \mathrm{~B}_{2} \mathrm{O}_{3}-16 \mathrm{GeO}_{2}-4 \mathrm{Bi}_{2} \mathrm{O}_{3}-$ $(53,33-\mathrm{x}) \mathrm{PbO}-\mathrm{xPbF}_{2}$.

2. Verificar o estado vítreo das amostras a partir de técnicas de caracterização convencionais, ou seja: observações visuais, difração de raios $\mathrm{X}$ e análise térmica.

3. Caracterizar a estabilidade térmica dos vidros frente à cristalização mediante a determinação das temperaturas características: $\mathrm{T}_{\mathrm{g}}$ (temperatura de transição vítrea), $\mathrm{T}_{\mathrm{x}}$ (temperatura de início de cristalização), $\mathrm{T}_{\mathrm{c}}$ (temperatura do máximo de cristalização), $\mathrm{T}_{\mathrm{f}}$ (temperatura de fusão) e $\mathrm{T}_{1}$ (temperatura de líquido)

4. Determinar a janela de transmissão óptica nas regiões do UV-Vis-NIR em função da concentração de $\mathrm{PbF}_{2}$.

5. Caracterizar a estrutura dos vidros em função da concentração de $\mathrm{PbF}_{2}$ através das técnicas de espectroscopia Raman e Infravermelho, difração de raios X, medidas de densidade e volume molar e experimentos de $(\mathrm{RMN})$ de alta resolução dos núcleos ${ }^{11} \mathrm{~B}$ e ${ }^{19} \mathrm{~F}$.

As informações obtidas deste trabalho são apresentadas em 4 capítulos, os quais elucidam aspectos teóricos no estudo dos vidros, as técnicas empregadas nas caracterizações, os resultados e discussões, e conclusões. 


\section{Introdução}

\subsection{Vidros}

\subsubsection{Definição e Teoria de Formação Vítrea}

O termo "vidros" é comumente utilizado para designar produtos obtidos a partir da fusão de materiais inorgânicos que foram colocados sob rápido resfriamento sem que ocorra a cristalização dos mesmos. Estudos sistemáticos sobre vidros tiveram início com Faraday no começo do século XIX e ainda hoje se trata de um tema em crescente desenvolvimento, seja no progresso de obtenção de novas composições vítreas com propriedades especiais para aplicações específicas, ou no emprego de novas técnicas científicas para melhorar a nossa compreensão sobre sua estrutura e comportamento.

De acordo com o contexto histórico, surgiram várias definições para o vidro. As definições iniciais eram relacionadas à sua viscosidade e seu aspecto brilhante até que se estabeleceram explicações descritivas da estrutura desse material, no qual o arranjo atômico era caracterizado por uma rede tridimensional estendida que apresentava ausência de simetria e periodicidade de longo alcance.

Hoje em dia, a definição é controversa. Alguns dizem que o vidro é um composto preparado através do resfriamento rápido do estado líquido, que o torna relativamente rígido com aumento progressivo da viscosidade, em suma, vidro é um produto inorgânico, resultante de uma fusão, enrijecido pelo resfriamento, sem cristalização [22]. Outros enunciam que o vidro é um sólido amorfo, não cristalino, podendo ser mencionado como um líquido super resfriado [23]. De acordo com Gupta em seu artigo "Non Crystalline Solids: Glasses and Amorphus Solids" um sólido não cristalino pode ser dividido, do ponto de vista termodinâmico, em duas classes distintas: vidros e sólidos amorfos. Sólidos não cristalinos seriam todos aqueles materiais que apresentassem uma rede tridimensional estendida e aleatória. Considerando o aspecto termodinâmico, um sólido não cristalino seria um vidro quando este apresenta o fenômeno de transição vítrea [24]. Em 1997, Shellby [25] propôs a definição mais aceita pela comunidade científica que trabalha na área de vidros.

"Vidro é um sólido amorfo com ausência completa de ordem a longo alcance e periodicidade, exibindo uma região de transição vítrea. Qualquer material, inorgânico, 
orgânico ou metal, formando por qualquer técnica, que exibe um fenômeno de transição vítrea é um vidro".

Com base na organização atômica, sólidos podem ser classificados em duas categorias. (i) cristalinos e (ii) amorfos. Um sólido cristalino pode apresentar periodicidade de longo e curto alcance, enquanto que materiais amorfos apresentam apenas periodicidade de curto alcance. A figura 1 simboliza uma representação esquemática de um mesmo composto $\left(\mathrm{SiO}_{2}\right)$ na sua forma cristalina (ordenado) e na sua forma amorfa (aleatória). Devido à periodicidade de curto alcance no arranjo atômico, o grau de desordem em um sólido amorfo será maior do que a mesma estrutura na forma cristalina, por isso, maior será a entropia de um arranjo desordenado. Devido à aleatoriedade do arranjo atômico, materiais amorfos também exibem propriedades isotrópicas, enquanto sólidos cristalinos exibem propriedades anisotrópicas.

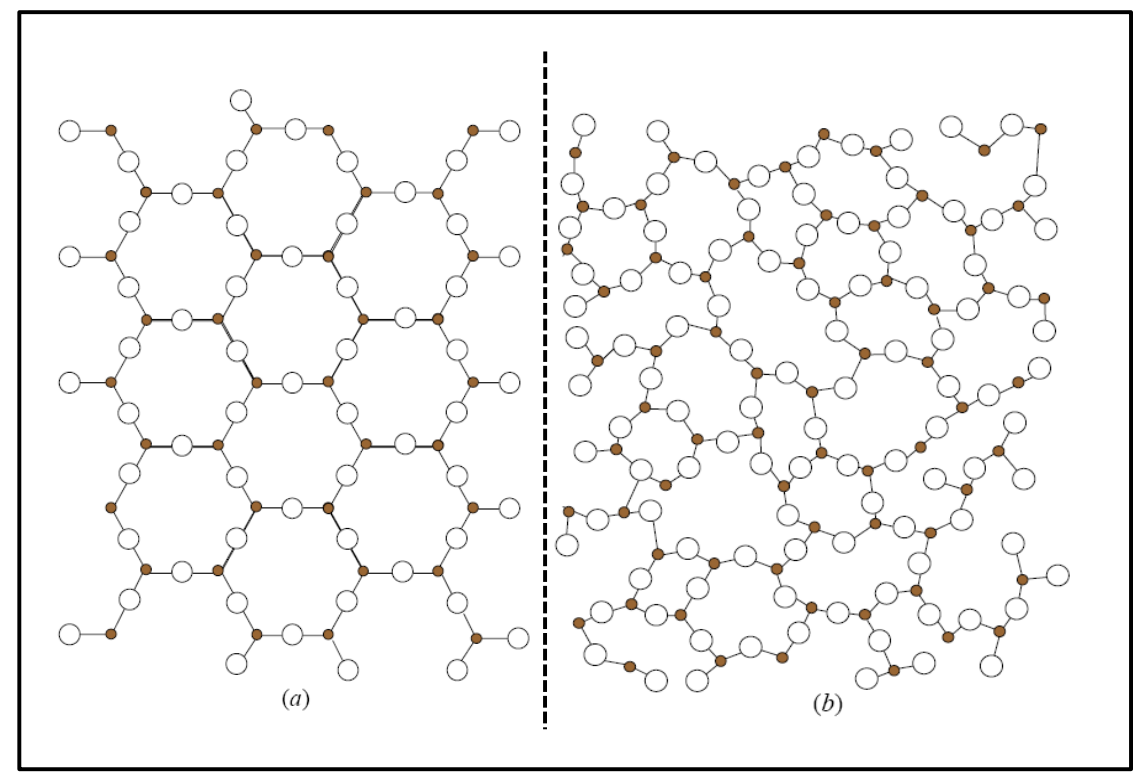

Figura 1- Representação bidimensional: (a) Arranjo cristalino simétrico e periódico do $\mathrm{SiO}_{2}$; (b) Representação da rede do vidro do mesmo composto, na qual fica caracterizada a ausência de simetria e periodicidade

A partir do estado fundido, existem dois caminhos que um líquido pode seguir em resfriamento para o estado sólido; (i) ele pode cristalizar na temperatura de fusão $\left(\mathrm{T}_{\mathrm{m}}\right)$, ou abaixo dela, ou (ii) ele pode resfriar rapidamente e formar um vidro sem cristalizar. Um vidro é geralmente obtido pelo rápido resfriamento de um líquido abaixo do seu ponto de solidificação. A explicação clássica para a formação de um vidro é que, quando um líquido é colocado sob super-resfriamento, a sua fluidez em certa temperatura abaixo do ponto de solidificação, torna-se aproximadamente zero. Isto é, o líquido torna-se rígido. A figura 2 
representa o comportamento do volume em função da temperatura para um líquido mediante diferentes taxas de resfriamento.

Quando um líquido é resfriado para formar um sólido, a curva de resfriamento resultante mostra diferenças distintas entre um sólido cristalino e um vidro. Quando um líquido solidifica-se na forma de um cristal existe uma descontinuidade acentuada no volume a uma temperatura bem definida, chamada ponto de fusão $\left(T_{f}\right)$ do material. Entretanto, se não ocorre a cristalização, o volume do líquido continua reduzindo na mesma taxa, até que haja uma diminuição no coeficiente de expansão em uma região chamada de transformação vítrea. Em outras palavras, a curva líquido super resfriado - vidro não apresenta qualquer descontinuidade. Em seguida, a curva mostra uma mudança na inclinação a uma temperatura chamada de temperatura de transição vítrea $\left(\mathrm{T}_{\mathrm{g}}\right)$. Abaixo dessa temperatura a estrutura vítrea não apresenta mobilidade atômica para essa razão de resfriamento utilizada.

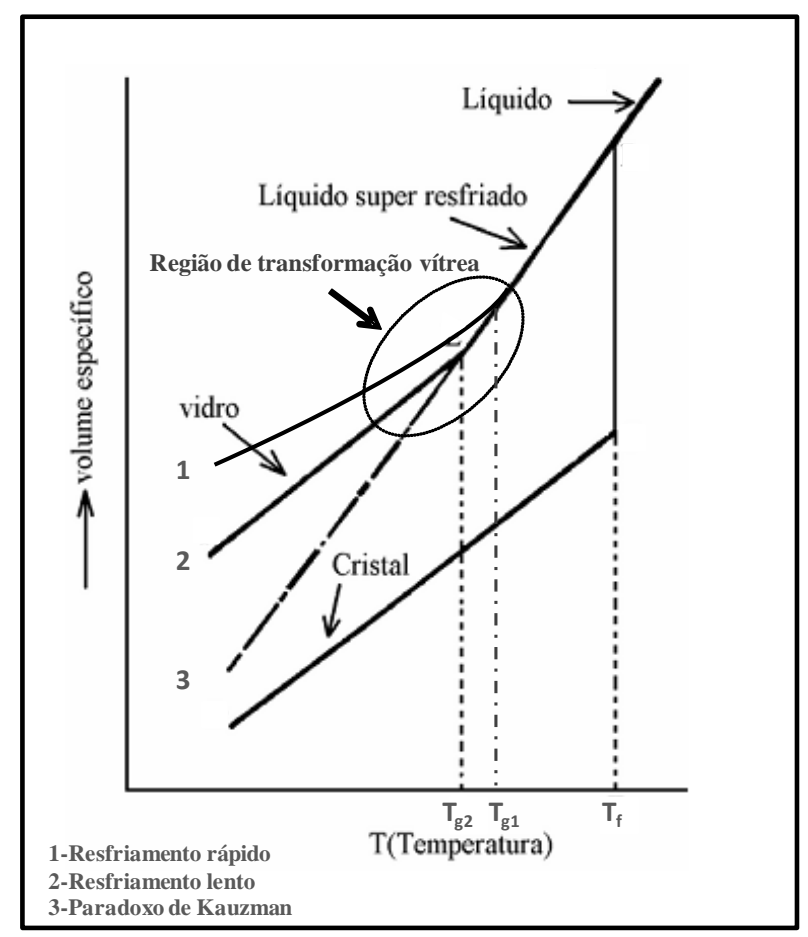

Figura 2-Variação do volume específico com a temperatura de um líquido durante o resfriamento

A temperatura de transição vítrea depende principalmente da razão de resfriamento do fundido, ou seja, o valor da $T_{g}$ não é bem definido em cada sistema vítreo, e sim uma função da taxa de resfriamento. Quanto mais prolongada à razão de resfriamento, menor é o valor da $\mathrm{T}_{\mathrm{g}}$, porém a $\mathrm{T}_{\mathrm{g}}$ não pode ser reduzida indefinidamente (paradoxo de Kauzmann) [26].

Vidros podem ser preparados usando diferentes tipos de Compostos. A habilidade de uma substância, para formar um vidro, não depende de qualquer propriedade físico-química 
particular. Praticamente, qualquer substância pode formar um vidro, desde que submetida a condições de resfriamento rápido.

Os óxidos, $\mathrm{B}_{2} \mathrm{O}_{3}, \mathrm{SiO}_{2}, \mathrm{GeO}_{2}$ e $\mathrm{P}_{2} \mathrm{O}_{5}$, são compostos derivados de elementos presentes em uma mesma região na tabela periódica (semi-metais) que quando fundidos e submetidos a alta taxa de resfriamento possuem habilidade de formar vidros sem a necessidade de outros componentes, por isso são geralmente conhecidos como "formadores vítreos óxidos". Estes compostos são elementos com eletronegatividade intermediária, isto é, são suficientemente eletropositivos para formar estruturas iônicas, mas não suficientemente eletronegativos para formar ligações covalentes, tais como pequenas estruturas moleculares. Ao invés disso, as estruturas são combinações de ligações covalentes e iônicas dando origem a compostos com rede tridimensionais. Por outro lado $\mathrm{TeO}_{2}, \mathrm{SeO}_{2}, \mathrm{MoO}_{3}, \mathrm{Bi}_{2} \mathrm{O}_{3}, \mathrm{Al}_{2} \mathrm{O}_{3}, \mathrm{Ga}_{2} \mathrm{O}_{3}$ e $\mathrm{V}_{2} \mathrm{O}_{3}$, chamados de formadores vítreos intermediários, não formam vidros sozinhos. Todavia, é possível obter vidros desses elementos quando são fundidos com uma substancial quantidade de outros óxidos não formadores de vidros. Por fim, existem alguns óxidos, como $\mathrm{Na}_{2} \mathrm{O}$, $\mathrm{Li}_{2} \mathrm{O}, \mathrm{K}_{2} \mathrm{O}$ e $\mathrm{CaO}$ que quando adicionados em pequenas porcentagens molares, provocam drásticas mudanças nas propriedades físicas dos vidros óxidos (ponto de fusão, condutividade iônica, etc.), sendo estes chamados de modificadores de rede

Várias tentativas foram feitas para explicar a tendência à formação de vidros a base de óxidos. Os critérios de Goldschmit's [27] fornecem uma correlação entre a habilidade de formação vítrea e o tamanho relativo do ânion oxigênio e do cátion. De acordo com ele, os óxidos formadores de vidro são aqueles em que a razão entre o raio iônico do cátion e do ânion $\left(R_{c} / R_{a}\right)$ está entre 0.2 e 0.4 . Junto a isso, deve existir 4 ânions ao redor de cada cátion, onde os ânions estão situados nos vértices de um tetraedro. Em outras palavras, uma configuração tetraédrica de óxidos é um pré-requisito para formação de um vidro.

Zachariasen [28] apontou em 1932 que os critérios de Goldschmit's não eram satisfatórios até mesmo como uma regra empírica, uma vez que nem todos os óxidos que possui uma razão $R_{d} / R_{a}$ entre os valores 0.2 e 0.4 são formadores vítreos (por exemplo, $\mathrm{BeO}$ apresenta $R_{B e} / R_{o}=0.221$ ). Uma vez não firmada esta teoria, Zachariasen tentou explicar por que certas coordenações favorecem a formação vítrea. Essencialmente, Zachariasen notou que silicatos que formavam mais prontamente um vidro, ao invés de se cristalizarem, exibiam a capacidade de formar cadeias, baseadas em conjuntos de tetraedros, conectados entre si pelos vértices. Vale comentar que as formas cristalinas também podem apresentar tais cadeias; contudo, no vidro, estas perdem a simetria e a periodicidade a longo alcance. Sendo assim, Zachariasen estabeleceu que a formação de cadeias fosse uma condição fundamental para a 
existência de um vidro e extraiu, como consequência deste requisito, outras conclusões sobre o arranjo ao redor dos átomos da rede:

(i) Nenhum átomo de oxigênio pode estar ligado a mais do que dois átomos formadores de rede.

(ii) Os poliedros devem ser conectados pelos vértices e não pelas arestas ou faces.

(iii) Pelo menos três vértices de cada poliedro devem ser compartilhados com outros poliedros.

A hipótese de Zachariasen para o processo de formação de vidros foi mais ou menos aceita universalmente. Assim, os óxidos alcalinos e alcalinos terrosos, $\mathrm{Na}_{2} \mathrm{O}, \mathrm{Li}_{2} \mathrm{O}, \mathrm{K}_{2} \mathrm{O}$ e $\mathrm{CaO}, \mathrm{BaO}, \mathrm{MgO}$, que não satisfazem aos critérios estabelecidos por Zachariasen não podem formar vidros, enquanto que óxidos como $\mathrm{B}_{2} \mathrm{O}_{3}, \mathrm{SiO}_{2}, \mathrm{GeO}_{2}$ e $\mathrm{P}_{2} \mathrm{O}_{5}$ satisfazem essa regra empírica e são considerados bons óxidos formadores de rede.

\subsubsection{Estrutura de Vidros Boratos}

Os Vidros são classificados de acordo com sua composição química e seus tipos de ligação. Dentre os mais estudados, podemos citar os vidros óxidos (silicatos, boratos, fosfatos, etc.). Neste texto, vamos apenas fazer uma breve introdução sobre as diferentes estruturas dos vidros óxidos a base de boro, sendo este o principal elemento formador de rede presente no sistema vítreo em estudo.

Em contraste com os vidros silicatos, em que o átomo de silício esta presente em tetraedros de $\mathrm{SiO}_{4}$, vidros boratos, dependendo da composição, contêm uma mistura de unidade trigonais $\mathrm{BO}_{3}$ e tetragonais $\mathrm{BO}_{4}$. Um importante constituinte dos vidros boratos é o grupo boroxol. Este grupo é formado por uma estrutura planar que contem átomos de boro e oxigênio alternados em um anel de seis membros que são aleatoriamente conectados, em uma rede tridimensional, através do compartilhamento dos três átomos de oxigênio com outras unidades $\mathrm{BO}_{3}$ adjacentes. Além disso, como resultado da configuração planar das unidades boratos, estes apresentam uma estrutura mais aberta comparada à estrutura dos vidros silicatos. Em consequência, a temperatura de fusão dos vidros contendo o precursor óxido de boro é menor que a dos vidros silicatos.

Intensas investigações foram realizadas em estruturas boratos vítreas e cristalinas. Krough-Moe [29-32] sugeriu que vidros boratos não são constituídos apenas por uma rede aleatória de unidades $\mathrm{BO}_{3}$ e $\mathrm{BO}_{4}$ conectadas pelos vértices, mas que realmente contêm diferentes grupos bem definidos e estáveis. Esses grupos boratos que estão presentes nas 
estruturas vítreas são idênticos aos grupos observados em estruturas boratos cristalinas. Pela combinação das técnicas de espectroscopia Raman, Infravermelho e Ressonância Magnética Nuclear, junto aos dados cristalográficos disponíveis, tais grupos foram claramente identificados. Esses diferentes grupos, podem ser mais bem observados pela figura 3.

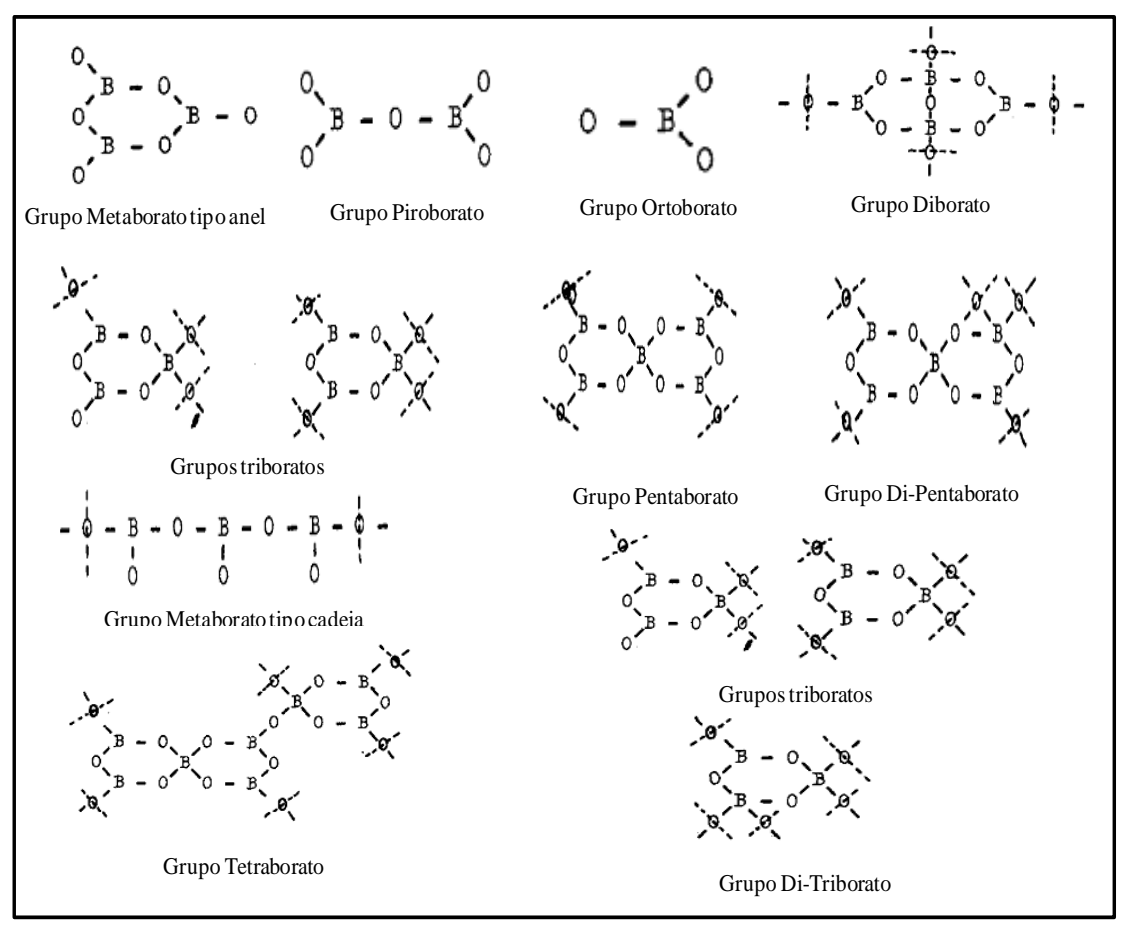

Figura 3- Representação esquemática de diferentes unidades estruturais presentes em vidros boratos

\subsubsection{Vidros Óxidos de Metais Pesados (HMOG)}

Nas últimas décadas, vidros óxidos de metais pesados têm sido muito estudados por apresentarem propriedades peculiares para aplicações em óptica e optoeletrônica [1-4]. Normalmente, as matrizes HMOG são formadas por cátions com elevada massa atômica, e baixa energia de ligação entre estes cátions e os átomos de oxigênio [33]. Essa baixa energia de ligação proporciona transmissão de luz com longos comprimentos de onda (região do infravermelho) e também menor energia de fônons quando comparados aos vidros silicatos. Deste modo, as perdas não radiativas de energia são menores e, como consequência, a eficiência da luminescência produzida pelos íons opticamente ativos é mais significativa nessa classe de vidros. Junto a isso, vidros mistos envolvendo óxidos de metais pesados e fluoretos, têm despertado bastante interesse pela possibilidade de combinar as propriedades mecânicas dos vidros óxidos e as qualidades ópticas aprimoradas pela presença de íons fluoretos [34] 
Para composições dopadas com íons $\mathrm{TR}^{3+}$ opticamente ativos, a substituição de íons oxigênio por fluoretos assegura ao $\mathrm{TR}^{3+}$ um ambiente mais propício a altas eficiências quânticas (maior hidrofobicidade, menor energia de fônons, possibilidade de cristalização controlada de fases fluoretos contendo o $\mathrm{TR}^{3+}$ ).

Entre as várias composições possíveis, vidros $\mathrm{HMOG}$ contendo $\mathrm{B}_{2} \mathrm{O}_{3}, \mathrm{Bi}_{2} \mathrm{O}_{3}$ e $\mathrm{PbO}$, são interessantes no que diz respeito à elevada estabilidade vítrea. Enquanto $\mathrm{B}_{2} \mathrm{O}_{3}$ é um típico formador vítreo óxido, $\mathrm{Bi}_{2} \mathrm{O}_{3}$ é indicado como um óxido formador de rede não convencional, e $\mathrm{PbO}$, dependendo de sua concentração, também pode ser considerado um óxido formador de rede [35].

No que concerne a janela de transmissão óptica no ultravioleta, verificou-se que o comprimento de onda de corte pode ser ajustado por variações composicionais em sistemas ternários e quaternários contendo $\mathrm{Bi}_{2} \mathrm{O}_{3}, \mathrm{PbO}$ e $\mathrm{GeO}_{2}$. Uma comparação direta entre vidros de sistemas semelhantes com os vidros obtidos nessa dissertação é feita na secção 3.1.

\subsubsection{Vidros Oxifluoroboratos}

Desde a publicação dos trabalhos pioneiros de Greeler and Shelby [10,11], nos sistemas vítreos $\mathrm{PbF}_{2}-\mathrm{B}_{2} \mathrm{O}_{3}$ e $\mathrm{PbO}-\mathrm{PbF}_{2}-\mathrm{B}_{2} \mathrm{O}_{3}$, a estrutura e propriedades dos vidros boratos contendo íons $\mathrm{F}^{-}$tem sido objeto de crescente interesse. Essa classe de vidros apresenta várias propriedades físicas interessantes, entre elas, a condutividade aniônica que confere aos vidros a denominação “condutores iônicos rápidos". Entretanto, existe uma controvérsia sobre o papel dos íons $\mathrm{F}^{-}$nas estruturas vítreas contendo boro.

Com base em um número de evidências indiretas, foi sugerido que a rede borato é modificada pelo elemento flúor, resultando na formação de ligações B-F, entretanto, nenhuma prova definitiva foi fornecida [10-16]. Até então, a principal evidência desta ligação foi exibida em espectros de XPS do $\mathrm{F}$ (1s) no sistema ternário (70-x) $\mathrm{PbOxPbF}_{2} 30 \mathrm{~B}_{2} \mathrm{O}_{3}$.[36].

Gopalakrishnan et al.[17] indicaram que nos vidros $\mathrm{xPbF}_{2}(1-\mathrm{x}) \mathrm{B}_{2} \mathrm{O}_{3}$ os íons $\mathrm{F}^{-}$são incorporados predominantemente como B-O-F em altas concentrações de $\mathrm{B}_{2} \mathrm{O}_{3}$, enquanto que para altas concentrações de $\mathrm{PbF}_{2}$ prevalecem as ligações $\mathrm{Pb}-\mathrm{O}-\mathrm{F}$.

Chowdari e Rong [37] verificaram que com o aumento da concentração de flúor em vidros fluoroboratos de lítio, o número de unidades estruturais básicas $\mathrm{BO}_{4}$ aumenta e grupos $\mathrm{BO}_{2} \mathrm{O}^{-}$conectados assimetricamente diminuem. Esse resultado sugere que o flúor participa da rede nas ligações B-O-F. Em espectros de XPS do F (1s), dois picos foram observados, um deles relacionado às ligações Li-F e o outro atribuído aos átomos de flúor nas extremidades 
das cadeias B-F. Esse último pode contribuir para a formação de unidades $\mathrm{BO}_{3} \mathrm{~F}^{-}$e $\mathrm{BO}_{2} \mathrm{~F}_{2}^{-}$. A formação dessas unidades estruturais foram confirmadas por $\mathrm{RMN}$ dos vidros $\mathrm{NaF}-\mathrm{Na}_{2} \mathrm{O}-$ $\mathrm{B}_{2} \mathrm{O}_{3}, \mathrm{NaF}-\mathrm{Na}_{2} \mathrm{O}-\mathrm{B}_{2} \mathrm{O}_{3}-\mathrm{Bi}_{2} \mathrm{O}_{3}$ e $\mathrm{Li}_{2} \mathrm{O}-\mathrm{SrO}-\mathrm{SrF}_{2}-\mathrm{B}_{2} \mathrm{O}_{3}$ [38].

Vidros fluoroboratos de alcalinos, com concentrações acima de $45 \%$ em mol de fluoretos alcalinos ( $\mathrm{LiF}, \mathrm{NaF}$ e $\mathrm{KF})$ apresentaram tendências semelhantes às observadas em vidros alcalino-boratos. Para explicar as diferenças de comportamento entre, os vidros fluoroboratos de alcalinos e os correspondentes vidros boratos de alcalinos, Shelby e Baker [39] propuseram um modelo estrutural baseado na substituição dos tetraedros $\mathrm{BO}_{4}$ por tetraedros de $\mathrm{BO}_{3} \mathrm{~F}^{-}$.

A hipótese de formação de diferentes tipos de unidades fluoroboratos $\left(\mathrm{BO}_{2} \mathrm{~F}\right.$ ou $\left.\mathrm{BOF}_{2}\right)$ foi adotada por Souto et al [40] no sistema $\mathrm{B}_{2} \mathrm{O}_{3}-\mathrm{Li}_{2} \mathrm{O}-\mathrm{LiX}(\mathrm{x}=\mathrm{F}, \mathrm{Cl}, \mathrm{Br}$, I), onde a ligação BF nessas unidades são terminais.

Por fim, Cattaneo et al [20] realizaram um estudo sobre a modificação estrutural da rede borato na presença de $\mathrm{PbF}_{2}$ através de experimentos de $\mathrm{RMN}$ de simples e dupla ressonância para os núcleos ${ }^{7} \mathrm{Li},{ }^{11} \mathrm{~B},{ }^{19} \mathrm{~F}$ e ${ }^{207} \mathrm{~Pb}$. Os resultados indicaram que tais unidades $\mathrm{BO}_{4 / 2}$ e $\mathrm{BO}_{3 / 2} \mathrm{~F}^{-}$são previsto para os vidros $\mathrm{B}_{2} \mathrm{O}_{3}-\mathrm{PbO}-\mathrm{LiF}$. Além disso, a formação de unidades $\mathrm{BO}_{2 / 2} \mathrm{~F}$ também é possível. Os autores também assumem uma distribuição aleatória dos íons $\mathrm{F}^{-}$com respeito aos íons $\mathrm{Pb}^{2+}$ sem preferencial formação de domínios semelhantes a $\mathrm{PbF}_{2}$.

\subsection{Teoria Básica de Ressonância Magnética Nuclear (RMN)}

\subsubsection{Mecânica Quântica do Momento angular}

Vários átomos possuem núcleos com momento angular intrínseco (o spin nuclear) e por consequência momento de dipolo magnético. O operador de momento de dipolo magnético nuclear $(\widehat{\boldsymbol{\mu}})$ é proporcional ao operador momento angular nuclear $(\boldsymbol{J})$ [41-44],

$$
\widehat{\boldsymbol{\mu}}=\gamma \widehat{\boldsymbol{J}}=\gamma \hbar \hat{\mathbf{I}},
$$

em que $\gamma$ é fator giromagnético, específico para cada núcleo, e î é o operador vetorial adimensional de spin, que pode ser escrito em termos de suas componentes: 


$$
\hat{\mathbf{I}}=\hat{\mathbf{I}}_{\mathbf{x}} \mathbf{i}+\hat{\mathbf{I}}_{\mathbf{y}} \mathbf{j}+\hat{\mathbf{I}}_{\mathbf{z}} \mathbf{k}
$$

As componentes do operador de spin nuclear e o momento total obedecem as seguintes relações de comutação:

$$
\begin{aligned}
& {\left[\hat{\mathbf{I}}^{2}, \hat{\mathbf{I}}_{\mathbf{x}}\right]=0 \quad\left[\hat{\mathbf{I}}^{\mathbf{2}}, \hat{\mathbf{I}}_{\mathbf{y}}\right]=0 \quad\left[\hat{\mathbf{I}}^{2}, \hat{\mathbf{I}}_{\mathbf{z}}\right]=0} \\
& {\left[\hat{\mathbf{I}}_{\mathbf{x}}, \hat{\mathbf{I}}_{\mathbf{y}}\right]=i \hat{\mathbf{I}}_{\mathbf{z}}\left[\hat{\mathbf{I}}_{\mathbf{y}}, \hat{\mathbf{I}}_{\mathbf{z}}\right]=i \hat{\mathbf{I}}_{\mathbf{x}} \quad\left[\hat{\mathbf{I}}_{\mathbf{z}}, \hat{\mathbf{I}}_{\mathbf{x}}\right]=i \hat{\mathbf{I}}_{\mathbf{y}} \quad .}
\end{aligned}
$$

$\mathrm{Na}$ presença de um campo magnético externo o momento de dipolo dos núcleos é quantizado na direção do campo (geralmente definido como eixo z). Relacionando os observáveis com os autoestados de spin do núcleo, temos as seguintes equações de autovalor $\operatorname{para} \hat{\mathbf{I}}^{2}$ e $\hat{\mathbf{I}}_{\mathrm{z}}$,

$$
\begin{aligned}
& \hat{\mathbf{I}}^{2}|I, m\rangle=I(I+1)|I, m\rangle \quad \text { com } \quad I=0, \frac{1}{2}, 1, \ldots \\
& \hat{\mathbf{I}}_{\mathbf{z}}|I, m\rangle=m|I, m\rangle \quad \text { com } \quad m=-I,-I+1, \ldots, I
\end{aligned}
$$

em que $m$ é o número quântico orientacional, e $I$ é o número quântico de spin de um determinado núcleo - que depende da relação entre prótons e nêutrons deste. $\hat{\mathbf{I}}_{\mathbf{x}}$ e $\hat{\mathbf{I}}_{\mathbf{y}}$ podem ser representados pelos operadores de deslocamento,

$$
\begin{aligned}
& \hat{\mathbf{I}}^{+}=\hat{\mathbf{I}}_{\mathbf{x}}+i \hat{\mathbf{I}}_{\mathbf{y}} \\
& \hat{\mathbf{I}}^{-}=\hat{\mathbf{I}}_{\mathbf{x}}-i \hat{\mathbf{I}}_{\mathbf{y}},
\end{aligned}
$$

que atuam sobre um autoestado $|I, m\rangle$ levando-o aos estados de maior e menor número quântico orientacional, através das seguintes relações:

$$
\begin{gathered}
\hat{\mathbf{I}}^{+}|I, m\rangle=\sqrt{I(I+1)-m(m+1)}|I, m+1\rangle \\
\hat{\mathbf{I}}^{-}|I, m\rangle=\sqrt{I(I+1)-m(m-1)}|I, m-1\rangle .
\end{gathered}
$$


Quando um campo magnético homogêneo e constante é aplicado, ocorre a remoção da degenerescência dos distintos estados orientacionais de spin nuclear. A contribuição de energia é definida por interação Zeeman, e é escrita como[43]:

$$
\widehat{\mathbf{H}}_{z}=-\widehat{\boldsymbol{\mu}} \cdot \mathbf{B}_{\mathbf{0}}=-\gamma \hbar \mathrm{B}_{0} \hat{\mathbf{I}}_{z}
$$

resultando na seguinte equação de autovalor:

$$
\begin{gathered}
\widehat{\mathbf{H}}_{\mathbf{z}}|I, m\rangle=E_{m}|I, m\rangle=-m \gamma \hbar \mathrm{B}_{0}|I, m\rangle \\
E_{m}=-m \gamma \hbar \mathrm{B}_{0}
\end{gathered}
$$

Em uma amostra com $N$ núcleos não interagentes e volume $V$, sob influência de um campo magnético $B_{0}$ e temperatura $T$, a magnetização na direção $\mathrm{z}$, paralela ao campo magnético, no regime de altas temperaturas $\left(\frac{E_{m_{I}}}{K_{B} T} \ll 1\right.$ válido em condições normais do experimento de RMN até $2 \mathrm{~K}$ ) é dada por:

$$
\begin{gathered}
\left\langle\widehat{M}_{z}\right\rangle=\frac{N}{V} \sum_{m_{I}=-I}^{I} \frac{\left(1+\gamma_{N} \hbar B_{0} m_{I} / K_{B} T\right)}{2 I+1} \gamma \hbar m_{I}=\frac{N}{V} \sum_{m_{I}=-I}^{I} \frac{\gamma_{N}^{2} \hbar^{2} m_{I}^{2} B_{0}}{(2 I+1) K_{B} T} \\
\left\langle\widehat{M}_{z}\right\rangle=\frac{N}{V} \frac{\gamma_{N}^{2} \hbar^{2} B_{0} I(I+1)}{3 K_{B} T}
\end{gathered}
$$

que é a lei de Curie para a magnetização de um conjunto de spins não interagentes.

Em um experimento típico de ressonância, um pulso de radifrequência promove transições entre estados vizinhos, o que resulta nas condições de ressonância:

$$
E_{r f}=\hbar \omega_{r f}=\gamma \hbar B_{0} \rightarrow \omega_{r f}=\gamma B_{0}
$$

Do ponto de vista do conjunto de spins de uma amostra, um pulso de r.f. em frequência de ressonância introduz momentaneamente um campo magnético ( $\left.\mathrm{B}_{1}\right)$, 
considerado estacionário em relação a magnetização inicial. A equação de movimento da magnetização é dada por:

$$
\tau=\frac{d \vec{M}}{d t}=\gamma \vec{M} \times \overrightarrow{\mathrm{B}}
$$

A magnetização inicial em z sofre um torque devido à r.f., e passa a apresentar magnetização transversal. Após a duração do pulso de r.f., a magnetização passa a precessionar em torno de $\mathrm{z}$ devido ao torque imposto por $\mathrm{B}_{0}$. A solução da equação diferencial acima no instante posterior ao pulso de r.f. é uma magnetização que precessiona com frequência de Larmor $\left|\omega_{0}\right|=\left|\gamma B_{0}\right|$ em torno do eixo z,

$$
\vec{M}=M_{x 0} \cos \left(\omega_{0} t\right) \vec{\imath}+M_{y 0} \operatorname{sen}\left(\omega_{0} t\right) \vec{\jmath}+M_{z 0} \vec{k}
$$

em que $M_{x 0}$ e $M_{y 0}$ são relacionados pela direção e intensidade da componente magnética do pulso, do tempo aplicado e do fator giromagnético do núcleo. Observe, portanto, que a frequência de ressonância $\left(\omega_{r f}\right)$ é então também a frequência de precessão da magnetização ( $\omega_{0}$ ). Entretanto, um pulso de r.f. não é monocromático, possuindo uma distribuição de frequências em torno de $\omega_{r f}$, ao passo que as amostras possuem um ambiente químico que desloca $\omega_{0}$ para distintos valores.

Pulsos convencionados por $(\pi / 2)_{x, y}$ são aqueles que formam a magnetização transversal máxima, enquanto os pulsos convencionados por $(\pi)_{x, y}$ invertem a magnetização inicial $\left\langle\hat{M}_{z}\right\rangle$.

À solução da equação de movimento da magnetização descrita acima é preciso adicionar os termos de relaxação da magnetização, empiricamente incluídos na equação de Bloch. Desta maneira, obtemos o retorno da magnetização longitudinal a situação de equilíbrio, a uma taxa de relaxação exponencial de $\frac{1}{T_{1}}$. Analogamente, a relaxação da magnetização transversal ou "relaxação spin-spin", cuja taxa de decaimento é dada por

$$
\frac{1}{T_{2}^{*}}=\frac{1}{T_{2}}+\frac{1}{T_{2}^{l}}
$$


em que o primeiro termo descreve uma defasagem dos spins devido às flutuações espaciais e temporais do campo magnético, e o segundo, do campo externo aplicado. Em sólidos, de modo geral, têm-se que $T_{2}<<T_{1}$.

Em um experimento de RMN uma espira orientada perpendicularmente a $\mathrm{B}_{0}$ é usada para geração do pulso de excitação e, posteriormente, para a detecção da variação da magnetização na amostra. A variação da magnetização é comumente denominada por "decaimento livre da indução" (em inglês free induction decay FID). Esta é, por motivos técnicos, medida no sistema de referência de rotação em torno de $\mathrm{z}$, a frequência $\omega_{r f}$. Dessa maneira, o "sinal" de RMN em pulso simples é detectado na forma:

$$
F I D(t) \approx \omega_{L} \cos \left(\left(\omega_{L}-\omega_{r f}\right) t\right) \exp \left[-\frac{1}{T_{2}^{*}}\right]
$$

Para se obter um espectro no domínio de frequência, o que torna a distinção dos diferentes ambientes químicos de uma amostra mais direta, a Transformada de Fourier sobre o FID é realizada, e o "sinal" de RMN é representado por:

$$
S\left(\omega_{L}-\omega_{0}\right)=\frac{1}{2 \pi} \int_{-\infty}^{\infty} F I D(t) \exp \left[\left(-i\left(\omega_{L}-\omega_{r f}\right) t\right] d t\right.
$$

Na parte real da transformada de Fourier do decaimento, os picos representam o deslocamento de frequência da precessão da magnetização enquanto a largura do pico é influenciada pelo tempo de relaxação transversal da magnetização.

\subsubsection{Descrição Geral das Interações}

Diferentes interações, adicionais à interação Zeeman, são provenientes do ambiente químico em que se encontra o núcleo, e são responsáveis pela forma final do espectro de RMN. Esta particularidade faz de RMN uma poderosa ferramenta de caracterização estrutural, de curto e médio alcance, na escala atômica. O Hamiltoniano de spin relevante para este estudo é dado por:

$$
\widehat{\mathcal{H}}=\widehat{\mathcal{H}}_{Z}+\widehat{\mathcal{H}}_{R F}+\widehat{\mathcal{H}}_{C S}+\widehat{\mathcal{H}}_{D D}+\widehat{\mathcal{H}}_{J}+\widehat{\mathcal{H}}_{Q}
$$


As diversas interações estão listadas na tabela 1.

Tabela 1- Sumário dos Hamiltonianos

\begin{tabular}{|c|c|}
\hline Hamiltoniano & Interações \\
\hline$\widehat{\mathcal{H}}_{Z}$ & Interação Zeeman \\
\hline$\widehat{\mathcal{H}}_{R F}$ & $\begin{array}{c}\text { Interação com o campo de uma onda de } \\
\text { radio frequência }\end{array}$ \\
\hline$\widehat{\mathcal{H}}_{C S}$ & $\begin{array}{c}\text { Blindagem magnética de spins nucleares } \\
\text { causada pelo ambiente eletrônico } \\
\text { (deslocamento químico) }\end{array}$ \\
\hline$\widehat{\mathcal{H}}_{D D}$ & Interação dipolar direta entre os núcleos \\
\hline$\widehat{\mathcal{H}}_{J}$ & $\begin{array}{l}\text { Interação magnética dipolo-dipolo } \\
\text { indireta, transmitida pelos elétrons } \\
\text { (acoplamento escalar) }\end{array}$ \\
\hline$\widehat{\mathcal{H}}_{Q} \quad I>1 / 2$ & $\begin{array}{c}\text { Interação do momento quadrupolar } \\
\text { elétrico de núcleos com gradientes de } \\
\text { campo elétrico }\end{array}$ \\
\hline
\end{tabular}

\subsubsection{Deslocamento Químico}

O campo magnético aplicado na amostra induz uma corrente na camada eletrônica, que gera um campo magnético adicional na direção oposta a $B_{0}$. Assim o campo magnético efetivo experimentado por um núcleo é dado pela soma do campo magnético externo e as componentes do campo magnético induzido [18,44].

$$
\mathrm{B}_{\text {eff }}=\mathrm{B}_{0}+\mathrm{B}_{\text {ind }}
$$

Essa interação altera a frequência de ressonância do núcleo e é, portanto, um indicador da densidade eletrônica nas proximidades do núcleo, o que caracteriza o ambiente vizinho. A blindagem magnética pode ser anisotrópica, uma vez que o campo induzido pode ter componentes não paralelas a $\mathrm{B}_{0}$. Sendo assim, o tensor de blindagem magnética $\overleftrightarrow{\sigma}$ é introduzido, o qual liga o campo magnético externo com o campo induzido a um núcleo i. 


$$
\mathrm{B}_{\text {ind }}=-\overleftrightarrow{\mathrm{\sigma}}(\mathrm{i}) \cdot \mathrm{B}_{0}
$$

em que: [59].

$$
\overleftrightarrow{\sigma}(\mathrm{i})=\left(\begin{array}{lll}
\sigma_{\mathrm{xx}} & \sigma_{\mathrm{xy}} & \sigma_{\mathrm{xz}} \\
\sigma_{\mathrm{yx}} & \sigma_{\mathrm{yy}} & \sigma_{\mathrm{yz}} \\
\sigma_{\mathrm{zx}} & \sigma_{\mathrm{zy}} & \sigma_{\mathrm{zz}}
\end{array}\right)
$$

O Hamiltoniano para essa interação é expresso por:

$$
\widehat{\mathcal{H}}_{C S}(\mathbf{i})=\hbar \sum_{\mathbf{i}}^{\text {spin }} \boldsymbol{\gamma}_{\mathbf{i}} \hat{\mathbf{I}}(\mathbf{i}) \cdot \overleftrightarrow{\sigma}(\mathbf{i}) \cdot \widehat{\mathbf{B}}_{\mathbf{0}}
$$

A matriz do tensor pode ser diagonalizável por uma transformação estável no sistema de eixo principal (do inglês PAS “principle axis system”). Convencionalmente, o PAS é escolhido de modo que a seguinte expressão é valida.

$$
\left|\sigma_{y y}^{p a s}-\sigma_{i s o}^{p a s}\right| \leq\left|\sigma_{x x}^{p a s}-\sigma_{i s o}^{p a s}\right| \leq\left|\sigma_{z z}^{p a s}-\sigma_{i s o}^{p a s}\right|
$$

Os três principais valores dos tensores componentes são frequentemente escritos como uma componente isotrópica $\boldsymbol{\sigma}_{\text {iso }}$, uma anisotrópica $\Delta \boldsymbol{\sigma}$, e o parâmetro de assimetria $\boldsymbol{\eta}$. Essas quantidades são definidas abaixo:

$$
\begin{gathered}
\sigma_{\mathrm{iso}}=\frac{1}{3}\left(\sigma_{\mathrm{zz}}^{\mathrm{pas}}+\sigma_{\mathrm{yy}}^{\mathrm{pas}}+\sigma_{\mathrm{xx}}^{\mathrm{pas}}\right) \\
\Delta \sigma=\sigma_{\mathrm{zz}}^{\mathrm{pas}}-\frac{1}{2}\left(\sigma_{\mathrm{yy}}^{\mathrm{pas}}+\sigma_{\mathrm{xx}}^{\mathrm{pas}}\right) \\
\eta=\frac{\sigma_{\mathrm{xx}}^{\mathrm{pas}}-\sigma_{\mathrm{yy}}^{\mathrm{pas}}}{\delta} \quad \operatorname{com} \quad \delta=\sigma_{\mathrm{zz}}^{\mathrm{pas}}-\sigma_{\text {iso }}
\end{gathered}
$$

Alternativamente, a frequência de deslocamento químico pode ser expressa como uma função desses tensores componentes. 


$$
\omega=\gamma B_{0}\left(1-\sigma_{\text {iso }}-\frac{1}{2} \Delta \sigma\left(3 \cos ^{2} \theta-1-\eta \operatorname{sen}^{2} \theta \cos 2 \phi\right)\right)
$$

A equação consiste de uma parte isotrópica e uma anisotrópica. O ângulo polar $\theta$ descreve o ângulo entre o eixo do PAS ao longo $\sigma_{z z}$ e a direção do campo magnético externo, $\Delta \sigma$ expressa a magnitude do deslocamento químico anisotrópico.. Em RMN de estado sólido a anisotropia do deslocamento químico causa um alargamento do sinal porque as amostras são policristalinas e todas as orientações contribuem para o espectro devido a sua abundância.

Experimentalmente, o desvio químico de uma amostra é medido com respeito a uma substância referência padrão, a qual é utilizada para calibração.

$$
\delta_{i s o}=\frac{\omega-\omega_{r e f}}{\omega_{r e f}}
$$

onde, $\delta_{\text {iso }}$ é adimensional e independente da magnitude do campo magnético externo. $\mathrm{O}$ deslocamento químico é o mais importante parâmetro de interação interna que influência na frequência de ressonância para núcleos com spin $1 / 2$.

\subsubsection{Interação Magnética Dipolo-Dipolo}

Como dito anteriormente, spins nucleares possuem momento magnético e, portanto, cada spin cria um campo magnético local, onde os spins vizinhos sentem e interagem com este campo. Em RMN de estado sólido essa interação causa um alargamento de linha. Classicamente, a magnitude do campo magnético local, criado por um momento $\mu_{j}$ e interagindo com outro momento $\mu_{i}$ pode ser calculado por $[18,44]$ :

$$
\mathbf{B}_{\mathbf{D}}(\mathbf{r})=\frac{\mu_{0}}{4 \pi}\left(\frac{\boldsymbol{\mu}_{\mathbf{j}}}{\mathrm{r}^{3}}-3 \boldsymbol{\mu}_{\mathbf{j}} \cdot \frac{\mathbf{r}}{\mathrm{r}^{5}} \mathbf{r}\right)
$$

onde $\mathbf{r}$ representa a distância vetorial entre os dois dipolos. Como resultado, a energia dessa interação é representada por:

$$
E_{D I P}(i, j)=-\mu_{i} \cdot B_{D}(\mathbf{r})
$$


Quanticamente, a energia dessa interação é descrita pelo respectivo Hamiltoniano, o qual pode ser calculado pelo somatório de todos os pares de spins.

$$
\widehat{\mathcal{H}}_{\mathrm{DIP}}=-\frac{\mu_{0}}{4 \pi} \sum_{\mathrm{i}}^{\text {spin spin }} \sum_{\mathbf{j}>i} \gamma_{\mathrm{i}} \gamma_{\mathbf{j}} \hbar^{2}\left[\frac{\hat{\mathbf{I}}(\mathbf{i}) \hat{\mathbf{I}}(\mathbf{j})}{\mathrm{r}^{3}}-\frac{\mathbf{3}(\hat{\mathbf{I}}(\mathbf{i}) \cdot \mathbf{r})(\hat{\mathbf{I}}(\mathbf{j}) \cdot \mathbf{r})}{\mathrm{r}^{5}}\right]
$$

Depois de realizar uma transformação de coordenadas para o sistema de coordenadas polares $(r, \theta, \phi)$ o Hamiltoniano dipolar pode ser escrito pelo formalismo conhecido como “Alfabeto Dipolar":

$$
\widehat{\mathcal{H}}_{\mathrm{DIP}}=-\mathbf{d}(\widehat{\mathbf{A}}+\widehat{\mathbf{B}}+\widehat{\mathbf{C}}+\widehat{\mathbf{D}}+\widehat{\mathbf{E}}+\widehat{\mathbf{F}})
$$

em que

$$
\begin{gathered}
\mathrm{d}=\frac{\mu_{0} \gamma_{\mathrm{i}} \gamma_{\mathrm{j}} \hbar^{2}}{4 \pi \mathrm{r}^{3}} \quad \text { constante de acoplamento dipolar } \\
\widehat{\mathbf{A}}=\widehat{\mathbf{I}_{\mathbf{z}}}(\mathbf{i}) \widehat{\mathbf{I}}_{\mathbf{z}}(\mathbf{j})\left(1-3 \cos ^{2} \theta\right) \\
\widehat{\mathbf{B}}=-\frac{\mathbf{1}}{4}\left(\widehat{\mathbf{I}^{+}}(\mathbf{i}) \widehat{\mathbf{I}^{-}}(\mathbf{j})+\widehat{\mathbf{I}^{-}}(\mathbf{i}) \widehat{\mathbf{I}^{+}}(\mathbf{j})\left(1-3 \cos ^{2} \theta\right)\right. \\
\widehat{\mathbf{C}}=-\frac{3}{2}\left(\widehat{\mathbf{I}^{+}}(\mathbf{i}) \widehat{\mathbf{I}} \mathbf{z}(\mathbf{j})+\widehat{\mathbf{I}^{+}}(\mathbf{j}) \widehat{\mathbf{I}}_{\mathbf{z}}(\mathbf{i}) \sin \theta \cos \theta \mathrm{e}^{-\mathbf{i} \phi}\right. \\
\widehat{\mathbf{D}}=-\frac{3}{2}\left(\widehat{\mathbf{I}^{-}}(\mathbf{i}) \widehat{\mathbf{I}_{\mathbf{z}}}(\mathbf{j})+\widehat{\mathbf{I}^{-}}(\mathbf{j}) \widehat{\mathbf{I}}_{\mathbf{z}}(\mathbf{i}) \sin \theta \cos \theta \mathrm{e}^{+\mathbf{i} \phi}\right. \\
\widehat{\mathbf{E}}=-\frac{3}{4}\left(\widehat{\mathbf{I}^{+}}(\mathbf{i}) \widehat{\mathbf{I}^{+}}(\mathbf{j})\right) \sin ^{2} \theta \mathrm{e}^{-2 i \phi} \\
\widehat{\mathbf{F}}=-\frac{3}{4}\left(\widehat{\mathbf{I}^{-}}(\mathbf{i}) \widehat{\mathbf{I}^{-}}(\mathbf{j})\right) \sin ^{2} \theta \mathrm{e}^{-2 i \phi}
\end{gathered}
$$

O termo $\widehat{\mathbf{A}}$ corresponde a interação clássica dipolo - dipolo em um sistema de dois spins $(i, j)$. 
O termo $\widehat{\mathbf{B}}$ é chamado de "flip-flop", pois descreve uma inversão na conversão de energia de ambas as direções de rotação. Basicamente, este tipo de transição só é possível se os spins são da mesma espécie (interação homonuclear), visto que eles precisão ter a mesma frequência de Larmor. Os termos $\widehat{\mathbf{C}}$ e $\widehat{\mathbf{D}}$ correspondem a uma transição de um spin para outro estado $\left(\Delta m={ }_{-}^{+} 1\right)$. Os termos $\hat{\mathbf{E}}$ e $\hat{\mathbf{F}}$ descrevem a transição de ambos os spins na mesma direção $\left(\Delta m={ }_{-} 2\right)$. Todas as transições descritas acima estão ilustradas na Figura 4.

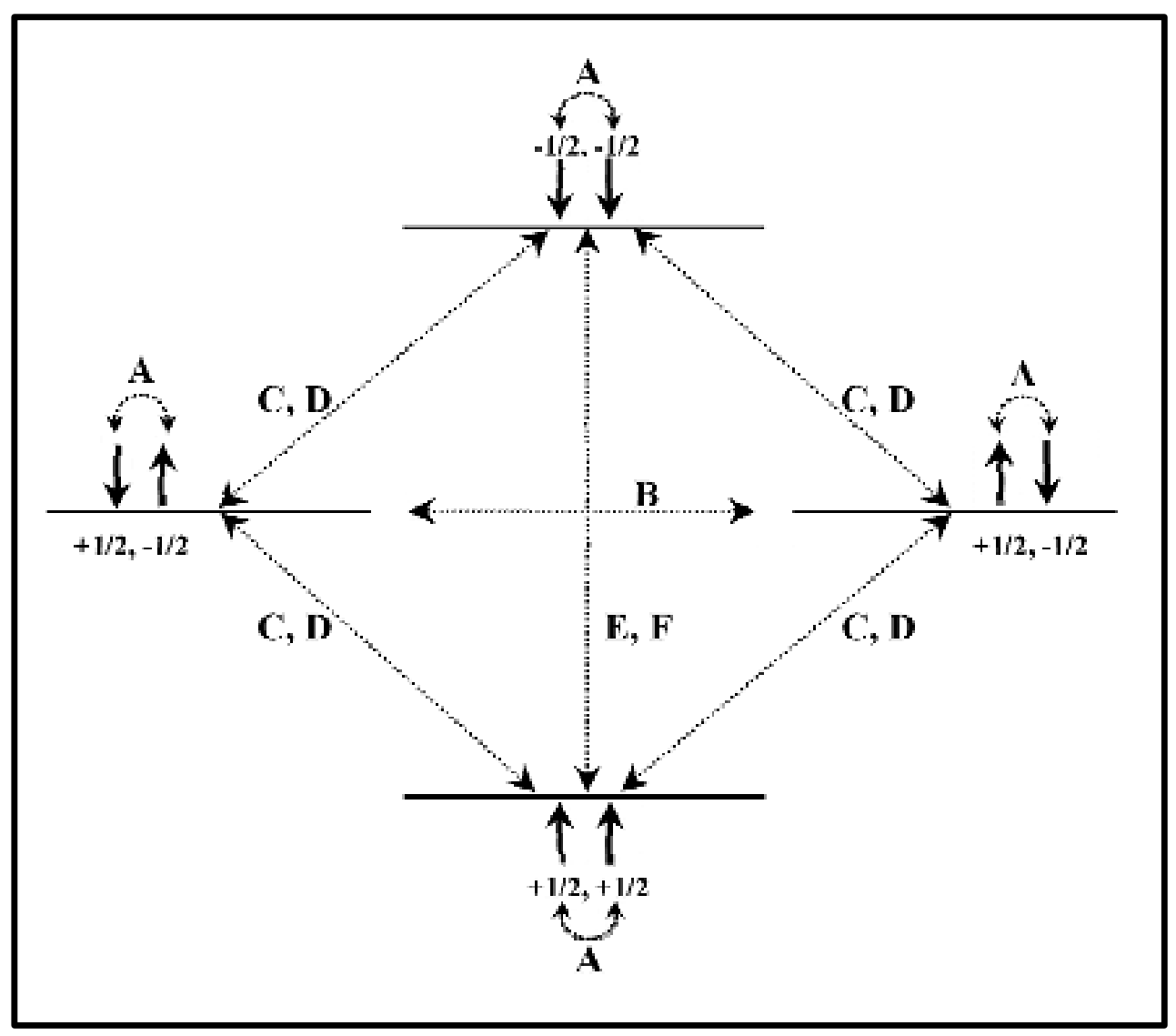

Figura 4- Esquema de um alfabeto dipolar para um sistema de dois spins com spin nuclear $1 \frac{1}{2}$ idêntico

No intuito de determinar os níveis de energia, apenas um cálculo de perturbação de primeira ordem é solicitado, isto porque a interação dipolo-dipolo é considerada mais fraca comparada à interação Zeeman. Por essa razão, somente as partes seculares do Hamiltoniano dipolar total, termos A e B que comutam com o operador Zeeman, são considerados. No caso de uma interação dipolo-dipolo homonuclear, a seguinte equação é válida:

$$
\widehat{\mathcal{H}}_{\mathrm{DIP}, \text { homo }}=-\frac{\mu_{0} \gamma_{\mathrm{i}} \gamma_{\mathbf{j}} \hbar^{2}}{8 \pi \mathrm{r}^{3}}\left(1-3 \cos ^{2} \theta\right)\left(3 \widehat{\mathbf{I}}_{\mathbf{z}}(\mathbf{i}) \widehat{\mathbf{I}}_{\mathbf{z}}(\mathbf{j})-\hat{\mathbf{I}}(\mathbf{i}) \hat{\mathbf{I}}(\mathbf{j})\right)
$$


No caso de um acoplamento dipolo-dipolo heteronuclear os spins não possuem a mesma frequência de LARMOR. O termo B não comuta com o operador Zeeman, porque as transições "flip-flop" não ocorrem com conservação de energia devido aos diferentes níveis Zeeman participantes. Sendo assim, o Hamiltoniano que contribui para esse determinado acoplamento é dado por:

$$
\widehat{\mathcal{H}}_{\text {DIP,hetero }}=-\frac{\mu_{0} \gamma_{\mathrm{i}} \gamma_{\mathrm{j}} \hbar^{2}}{4 \pi r^{3}}\left(1-3 \cos ^{2} \theta\right) \hat{\mathbf{I}}_{\mathbf{z}} \widehat{\mathbf{S}}_{\mathbf{z}}
$$

A interação dipolo-dipolo é principalmente uma função do ângulo entre a distância do vetor $\mathbf{r}$ e o campo magnético externo $\mathbf{B}_{\mathbf{0}}$. Além disso, a forma de linha depende da distribuição estatística dos ângulos. Usualmente, não existem pares de spins isolados em materiais sólidos, mas sim um sistema de múltiplos spins. Em amostras pulverizadas, a distribuição estatística dos ângulos em sistemas de múltiplos spins causa um alargamento na forma de linha gaussiana.

Devido à complexa dependência geométrica de sistemas de múltiplos spins, os cálculos são considerados bastante complicados. Sem ter conhecimento dos autovalores do Hamiltoniano total, o Método de Momentos desenvolvido por van Vleck é capaz de quantificar a interação dipolar em sistemas de múltiplos spins [47].

\subsubsection{Interação Quadrupolar}

Aproximadamente $74 \%$ dos núcleos ativos têm spin nucleares maiores que $1 / 2$. Sendo assim, devido à regra de paridade, estes núcleos não possuem um momento de dipolo elétrico, mas um momento de quadrupolo elétrico, que resulta em uma distribuição assimétrica das cargas no núcleo. Esse momento de quadrupolo é definido a partir do produto da carga pela área que é descrita pelo escalar $e Q$ [44]. Este escalar interage apenas com um gradiente de campo elétrico diferente de zero, assim as informações do ambiente elétrico ao redor do núcleo podem ser obtidas. O gradiente de campo elétrico é descrito por um tensor, que é diagonalizável por um PAS, no qual suas componentes individuas são dadas pela derivada segunda do potencial elétrico na posição do núcleo.

$$
V_{\alpha, \beta}=\left(\frac{\partial^{2} V}{\partial \alpha \partial \beta}\right)_{r=0} \quad \operatorname{com} \quad \alpha, \beta=x, y, z
$$


O tensor gradiente de campo elétrico não apresenta nenhuma componente isotrópica. O sistema de eixo principal (PAS) é escolhido de modo que a seguinte expressão seja válida:

$$
\left|\mathrm{V}_{\mathrm{zz}}^{\mathrm{PAS}}\right| \geq\left|\mathrm{V}_{\mathrm{yy}}^{\mathrm{PAS}}\right| \geq\left|\mathrm{V}_{\mathrm{xx}}^{\mathrm{PAS}}\right|
$$

cujos parâmetros são definidos

$$
\begin{gathered}
e q=\mathrm{V}_{\mathrm{zz}}^{\mathrm{PAS}} \\
\eta_{q}=\frac{\mathrm{V}_{\mathrm{xx}}^{\mathrm{PAS}}-\mathrm{V}_{\mathrm{yy}}^{\mathrm{PAS}}}{\mathrm{V}_{\mathrm{zz}}^{\mathrm{PAS}}}
\end{gathered}
$$

onde $\eta_{q}$ é o parâmetro assimétrico quadrupolar indicando o desvio do gradiente de campo elétrico a partir da simetria axial.

A magnitude da interação quadrupolar é dada pela constante de acoplamento

$$
\mathrm{C}_{\mathrm{q}}=\frac{\mathrm{e}^{2} \mathrm{qQ}}{\hbar}
$$

e a frequência de acoplamento quadrupolar é conhecida como:

$$
\omega_{\mathrm{q}}=\frac{3 \mathrm{e}^{2} \mathrm{qQ}}{2 \mathrm{I}(2 \mathrm{I}-1) \hbar}
$$

A orientação do PAS é determinada pela estrutura química ao redor do núcleo, neste quadro, o Hamiltoniano quadrupolar é dado por:

$$
\widehat{\mathcal{H}}_{q}=\frac{\mathrm{e}^{2} \mathrm{qQ}}{4 \mathrm{I}(2 \mathrm{I}-1) \hbar}\left(3 \hat{\mathbf{I}}_{\mathrm{z}^{\mathrm{PAS}}}^{2}-\hat{\mathbf{I}}^{2}+\frac{1}{2} \eta_{\mathrm{q}}\left(\hat{\mathbf{I}}_{\mathrm{x}^{\mathrm{PAS}}}^{2}-\hat{\mathbf{I}}_{\mathbf{y}^{\mathrm{PAS}}}^{2}\right)\right)
$$

Esta formulação não é muito útil para lidar com experimentos de RMN, isto porque a interação Zeeman descrita no sistema de coordenada de laboratório - LAS (do inglês “Laboratry System Axis”) é a interação dominante [43]. Por esse motivo uma nova expressão do Hamiltoniano quadrupolar em termos do LAS deve ser obtida. Somente dois ângulos são necessários $(\theta, \phi)$ para descrever a relação entre os dois sistemas coordenados, visto que x e y 
do LAS são arbitrários. No caso da interação quadrupolar que causa desdobramentos inferiores a $10 \%$ do desdobramento Zeeman no campo específico, um cálculo de perturbação de primeira ordem é usualmente suficiente para determinação dos níveis de energia. $\mathrm{O}$ Hamiltoniano quadrupolar de primeira ordem é:

$$
\widehat{\mathcal{H}}_{\mathrm{q}}^{(1)}=\frac{\mathrm{e}^{2} \mathrm{qQ}}{8 \mathrm{I}(2 \mathrm{I}-1) \hbar}\left(3 \hat{\mathrm{I}}_{\mathrm{z}}^{2}-\mathrm{I}(\mathrm{I}+1)\left(3 \cos ^{2} \theta-1+\eta_{\mathrm{q}} \operatorname{sen}^{2} \theta \cos 2 \phi\right)\right.
$$

Se nenhuma outra interação estiver presente e se o gradiente de campo elétrico é simplificado para simetria axial, o conjunto de energia pode ser escrito como:

$$
\mathrm{E}_{\mathrm{m}}=\mathrm{E}_{\mathrm{z}}+\mathrm{E}_{\mathrm{Q}}^{(1)}=-\gamma \hbar \mathrm{mB} \mathrm{B}_{0}+\frac{\mathrm{e}^{2} \mathrm{qQ}}{8 \mathrm{I}(2 \mathrm{I}-1)}\left(3 \mathrm{~m}^{2}-\mathrm{I}(\mathrm{I}+1)\right)\left(3 \cos ^{2} \theta-1\right)
$$

Mas quando o acoplamento quadrupolar é grande, um cálculo de perturbação de segunda ordem é necessário, resultando na seguinte expressão:

$$
\begin{aligned}
\mathrm{E}_{\mathrm{Q}}^{2}=-\left(\frac{\mathrm{e}^{2} \mathrm{qQ}}{4 \mathrm{I}(2 \mathrm{I}-1) \hbar}\right)^{2} \frac{\mathrm{m}}{\omega_{0}}\left\{-\frac{1}{5}\left(\mathrm{I}(\mathrm{I}+1)-3 \mathrm{~m}^{2}\right)\left(3+\eta_{\mathrm{Q}}^{2}\right)\right. \\
+\frac{1}{28}\left(8 \mathrm{I}(\mathrm{I}+1)-12 \mathrm{~m}^{2}-3\right)\left[\left(\eta_{\mathrm{Q}}^{2}-3\right)\left(3 \cos ^{2} \theta-1\right)+6 \eta_{\mathrm{Q}} \operatorname{sen}^{2} \theta \cos 2 \phi\right] \\
+\frac{1}{8}\left(18 \mathrm{I}(\mathrm{I}+1)-34 \mathrm{~m}^{2}-5\right)\left[\frac{1}{140}\left(18+\eta_{\mathrm{Q}}^{2}\right)\left(35 \cos ^{4} \theta-30 \cos ^{2} \theta+3\right)\right. \\
+\frac{3}{7} \eta_{\mathrm{Q}} \operatorname{sen}^{2} \theta\left(7 \cos ^{2} \theta-1\right) \cos 2 \phi+\frac{1}{4} \eta_{\mathrm{Q}}^{2} \operatorname{sen}^{4} \theta \cos 4 \phi
\end{aligned}
$$

Para um núcleo quadrupolar semi-inteiro, a correção da energia, em primeira ordem devido ao acoplamento quadrupolar, para a chamada transição central $(+1 / 2 \rightarrow-1 / 2)$, é zero. Espera-se que esta transição seja estreitada, em contraste com as transições satélites que estão sujeitas a um alargamento do sinal em uma amostra pulverizada, devido a sua dependência angular. No caso da correção da energia em segunda ordem, a transição central também é afetada. Para uma amostra pulverizada, o sinal será alargado.

O efeito da interação de acoplamento quadrupolar sobre os níveis Zeeman é apresentado na Figura 5. 
Experimentalmente, a força de interação quadrupolar pode ser maior que a força de interação com o pulso de radio frequência. Portanto, durante um pulso de rádio frequência a interação quadrupolar não pode ser ignorada. No caso de acoplamento quadrupolar intenso e aplicações de pulsos de baixa amplitude ("pulsos suaves", $\omega_{Q} \gg \omega_{R F}$ ), somente a transição central é representativa, enquanto as transições satélite são suprimidas. Se um curto pulso com alta amplitude do campo $B_{1}$ é aplicado, todas as transições são irradiadas não seletivamente.

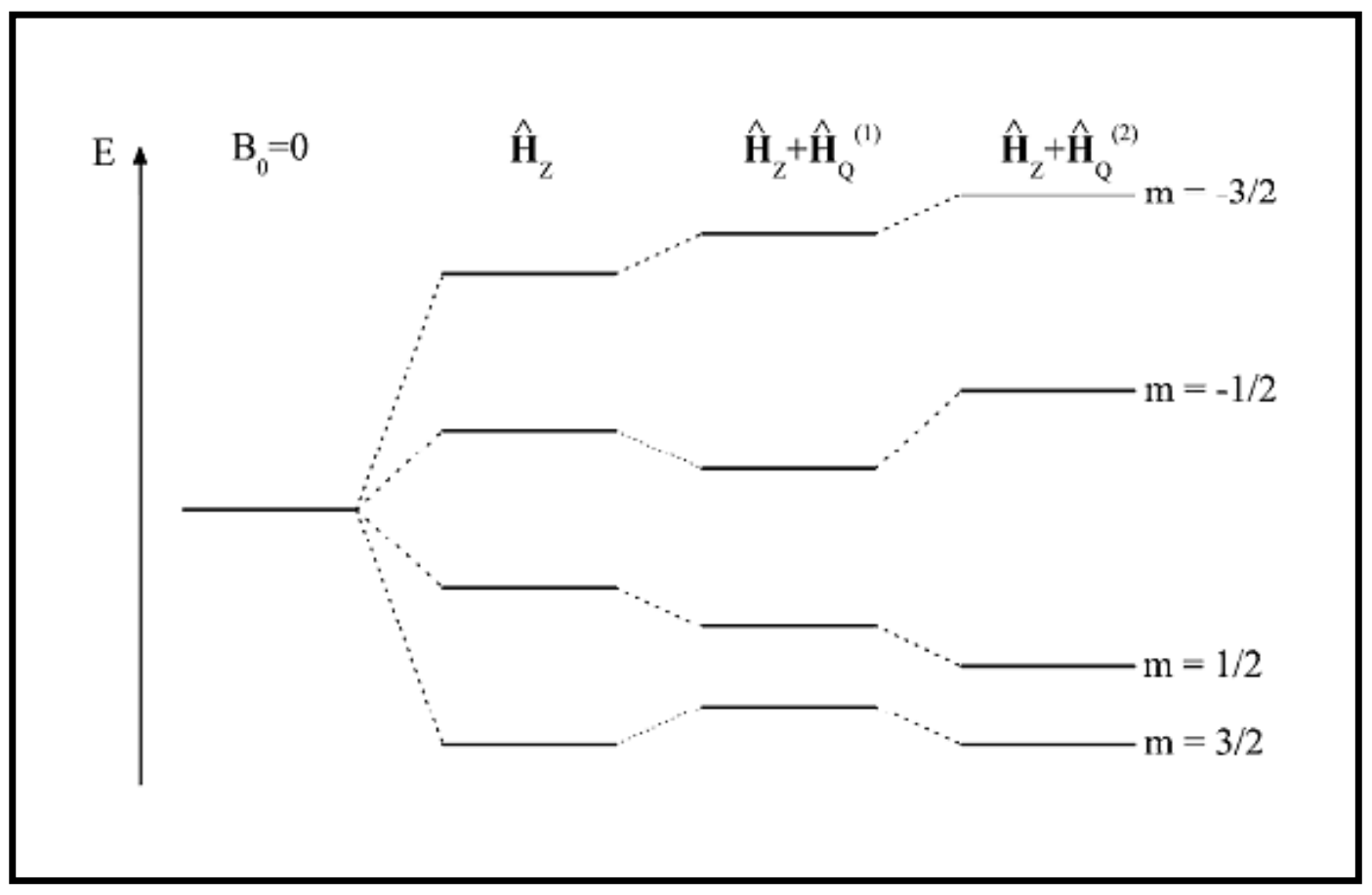

Figura 5- Níveis Zeeman de um núcleo quadrupolar (I=3/2) e seus respectivos desdobramentos

\subsection{Técnicas de RMN de alta resolução}

\subsubsection{Rotação em ângulo mágico (MAS)}

Geralmente, aplica-se RMN de estado sólido em amostras pulverizadas, que consistem de vários cristalitos com orientações aleatórias [42]. Na seção anterior todas as interações com contribuições anisotrópicos (que dependem da orientação dos cristalitos) foram descritas. Como já mencionado, os espectros de RMN para amostras pulverizadas contêm linhas alargadas (padrão de pó), que usualmente podem dar informações úteis sobre as interações isotrópicas e anisotrópicas e, portanto, sobre o sistema químico. Contudo, se várias interações ocorrem e se diversos sítios inequivalentes estão presentes, pode existir uma sobreposição de todos os estados de energias desdobrados resultando em um espectro de RMN complicado de 
difícil interpretação. Em meio líquido, todas as contribuições anisotrópicas são calculadas com base no rápido movimento aleatório das partículas, com respeito à escala de tempo de RMN. Assim, espectros de alta resolução com linhas estreitas são obtidos.

É possível obter esse mesmo resultado para os sólidos quando as amostras são postas sob rotação em ângulo mágico [45]. Devido ao fato da anisotropia do deslocamento químico, interação dipolo-dipolo e interação quadrupolar de primeira ordem possuírem a mesma dependência orientacional $\left(3 \cos ^{2} \theta-1\right)$, essas contribuições anisotrópicas podem ser eliminadas pela rotação de uma amostra em alta velocidade ao redor de um eixo inclinado do chamado ângulo mágico $\left(54,7^{\circ}\right)$ relativo ao campo aplicado (Figura 6). A frequência de rotação deve ser maior que a largura da linha do espectro estático, isto é, maior que a largura em frequência do espectro obtido para a amostra sem rotação, caso contrário, a interação dipolo-dipolo e o deslocamento químico anisotrópico não são completamente eliminados.

Existe também a interação quadrupolar de segunda ordem que pode ser eliminada parcialmente devido à complicada dependência angular (ver equação 55).

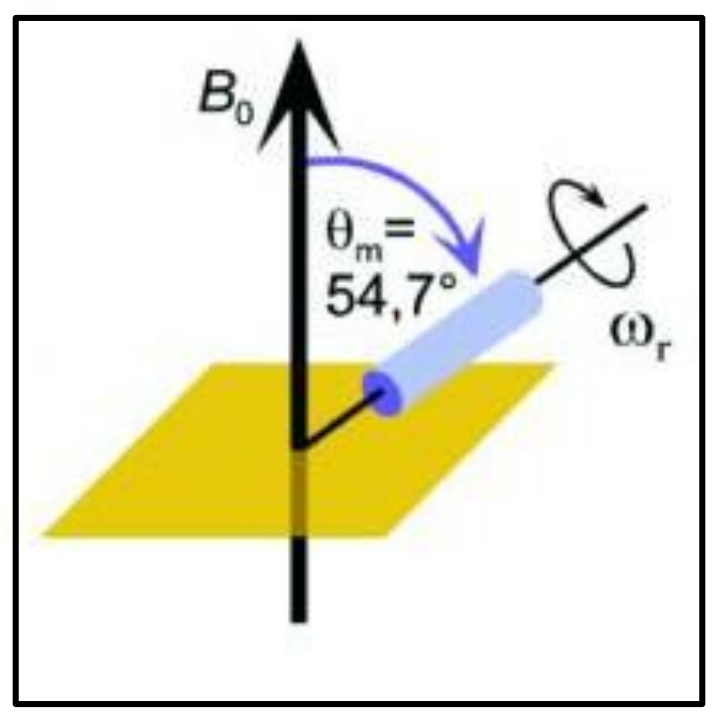

Figura 6- Rotação da amostra na condição de ângulo mágico sob ação de um campo magnético $\mathrm{B}_{0}$

\subsubsection{Eco rotacional de dupla ressonância (REDOR - Rotacional Echo Doble Ressonance)}

Técnicas modernas de RMN de estado sólido apresentam poderosas oportunidades para uma análise quantitativa de interações magnéticas dipolo-dipolo, de maneira a fornecer informações úteis sobre distâncias internucleares e distribuições espaciais. Para se beneficiar da resolução espectral característica, experimentos são realizados sob MAS para eliminar as 
interações dipolares. Utilizando sequência de pulsos apropriados, essas interações podem ser reintroduzidas seletivamente dentro do Hamiltoniano MAS. Existem numerosos experimentos para estudar acoplamentos dipolares heteronucleares. Muitos destes são fundamentados em experimentos do tipo Eco rotacional de dupla ressonância [42]. REDOR é um experimento quantitativo e, portanto, bem adequado para análise quantitativa das interações dipolares.

O Hamiltoniano de um sistema com dois spins heteronucleares ( $I$ e $S$ ) sob condições de MAS é dado por [46]:

$$
\widehat{H}_{D}(t)=\hbar \omega_{D}(\alpha, \beta, t) \hat{I}_{z} \hat{S}_{z}
$$

onde,

$$
\omega_{D}(\alpha, \beta, t)={ }_{-}^{+} d\left(\operatorname{sen}^{2} \beta \cos 2\left(\alpha-\omega_{R} t\right)-\sqrt{2} \operatorname{sen} 2 \beta \cos \left(\alpha-\omega_{R} t\right)\right.
$$

$\mathrm{O}$ ângulo $\alpha$ e $\beta$ descreve a orientação do vetor entre os spins I e $\mathrm{S}$ com respeito ao eixo de rotação, $\omega_{R}$ é a frequência de rotação da amostra e d é a constante de acoplamento dipolar. De acordo com a expressão acima, a dependência temporal da frequência de rotação é dado pela soma de duas funções coseno, resultando em um comportamento periódico. A média do Hamiltoniano dipolar após um período $T_{R}$ do rotor pode ser calculado a partir da seguinte expressão:

$$
\left\langle\widehat{H}_{D}\right\rangle=\frac{1}{T_{R}} \int_{0}^{T_{R}} \widehat{H}_{D}(t) d t
$$

A técnica experimental REDOR consiste em duas partes, como esquematizado na figura 7. 


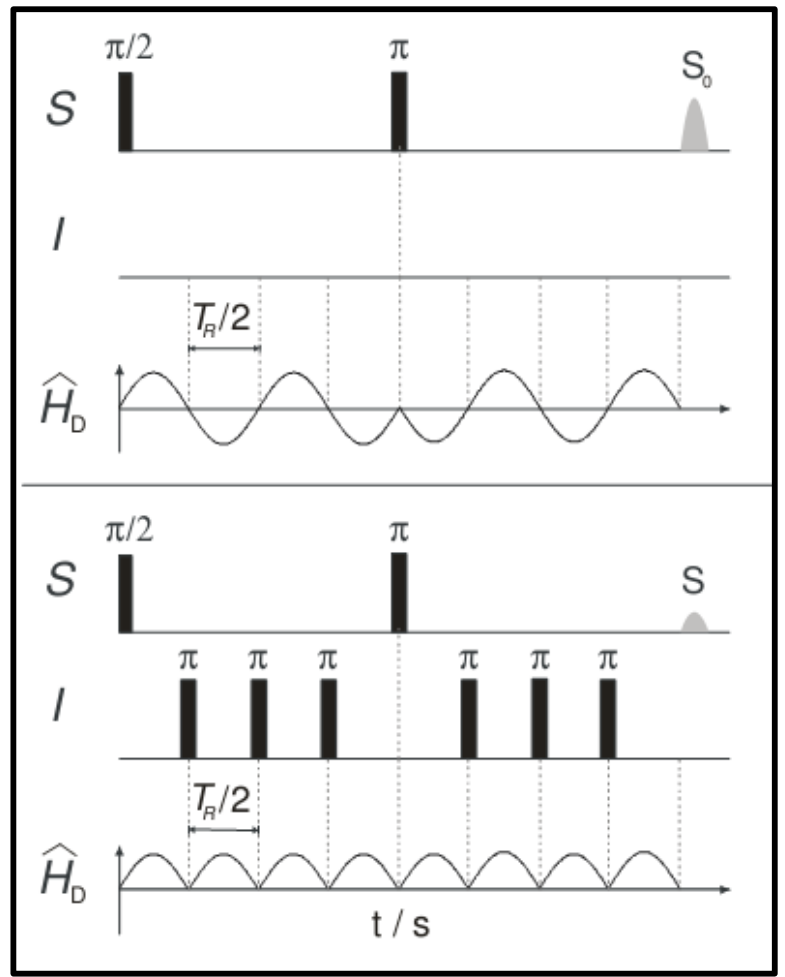

Figura 7- Descrição da sequência de pulso utilizada por um experimento REDOR

A primeira parte representa um experimento spin-echo com rotor sincronizado, onde o Hamiltoniano dipolar é eliminado após um ou múltiplos períodos do rotor $\left(N T_{R}\right)$. A intensidade do sinal $S_{0}$ obtida pelo experimento referência decai com um tempo de evolução crescente devido à relaxação spin-spin [47]:

$$
S_{0}=S_{i} e^{\frac{N T_{R}}{T_{2}}}
$$

no qual $S_{i}$ é a intensidade do sinal após o primeiro pulso de $90^{\circ}$.

$\mathrm{Na}$ segunda parte do experimento, o acoplamento heteronuclear dipolo-dipolo é seletivamente reintroduzido. Isto é realizado por pulsos de $180^{\circ}(\pi)$ aplicados sobre os núcleos não observados (canal I) em intervalos múltiplos da metade do período do rotor $\left(\frac{N T_{R}}{2}\right)$. Entretanto, quando o pulso de eco é aplicado sobre o canal observado S, deixa-se de aplicar o pulso de reacoplamento no canal não observado I. Assim o sinal do $\widehat{H}_{D}$ é invertido a cada pulso de $180^{\circ}$, e a média do Hamiltoniano dipolar é diferente de zero durante os múltiplos do período do rotor. Consequentemente, um decaimento adicional na intensidade do sinal pode ser observado: 


$$
S_{0}=S_{i} e^{\frac{N T_{R}}{T_{2}}} \cos \Delta \phi
$$

com o ângulo de defasagem

$$
\Delta \phi=\overline{\omega_{D}} \tau_{D}
$$

em que $\tau_{D}$ denota a defasagem ou tempo de evolução. A média da constante de acoplamento dependente do tempo é resultado da integração ao longo do tempo de evolução, que tem que ser um múltiplo do período do rotor.

A atenuação adicional resultante da interação heteronuclear dipolar pode ser quantificada através do cálculo da diferença normalizada do sinal $\Delta S=\left(S_{0}-S\right) / S_{0}$ dos dois experimentos realizados na ausência e na presença de pulsos $\pi$ sobre o canal não observado. De modo geral, a magnitude dessa diferença de sinal normalizada depende da constante de acoplamento de dipolo-dipolo heteronuclear e da duração do tempo de evolução $N T_{R}$ durante o qual o acoplamento dipolar está ativo. Assim, um gráfico da diferença normalizada do sinal $\Delta \mathrm{S}=\left(\mathrm{S}_{\mathrm{o}}-\mathrm{S}\right) / \mathrm{S}_{\mathrm{o}}$ em relação ao tempo em que o pulso é aplicado (número de pulso x do período do rotor) dá informações sobre a distância do acoplamento dipolar.

Em sistemas de múltiplos spins, tem-se que a curva de defasagem REDOR depende fortemente da geometria do sistema estudado. No entanto, em caso de sistemas desordenados (por exemplo, vidros), a geometria do sistema é usualmente desconhecia devido às diferentes distribuições de distâncias internucleares e ângulos de ligações. Com base em simulações das distâncias entre os núcleos heteronucleares, Eckert et al. [48] relataram que a dependência geométrica na curva de defasagem é negligenciável no período de curtos tempos de evolução dipolares. Nesse caso, a curva REDOR pode ser aproximada por uma simples parábola, de acordo com:

$$
\frac{\Delta S}{S_{0}}=\frac{16}{15}\left(N T_{R}\right)^{2} \sum_{i=1}^{n} d_{i}^{2}
$$

em que a soma de todas as constantes dipolares $d_{i}$ pode ser relacionada com o segundo momento de dipolo heteronuclear, levando a seguinte expressão: 


$$
\frac{\Delta S}{S_{0}}=\frac{1}{I(I+1) \pi^{2}}\left(N T_{R}\right)^{2} M_{2, \text { hetero }}^{i}
$$

Nesta expressão $I$ denota o número quântico de spin do núcleo não observado e $M_{2}$ para um sistema amorfo ou poli cristalino é dado por:

$$
M_{2}=\frac{3}{5}\left(\frac{\mu_{0}}{4 \pi}\right)^{2} \gamma_{I}^{2} \gamma_{S}^{2} \hbar^{2} I(I+1) \sum_{S} r_{I S}^{-6}
$$

\subsubsection{Polarização Cruzada (CP) e correlação heteronuclear em 2D da polarização cruzada (CP-HETCOR)}

A técnica de polarização cruzada (CP) permite amplificar o sinal de um núcleo com baixa abundância natural e pequeno valor de $\gamma$ devido à transferência de magnetização a partir de outro núcleo abundante contendo elevado valor de $\gamma$ [49]. Pelo fato da transferência de magnetização proceder do acoplamento dipolar heteronuclear, o experimento de polarização cruzada contém também informações sobre o ambiente do núcleo observado. Nas medidas de CP, são observados apenas núcleos que estão espacialmente próximos a fonte de magnetização, enquanto que, no espectro de pulso simples, é possível observar todos os núcleos da amostra. Portanto, uma conclusão sobre o envolvimento específico do núcleo observado pode ser feita.

$\mathrm{O}$ requisito básico para um experimento de $\mathrm{CP}$ bem sucedido é a análise do comportamento do acoplamento de spin dos núcleos envolvidos. Para que dois conjuntos de spins distintos (I e S) sejam bem acoplados, inicialmente a magnetização de um determinado núcleo (I), após um pulso de $90^{\circ}$, deve ser conservada no plano xy por alguns milissegundos. Para ocorrer transferência da magnetização transversal, as frequências de precessão da magnetização dos núcleos I e S devem ser iguais, fenômeno conhecido como condição de Hartmann Hahn, que pode ser apresentada da seguinte maneira:

$$
v_{1}(I)=v_{1}(S)
$$

Se este for o caso, ambos os núcleos possuem a mesma diferença de energia entre os estados vizinhos e a magnetização pode ser transferida sob conservação de energia através do termo heteronuclear "flip-flop", descrito pelos operadores dipolares $\hat{I}^{+} \hat{S}^{-}$e $\hat{S}^{+} \hat{I}^{-}$. Ao 
introduzirmos no experimento rotação em ângulo mágico, a condição de Hartmann Hahn é modulada pela frequência de rotação.

$$
v_{1}(I)=v_{1}(S)_{-}^{+} n v_{r}
$$

Com a variação do tempo de evolução $t_{1}$ entre o primeiro pulso de $90^{\circ}$ e o pulso de acoplamento, uma segunda dimensão pode ser acrescentada, de modo que a proximidade espacial de sítios nucleares I e S aparecem nos espectros de HETCOR-2D-CP. A projeção de cada dimensão no espectro 2D representa o espectro regular de CP para ambos os núcleos.

\subsubsection{Experimento de Spin-Echo}

O experimento de Spin Echo, o mais conhecido experimento de RMN pulsado, é uma ferramenta poderosa para medir acoplamentos dipolo-dipolo homonucleares e como consequência, é componente de um número considerável de estudos por RMN. Sua sequência de pulsos, desenvolvida em 1950 por Hahn [50], é bastante simples e está esquematizada na figura 8 .

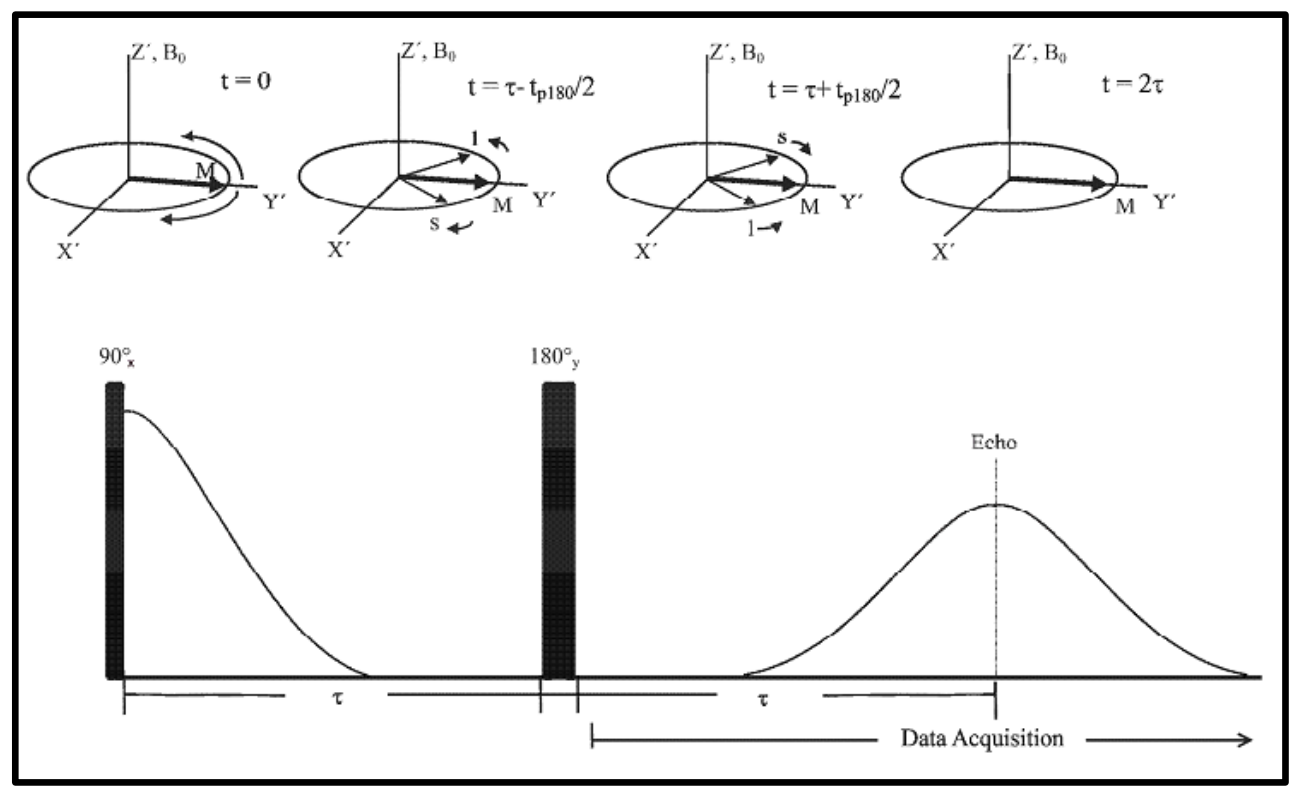

Figura 8- Vetor modelo e sequência de pulso spin echo

O experimento pode ser facilmente explicado considerando-se o vetor modelo apresentado na parte superior da figura 8. Depois de aplicar um pulso de $90^{\circ}$ a magnetização transversal retorna durante um período de evolução $\tau$ devido às diferentes interações locais, 
por exemplo, inomogeneidade do campo, interações homo e heteronucleares e deslocamento químico anisotrópico. Em relação ao vetor modelo, estas interações causam uma defasagem em diferentes spins isocromáticos (spins de mesma fase e frequência de precessão), onde cada um apresenta suas próprias características, tais como: amplitude, fase inicial e frequência de precessão. Experimentalmente, dois isocromáticos, I e S, que estão descritos na figura 12, precessionam mais lentamente (I) ou mais rapidamente (S) do que a magnetização central, cuja frequência de precessão é igual à frequência de Larmor $\omega_{0}$, presumindo-se que $\omega_{0}$ indica a média da distribuição de frequência de precessão. Posterior a um pulso de $180^{\circ}$ na direção y', os spins isocromáticos individuais são invertidos e por isso, atingem y' simultaneamente, em um tempo $\tau$ igual ao primeiro período de evolução. Por isso, o sinal refocado em $\mathrm{t}=2 \tau$ é chamado de eco. Entretanto, o pulso de $180^{\circ}$ reorienta a parte do decaimento devido a todas as interações que comutam com $\hat{\boldsymbol{I}}_{\mathbf{z}}$ (acoplamento dipolar heteronuclear, deslocamento químico isotrópico e inomogeneidade do campo). Por outro lado, sabendo que o acoplamento dipolar homonuclear é proporcional a $\widehat{I}_{\mathbf{z}}^{2}$, este não é reorientado. Como resultado, o decaimento da magnetização transversal depende apenas do acoplamento dipolar homonuclear, que pode ser determinado pela sequência de pulsos descrita na figura 8 . Se o acoplamento torna-se forte, o decaimento será cada vez mais rápido. 


\section{Procedimentos experimentais}

\subsection{Síntese das amostras vítreas}

Neste trabalho, os compostos precursores foram homogeneizados em um almofariz de ágata e colocados em um cadinho de platina antes de serem levados ao forno. Durante o processo inicial de aquecimento, estes passam por uma série de transformações físicas e químicas para produzir o fundido. A conversão do fundido em um líquido homogêneo pode requerer outros processamentos, incluindo a remoção de componentes não fundidos, impurezas e bolhas. As temperaturas e o tempo de aquecimento variam de acordo com a composição da mistura: por exemplo, misturas produzindo um líquido de alta viscosidade, requerem geralmente maiores temperaturas e tempos de fusão para produzir o fundido. Neste trabalho, os vidros com composições $26,66 \mathrm{~B}_{2} \mathrm{O}_{3}-16 \mathrm{GeO}_{2}-4 \mathrm{Bi}_{2} \mathrm{O}_{3}-(53,33-\mathrm{x}) \mathrm{PbO}-\mathrm{xPbF}_{2}(0 \leq$ $\mathrm{x} \leq 40$ ) foram sintetizados em temperaturas de $850^{\circ} \mathrm{C}$ e tempos de fusão próximos de 15 min. As amostras obtidas foram rotuladas como BPBG, BPBG15, BPBG30 e BPBG40. Os precursores estão resumidos na tabela 2

Tabela 2- Precursores utilizados na síntese das amostras

\begin{tabular}{cccc}
\hline COMPOSTO & NOME & PROCEDÊNCIA & PUREZA (\%) \\
\hline $\mathrm{B}_{2} \mathrm{O}_{3}$ & Óxido de Boro & Alfa Aesar & 99,98 \\
$\mathrm{PbO}$ & Óxido de Chumbo & Alfa Aesar & 99,99 \\
$\mathrm{GeO}_{2}$ & Óxido de Germânio & Preussaug Mettal-Goslar & 99,99 \\
$\mathrm{Bi}_{2} \mathrm{O}_{3}$ & Óxido de Bismuto & Alfa Aesar & 99,99 \\
$\mathrm{PbF}_{2}$ & Fluoreto de Chumbo & Merck & 99,99 \\
\hline
\end{tabular}

Durante o período de fusão a massa fundida foi submetida a movimentos circulares para garantir a completa homogeneização. Após a etapa de fusão, a massa fundida foi vertida num molde de grafite, pré-aquecido, $50^{\circ} \mathrm{C}$ abaixo da temperatura de transição vítrea $(\mathrm{Tg}) \mathrm{e}$ mantida em recozimento por 12 horas, para promover o choque térmico necessário à vitrificação do material, bem como para aliviar as tensões mecânicas, para posterior corte e polimento das amostras. Em seguida, as amostras foram resfriadas lentamente até temperatura ambiente. $\mathrm{O}$ cadinho de platina foi utilizado devido a sua baixa reatividade química em altas temperaturas. 


\subsection{Caracterizações Convencionais}

Para todas as amostras, o estado vítreo foi confirmado a partir dos padrões de difração de raios x obtidos para amostras pulverizadas utilizando um difratômetro modelo RIGAKUULTIMA IV, com radiação $K \alpha$ do cobre $\left(\lambda=1,54 \AA\right.$ ), no intervalo $2 \Theta$ entre 2 e $80^{\circ}$, taxa de aquisição de dados $2 \%$ min e ângulo de incidência normal.

A densidade dos vidros foi determinada pelo método de Arquimedes em água destilada utilizando uma balança digital (Mettler Toledo, modelo AG285, com precisão de $0,0001 \mathrm{~g}$ ) equipada com aparato próprio para medida de densidade. $\mathrm{O}$ procedimento utilizado para cada medida se resume da seguinte forma: a) mediu-se seis vezes a massa de cada amostra $m_{a}$ b) mediu-se seis vezes as massas de cada amostra submersa no líquido $m_{b}$ c) tomou-se nota da temperatura ambiente d) foram feitos os cálculos da densidade considerando-se os erros das medidas (equação 67)

$$
. \rho=\frac{m_{a}}{m_{a}-m_{b}}\left(\rho_{0}-\rho_{l}\right)+\rho_{l}
$$

onde $\rho_{0}$ é a densidade do líquido, que neste caso foi utilizado água destilada, na temperatura de $23,6{ }^{\circ} \mathrm{C}$ e $\rho_{l}$ é a densidade do ar.

/ Outra importante grandeza que foi calculada, a partir dos resultados obtidos para as densidades dos vidros, é o volume molar. O volume molar é inversamente proporcional à densidade e diretamente proporcional à massa molecular das amostras, como mostra a equação 67 ,

$$
V_{m}=\frac{M}{\rho}
$$

em que M é a massa molecular de $1 \mathrm{~g}$ de vidro e $\rho$ é a densidade da amostra em $\mathrm{g} / \mathrm{cm}^{3}$.

A temperatura de transição vítrea e a temperatura de cristalização foram obtidas a partir de um calorímetro, modelo DSC 2090 Differential Scanning Calorimeter, da TA Instruments. As amostras foram trituradas, a granulometria controlada e uma massa constante de $40 \mathrm{mg}$, para cada amostra, foi introduzida em panela de platina aberta. As análises foram realizadas entre $100^{\circ} \mathrm{C}$ e $600^{\circ} \mathrm{C}$ com taxa de aquecimento de $10^{\circ} \mathrm{C} / \mathrm{min}$ sob fluxo de $\mathrm{N}_{2}$ 
As medidas de absorção óptica foram realizadas utilizando um equipamento Shimadzu, UV/Vis-Nir - 2550 Spectrometer. Os espectros foram coletados em um intervalo de comprimento de onda, $\lambda$, entre 200 e $1100 \mathrm{~nm}$, com resolução de $1 \mathrm{~nm}$. Todas as amostras foram cortadas com $1 \mathrm{~cm}$ de espessura e polidas na tentativa de comparar, de maneira direta, todos os espectros obtidos. A partir dos espectros obtidos foi possível estimar o valor da “Energia de gap" pela equação:

$$
E_{g}=\frac{h c}{\lambda_{c}}
$$

onde $h$ é a constante de Plank, $c$ a velocidade da luz e $\lambda_{c}$ o compirmento de onda de corte na região do UV.

As medidas espectroscópicas na região do infravermelho, no modo de absorbância, foram realizadas utilizando-se um equipamento Bruker Vertex 70 com transformada de Fourier (FTIR). Os espectros foram coletados no intervalo entre 400 a $1500 \mathrm{~cm}^{-1}$, em temperatura ambiente. As amostras utilizadas nas medidas de absorção IR foram preparadas na forma de pastilhas com $0,3 \mathrm{~g}$ de $\mathrm{KBr}$ e $0,03 \mathrm{~g}$ da amostra. A pressão uniaxial usada para a conformação das pastilhas foi de aproximadamente $350 \mathrm{Kgf.cm}{ }^{-2}$.

Os espectros Micro Raman foram obtidos com um microscópio confocal modelo Witec Alpha-300s A/R. As amostras foram excitadas utilizando-se um laser de $\mathrm{Ar}^{+}$(Melles Griot, modelo 35-LAL-515-230) sintonizado em 514,5 nm para as amostras contendo até 30\% de $\mathrm{PbF}_{2}$ e $634 \mathrm{~nm}$ para a amostra contendo $40 \%$ de $\mathrm{PbF}_{2}$. Todos os espectros foram coletados com um tempo de integração de $80 \mathrm{~s}$, entre 100 e $1500 \mathrm{~cm}^{-1}$.

\subsection{Medidas de RMN de estado sólido}

Experimentos de RMN de ${ }^{11} \mathrm{~B}$ por pulso simples (PS), sob condições de rotação em ângulo mágico MAS, foram realizados em um espectrômetro Bruker DSX 500 com frequência de ressonância de 160,485 MHz. Os experimentos de pulso simples foram obtidos a partir de pulsos de $0,54 \mu$ s correspondentes a uma nutação de $15^{\circ}$, com tempo de relaxação de $0,5 \mathrm{~s}$ em frequência MAS de $12 \mathrm{kHz}$. Como referência dos deslocamentos químicos foi utilizado o $\mathrm{BF}_{3} \cdot \mathrm{OEt}_{2}$ a 0 ppm. Experimentos de RMN por PS-MAS em ${ }^{19} \mathrm{~F}$ foram realizados em uma interface Bruker DSX-400 a campo magnético de 4,65 T (correspondente a um magneto de $200 \mathrm{MHz}$ ). Os experimentos foram obtidos a frequência de ressonância de 
$188,357 \mathrm{MHz}$, com pulsos de $1 \mu$ s correspondendo a frequência de nutação de $90^{\circ}$, tempo de relaxação de $20 \mathrm{~s}$ e frequência de rotação MAS de $25 \mathrm{kHz}$. Neste caso, $\mathrm{CFCl}_{3}$ foi utilizado como referência a $0 \mathrm{ppm}$ e $\mathrm{AlF}_{3}$ foi utilizado como referência secundária a $-172 \mathrm{ppm}$. A distribuição espacial de íons de flúor foi inferida através de pulsos de Hahn spin eco, de modo análogo ao da referência [51], que consiste em um pulso de $90^{\circ}$ seguido de um pulso de $180^{\circ}$, com tempos de 3,0 e 6,0 s, respectivamente. As intensidades dos ecos em relação ao tempo de evolução entre os pulsos de $90^{\circ}$ e $180^{\circ}$ foram ajustadas a curva de decaimento do tempo de relaxação longitudinal $\left(\mathrm{t}_{1}\right)$ dado por:

$$
I=I_{0} e^{\left\{\left(-2 t_{1}\right)^{2} M_{2} / 2\right\}}
$$

onde a $\mathrm{M}_{2}$ é o segundo momento dipolar homonuclear de van Vleck que caracteriza a magnitude média da interação magnética homonuclear de dipolo-dipolo entre dois núcleos de ${ }^{19} \mathrm{~F}$.

Para investigar as conectividades e proximidades espaciais entre átomos de ${ }^{19} \mathrm{~F}$ e ${ }^{11} \mathrm{~B}$ em diferentes ambientes locais, alguns experimentos de dupla ressonância entre estes isótopos foram realizados. Entre os experimentos realizados, destacam-se os de eco rotacional de dupla ressonância REDOR. No presente trabalho, estes experimentos foram realizados observandose ${ }^{19} \mathrm{~F}$ (portanto, pulsando $180^{\circ}$ em ${ }^{11} \mathrm{~B}$ ), denotado por ${ }^{19} \mathrm{~F}\left\{{ }^{11} \mathrm{~B}\right\}$, bem como inversamente, observando-se ${ }^{11} \mathrm{~B}$ e pulsando-se em ${ }^{19} \mathrm{~F}\left({ }^{11} \mathrm{~B}\left\{{ }^{19} \mathrm{~F}\right\}\right)$. Os experimentos REDOR de ${ }^{19} \mathrm{~F}\left\{{ }^{11} \mathrm{~B}\right\}$ foram realizados em um espectrômetro Bruker DSX 500 (com frequências de ressonância de 470,6 e 160,4 MHz, respectivamente), usando a sequência de pulso desenvolvida por Gullion e Schaefer [52], operando a frequência de MAS de $30 \mathrm{kHz}$. Pulsos de $180^{\circ}$ foram obtidos a $3,3 \mu$ s e $3,7 \mu$ s para os núcleos de ${ }^{19} \mathrm{~F}$ e ${ }^{11} \mathrm{~B}$, com tempo de relaxação de $20 \mathrm{~s}$. Os experimentos REDOR ${ }^{11} \mathrm{~B}\left\{{ }^{19} \mathrm{~F}\right\}$ foram realizados em um espectrômetro Bruker DSX 400 (com frequências de ressonância de 376,63 e 128,42 MHz, respectivamente), com pulsos de $180^{\circ}$ com $6,0 \mu \mathrm{s}$ tanto para o ${ }^{19} \mathrm{~F}$ quanto para o ${ }^{11} \mathrm{~B}$.

Para explorar a possibilidade de detectar espécies borato conectadas ao flúor (ou seja, $\mathrm{F}-\mathrm{B}(\mathrm{III})-\mathrm{O}_{2}$ ou $\left.\mathrm{F}-\mathrm{B}(\mathrm{IV})-\mathrm{O}_{3}\right)$, experimentos de polarização cruzada CP-MAS ${ }^{11} \mathrm{~B}\left\{{ }^{19} \mathrm{~F}\right\}$ foram realizados em condições de rotação em ângulo mágico MAS de $14 \mathrm{kHz}$, com tempo de relaxação de $20 \mathrm{~s}$. Boas condições de transferência de magnetização foram obtidas a frequências de nutação de 65.8 e $50 \mathrm{kHz}$ para o ${ }^{11} \mathrm{~B}$ e ${ }^{19} \mathrm{~F}$, respectivamente. 1024 varreduras foram acumuladas sob variação sistemática do tempo de contato. 
Experimentos de correlação heteronuclear em 2D da polarização cruzada ${ }^{11} \mathrm{~B}\left\{{ }^{19} \mathrm{~F}\right\}$ (em inglês, "Heteronuclear Correlation"- HETCOR) foram realizados com tempo de contato de 50, 200 e $5000 \mu$ s e incrementos dos tempos de pré-contato em passos de $5 \mu$ s. Experimentos com o observável reverso, ou seja, ${ }^{19} \mathrm{~F}\left\{{ }^{11} \mathrm{~B}\right\}$ não foram satisfatórios devido fraca condição de transferência de magnetização do núcleo quadrupolar de ${ }^{11} \mathrm{~B}$.

Todos experimentos de RMN foram realizados em colaboração com o grupo do Prof. Dr. Hellmut Eckert, da Westfälishe Wilhelm Universität Münster, em Muenster, Alemanha. 


\section{Resultados e discussões}

\subsection{Influência do $\mathrm{PbF}_{2}$ nas propriedades físicas dos vidros estudados}

A Figura 9 apresenta fotografias das amostras obtidas. Observe na sequência que as amostras BPBG até BPBG30 são transparentes, homogêneas e apresentam-sebrilhantes, características de fases vítreas. Além disso, o aumenta da concentração de $\mathrm{PbF}_{2}$ resulta em amostras mais transparentes na região do visível.

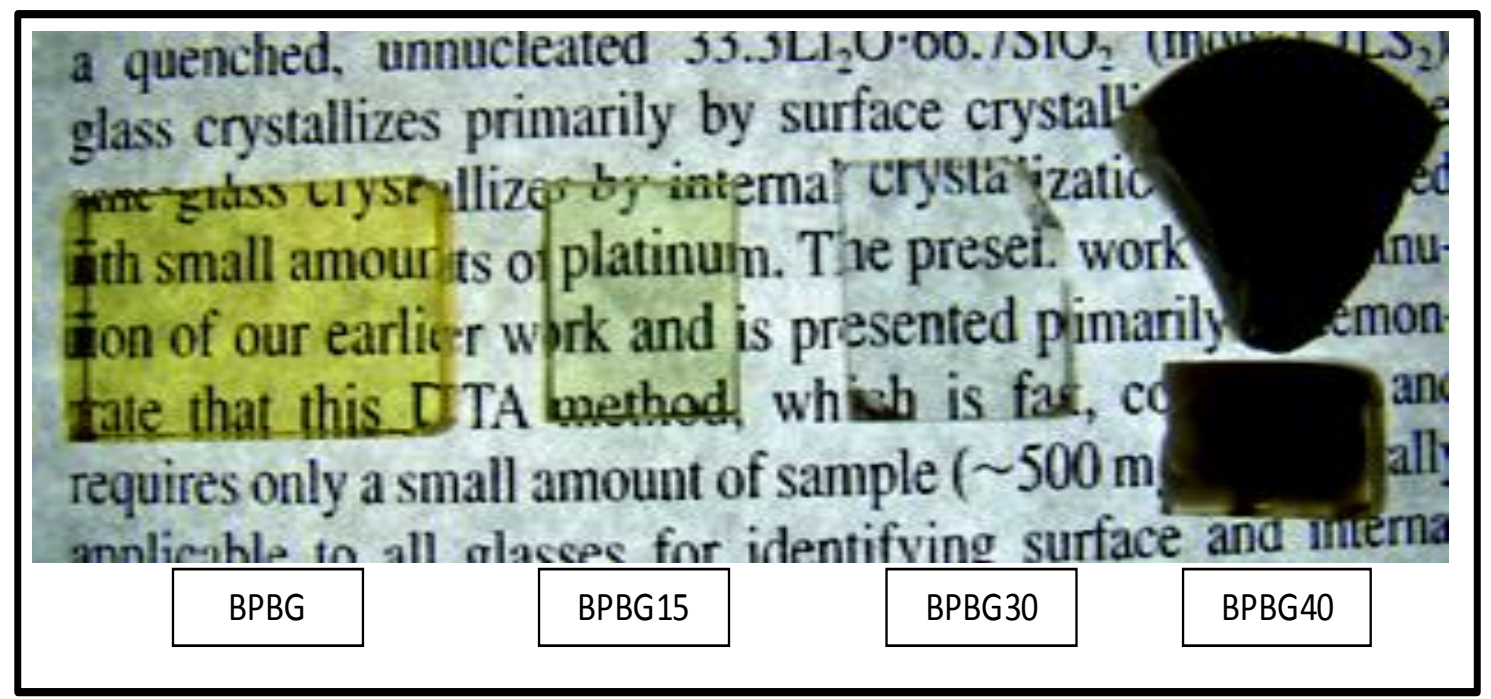

Figura 9- Fotografias das amostras sintetizadas após corte e polimento

Por outro lado, a amostra BPBG40, apresentou um aspecto vitrocerâmico, ou seja, uma fase aparentemente vítrea na superfície e cristalina no volume. Essa observação está em concordância com uma composição apresentando baixa habilidade de formar vidro nessas condições de síntese. Por isso, a superfície que experimenta uma taxa de resfriamento maior, vitrifica, enquanto o interior da amostra cristaliza. Essas observações visuais sugerem que a incorporação de $\mathrm{PbF}_{2}$ reduz progressivamente a estabilidade do vidro frente a cristalização. Outro aspecto importante a ser observado é a estabilidade química do vidro frente à umidade atmosférica, isto porque, normalmente, vidros contendo precursores a base de óxido de boro apresentam elevada higroscopicidade. Para os vidros sintetizados este efeito não foi observado. A tabela 3 mostra um resumo das amostras sintetizadas junto a suas designações. 
Tabela 3- Amostras obtidas e seus aspectos visuais

\begin{tabular}{cccc}
\hline Amostra & Composição nominal (\% mol) & Coloração & Classificação \\
\hline BPBG & $(26,66) \mathrm{B}_{2} \mathrm{O}_{3}(53,33) \mathrm{PbO}(16) \mathrm{GeO}_{2}(4) \mathrm{Bi}_{2} \mathrm{O}_{3}$ & Amarelo ouro & Vidro \\
BPBG15 & $(26,66) \mathrm{B}_{2} \mathrm{O}_{3}(38,33) \mathrm{PbO}(16) \mathrm{GeO}_{2}(4) \mathrm{Bi}_{2} \mathrm{O}_{3}(15) \mathrm{PbF}_{2}$ & Amarelo esverdeado & Vidro \\
BPBG30 & $(26,66) \mathrm{B}_{2} \mathrm{O}_{3}(23,33) \mathrm{PbO}(16) \mathrm{GeO}_{2}(4) \mathrm{Bi}_{2} \mathrm{O}_{3}(30) \mathrm{PbF}_{2}$ & Transparente & Vidro \\
BPBG40 & $(26,66) \mathrm{B}_{2} \mathrm{O}_{3}(13,33) \mathrm{PbO}(16) \mathrm{GeO}_{2}(4) \mathrm{Bi}_{2} \mathrm{O}_{3}(40) \mathrm{PbF}_{2}$ & Opaca & vitrocerâmica \\
\hline
\end{tabular}

Após a síntese, a classificação dos vidros foi confirmada por difratometria de raios X. A figura 10 apresenta os difratogramas das amostras vítreas estudadas, através dos quais confirmamos o caráter amorfo dos vidros para amostras contendo até $30 \% \mathrm{em} \mathrm{mol} \mathrm{de} \mathrm{PbF}_{2}$. Para essas amostras, podemos observar halos característicos de materiais amorfos, ou seja, que apresentam ordem somente de curto alcance, enquanto que, a amostra contendo $40 \%$ de $\mathrm{PbF}_{2}$ apresenta picos de difração característicos de uma estrutura cristalina, exibindo o limite para obtenção de vidros. A fase indexada foi a $\beta-\mathrm{PbF}_{2}$, que foi verificada através do banco de dados JCPDS ( Joint Committee on Powder Diffraction Standards, Swathmore, USA).

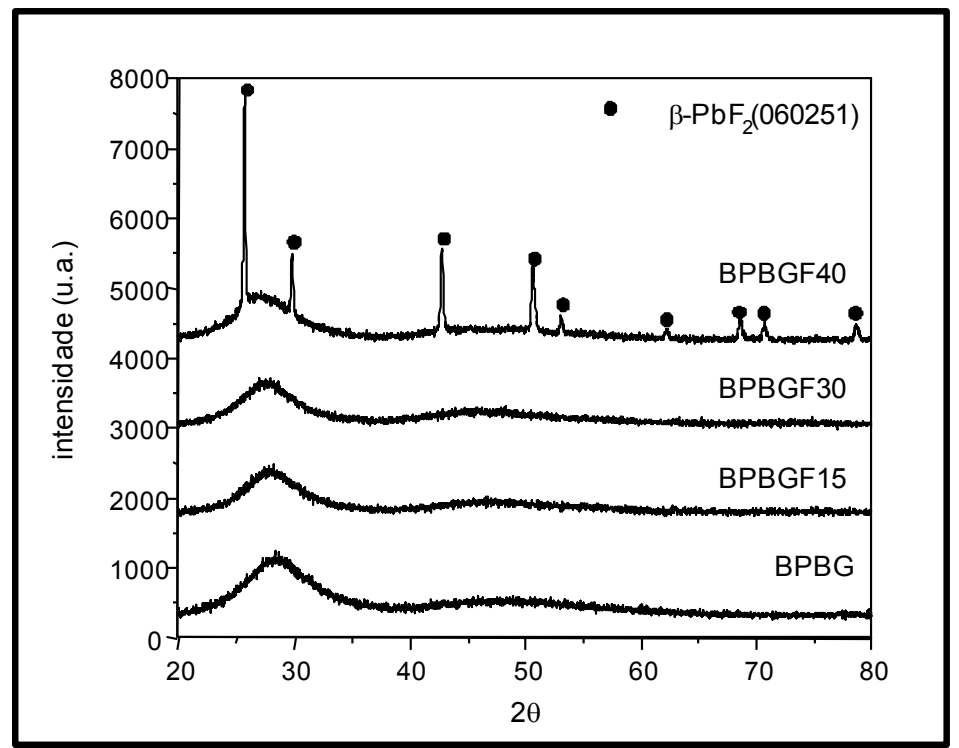

Figura 10- Difratogramas de raios $\mathrm{X}$ em pó dos vidros estudados

No intuito de melhor compreender a estrutura e sua influência sobre as propriedades térmicas e ópticas dos vidros em estudo, empregou-se as técnicas espectroscópicas Raman e infravermelho. Os espectros de absorção na região do IV para os vidros contendo até $40 \%$ de $\mathrm{PbF}_{2}$, junto as suas respectivas assinaturas estão resumidas na Figura 11 e tabela 4. 
Cinco modos vibracionais, bem definidos, foram identificados na região espectral entre $400-1500 \mathrm{~cm}^{-1}$. Além disso, nota-se dois ombros na região de baixas frequências. $\mathrm{O}$ primeiro ombro em $415 \mathrm{~cm}^{-1}$ é atribuído ao estiramento simétrico do oxigênio em ponte com dois outros átomos de chumbo $\mathrm{Pb}-\mathrm{O}-\mathrm{Pb}$, enquanto que, o segundo ombro centrado em 550 $\mathrm{cm}^{-1}$ é atribuído às vibrações de grupos metaboratos com alto teor de $\mathrm{Pb}$. A banda localizada ao redor de $700 \mathrm{~cm}^{-1}$ é característica das flexões de grupos $\mathrm{BO}_{3}$. Por fim, duas bandas largas posicionadas em mais altos números de ondas, entre $805-1120 \mathrm{~cm}^{-1}$ e $1120-1470 \mathrm{~cm}^{-1}$ respectivamente, também foram observadas. A primeira é característica dos estiramentos vibracionais da ligação $\mathrm{B}-\mathrm{O}$ presentes nas unidades estruturais básicas $\mathrm{BO}_{4}$, enquanto a segunda banda larga pode ser atribuída a uma sobreposição dos seguintes modos vibracionais: (i) $\mathrm{B}-\mathrm{O}^{-}$em unidades $\mathrm{BO}_{2} \mathrm{O}^{-}$, (ii) unidades trigonais $\mathrm{BO}_{2} \mathrm{O}^{-}$conectados a unidades $\mathrm{BO}_{4}$ e (iii) estiramento em unidades trigonais $\mathrm{B}_{3}$ que estão assimetricamente conectados. A maioria dos modos vibracionais (bandas centradas em 415 e $550 \mathrm{~cm}^{-1}$ ) não apresenta alterações significativas quando $\mathrm{PbF}_{2}$ é acrescido ao sistema. Por outro lado, quando as curvas estão sobrepostas (figura 11 b) é possível observar uma variação nas intensidades relativas entre as duas bandas largas centradas em 920 e $1290 \mathrm{~cm}^{-1}$. A partir dessas observações, podemos sugerir que existe uma tendência na conversão de unidades estruturais básicas $\mathrm{BO}_{3}$ para $\mathrm{BO}_{4}$. Posteriormente, esses resultados serão confirmados pelas medidas de RMN-MAS ${ }^{11} \mathrm{~B}$.

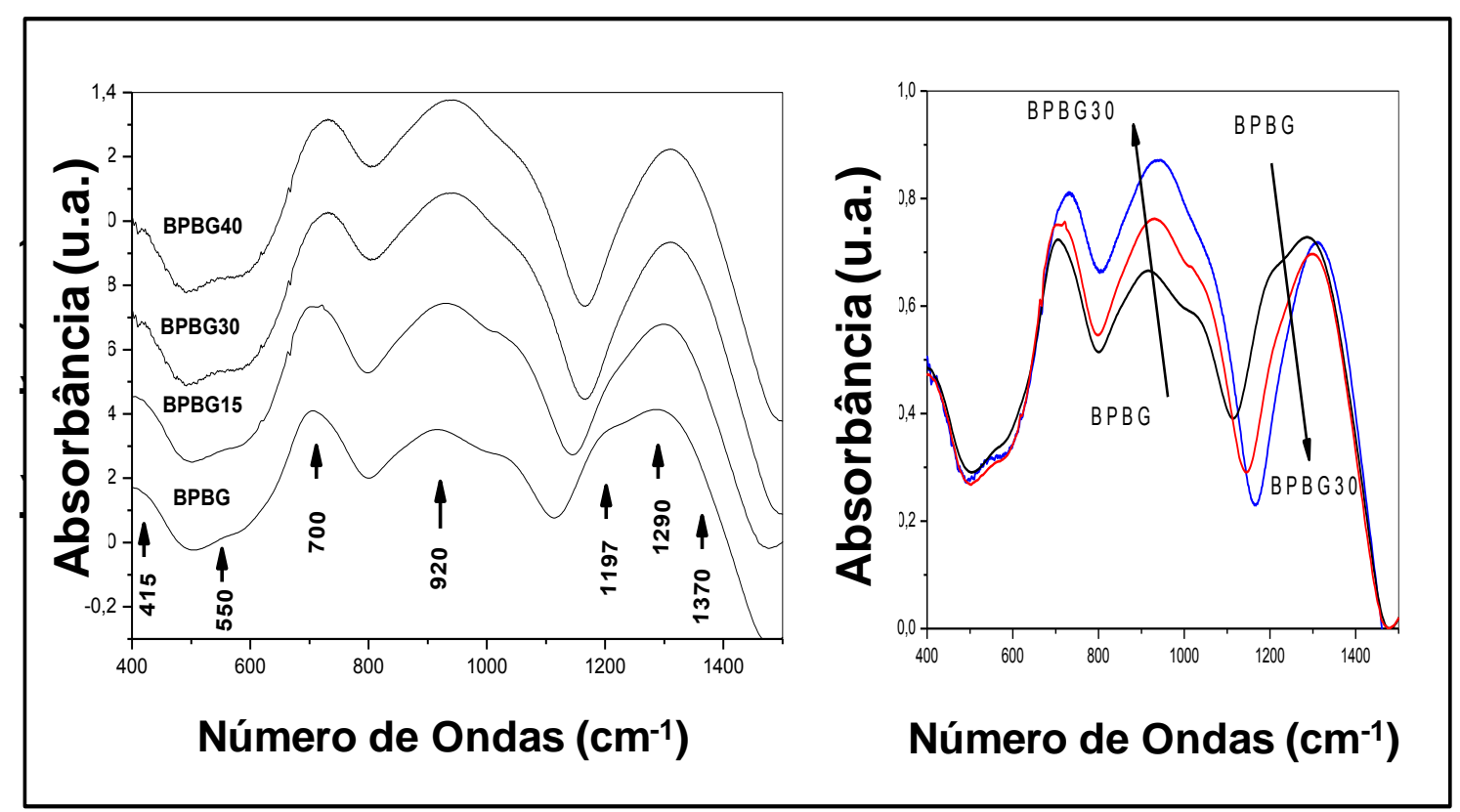

Figura 11- a) Espectros de absorção no IV de todas amostras estudadas e b) Comparação entre os espectros no IV para as amostras BPBG, BPBG15 e BPBG30 
Tabela 4- Atribuição das bandas de absorção no IV para o vidro BPBG

\begin{tabular}{|c|c|c|}
\hline $\begin{array}{c}v\left(\mathrm{~cm}^{-1}\right) \\
{[\text { Ref. }(1) /(15) /(53) /(54)]}\end{array}$ & $v\left(\mathrm{~cm}^{-1}\right)$ & Atribuições \\
\hline$-/-/-/ 420$ & $\sim 415$ & Estiramento simétrico do oxigênio em ponte $\mathrm{Pb}-\mathrm{O}-\mathrm{Pb}$ \\
\hline $570 / 570 /-/-$ & $\sim 550$ & Vibrações de grupos metaboratos com elevado teor de $\mathrm{Pb}$ \\
\hline $705 / 700 /-/$ - & $\sim 700$ & Flexões das unidades $\mathrm{BO}_{3}$ \\
\hline 915 / $910 / 930 /-$ & $\sim 920$ & $\begin{array}{l}\text { Estiramento vibracional da ligação } \mathrm{B} \text {-O presentes em unidades } \\
\text { estruturais básicas } \mathrm{BO}_{4}\end{array}$ \\
\hline 1185 / - / 1170 / 1176 & $\sim 1197$ & Estiramento $\mathrm{B}-\mathrm{O}^{-}$em unidades $\mathrm{BO}_{2} \mathrm{O}^{-}$ \\
\hline 1260 / - / 1290 / 1280 & $\sim 1290$ & Triângulos $\mathrm{BO}_{2} \mathrm{O}^{-}$conectados em unidades $\mathrm{BO}_{4}$ \\
\hline$-\quad /-/ 1320 / 1380$ & $\sim 1370$ & $\begin{array}{l}\text { Estiramento em triângulos BO3 que estão assimetricamente } \\
\text { conectados }\end{array}$ \\
\hline
\end{tabular}

Uma vez que nos espectros de IV não foram observadas algumas transições vibracionais esperadas para o sistema vítreo em questão, recorremos à espectroscopia Raman na tentativa de examinar a presença dos correspondentes modos vibracionais. Para analisar os resultados de espalhamento Raman nos vidros, os espectros obtidos foram tratados com o auxílio do software Peak Fit. Inicialmente foi feita a seleção do intervalo de interesse, número de ondas entre $\left(100-1500 \mathrm{~cm}^{-1}\right)$. Em seguida inserimos picos sobre os máximos locais observados nos espectros Raman adquiridos experimentalmente e o procedimento de deconvolução utilizado foi uma função de resposta Gaussiana (figura 12 b).

Para analisarmos os espectros, separamos as curvas em duas regiões espectrais distintas. Em menores valores de número de ondas existe uma grande influência dos compostos óxidos de metais pesados, enquanto que para maiores números de ondas os picos observados são referentes às diferentes unidades estruturais boratos.

A parte a, da figura 12, apresenta os espectros Raman para os vidros BPBG, BPBG15, BPBG30, BPBG40_vidro (laser focado na parte vítrea da amostra) e BPBG40_cristal (laser focado na parte cristalina da amostra). Todas atribuições referentes aos máximos locais estão resumidos na tabela 5 . 


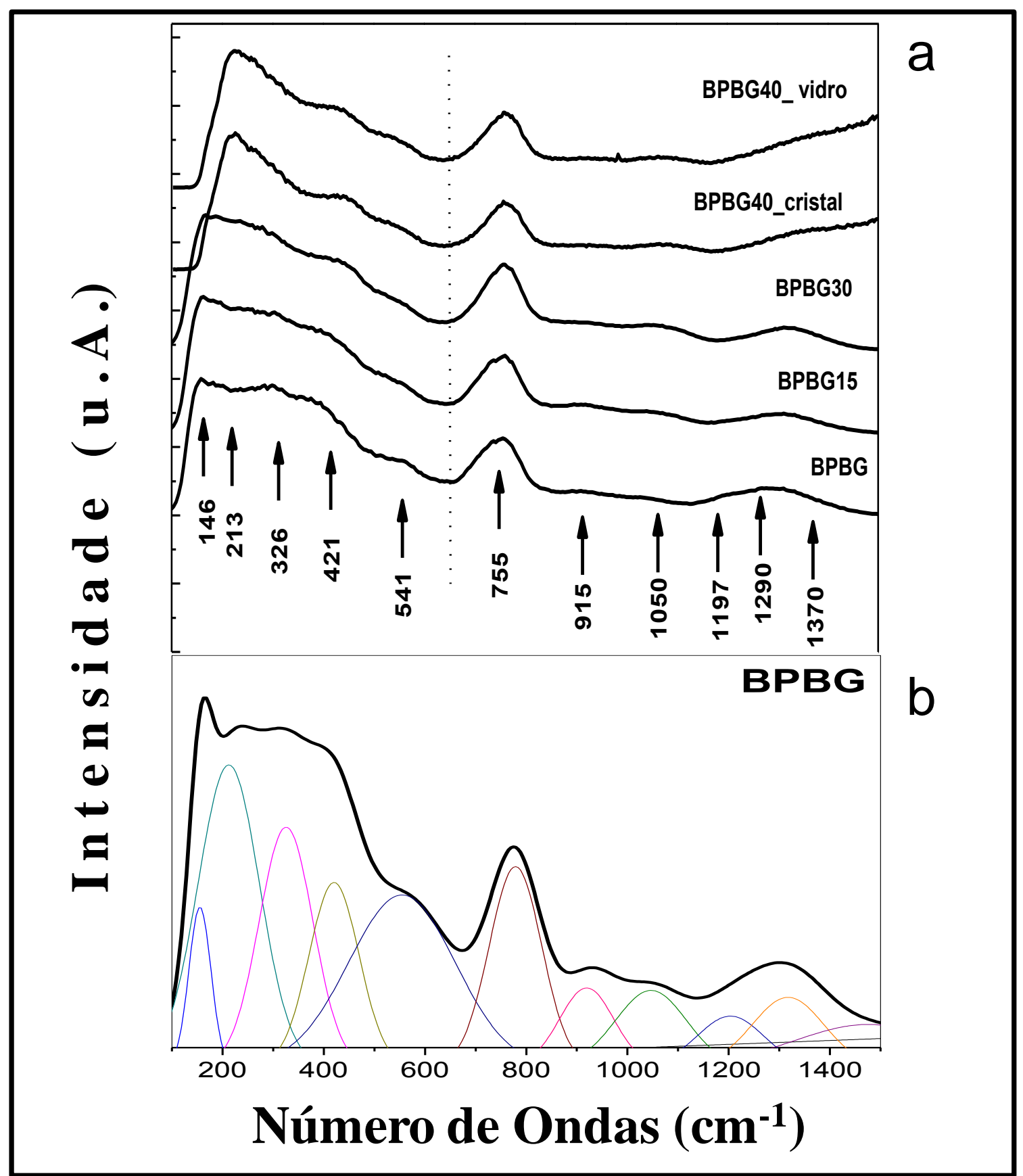

Figura 12- (a) Espectros de espalhamento micro-Raman obtido para todos os vidros (b) Simulação da amostra BPBG e suas deconvoluções em múltiplas Gaussianas comparada com a curva experimental 
Tabela 5- Número de ondas e atribuições às bandas observadas nos espectros Raman

\begin{tabular}{|c|c|c|}
\hline $\begin{array}{c}v\left(\mathrm{~cm}^{-1}\right) \\
{[\text { Ref. }(1) /(55) /(56) /(57) /(58) /(59) /(60) /(15) /(8)]}\end{array}$ & $v\left(\mathrm{~cm}^{-1}\right)$ & Atribuições \\
\hline $140 / 120-140 / 134 /-/-/-/-/-$ & $\sim 146$ & $\begin{array}{c}\text { Vibração dos ions de metais pesados }-\mathrm{Bi}^{3+} \text { ou } \\
\mathrm{Pb}^{2+}\end{array}$ \\
\hline $208 /-/-/-/-/-/-/-$ & $\sim 213$ & $\begin{array}{c}\text { Estiramento vibracional } B i-O \\
\text { e flexões } B i-O-B i\end{array}$ \\
\hline $254 /-/-/ 250 /-/-/-/-$ & $\sim 326$ & $\begin{array}{c}\text { Vibrações } \mathrm{Bi}-\mathrm{O} \text { em unidades piramidais } \mathrm{BiO}_{3} \\
\text { Movimento devido o estiramento simétrico do }\end{array}$ \\
\hline $420 /-/ 375 /-/ 380 /-/-/-$ & $\sim 421$ & $\begin{array}{c}\text { oxigênio em ponte em } \\
B i-\mathrm{O}-\mathrm{Bi} \text { e } \mathrm{Pb}-\mathrm{O}-\mathrm{Pb} \text { combinado com com } \mathrm{Bi}- \\
\mathrm{O}-\mathrm{Pb} \text { e } \mathrm{Bi}-\mathrm{O}-\mathrm{Ge}\end{array}$ \\
\hline$-/-/ 572 /-/-/ 551 /-/-$ & -541 & $\begin{array}{l}\text { Estiramento simétrico das ligações } \\
\qquad G e-O-G e\end{array}$ \\
\hline $760 /-/-/-/-/-/ 765 /-$ & $\sim 755$ & Estiramento simétrico das ligações $\mathrm{Ge}-\mathrm{O}^{-}$ \\
\hline $920 /-/-/-/-/-/-/ 915$ & $\sim 915$ & Presença de grupos orto e penta boratos \\
\hline$-/-/-/-/-/-/-/ 1030$ & $\sim 1050$ & Presença de grupos diboratos \\
\hline $1176 /-/-/-/-/-/-/ 1185 / 1170$ & $\sim 1197$ & Estiramento de $\mathrm{B}-\mathrm{O}^{-}$em unidades $\mathrm{BO}_{2} \mathrm{O}^{-}$ \\
\hline$-/-/-/-/-/-/-/ 1260 / 1290$ & $\sim 1290$ & unidades $\mathrm{BO}_{2} \mathrm{O}^{-}$conectados em unidades $\mathrm{BO}_{4}$ \\
\hline $1320 /-/ 1353 /-/-/-/-/-/ 1380$ & $\sim 1370$ & $\begin{array}{c}\text { Estiramento de unidades } \mathrm{BO}_{3} \text { que estão } \\
\text { assimetricamente conectados. }\end{array}$ \\
\hline
\end{tabular}

Os valores de $T_{g}, T_{c}$ e $T_{x}-T_{g}$ como determinados pela técnica DSC, estão resumidos na tabela 6. $\mathrm{O}$ valor da $\mathrm{T}_{\mathrm{g}}$ depende geralmente da força de ligação química covalente $\mathrm{e}$ também da conectividade dos constituintes presentes na rede vítrea. A conectividade se refere ao caráter tridimensional da rede. Por exemplo, quando um elemento tetraédrico é substituído por um elemento octaédrico na rede, a conectividade e consequentemente a $T_{g}$ aumentam. A primeira observação possível a partir das curvas DSC, é a diminuição linear da temperatura de transição vítrea com o aumento da concentração de $\mathrm{PbF}_{2}$ (figura 13), desta forma, os valores da $T_{g}$ dependem fortemente da razão de $\mathrm{O} / \mathrm{F}$ na composição vítrea. Esse resultado está de acordo com Shelby [10] para o sistema $\mathrm{B}_{2} \mathrm{O}_{3}-\mathrm{PbF}_{2}$. Portanto, presumimos que o $\mathrm{PbF}_{2}$ atua como modificador de rede. Além disso, a covalência das ligações $\mathrm{Pb}-\mathrm{F}$ é menor que a da ligação $\mathrm{Pb}$ - $\mathrm{O}$ devido sua grande diferença de eletronegatividade. Por isso, baseado na evolução da $T_{g}$, é possível que a introdução da componente fluoreto reduza a força média das ligações químicas produzindo uma menor conectividade da rede.

Como mencionado anteriormente, o parâmetro $\left(\mathrm{T}_{\mathrm{x}}-\mathrm{T}_{\mathrm{g}}\right)$ é definido como a estabilidade térmica do vidros frente a cristalização. A utilidade desse parâmetro é que ele define simultaneamente a estabilidade térmica do vidro frente à cristalização, bem como a faixa de temperatura de trabalho do vidro. Para o vidro em estudo, observamos uma oscilação nos 
valores da estabilidade térmica frente à cristalização (figura 13). Para concentrações até $15 \%$ de $\mathrm{PbF}_{2}$, ocorre um aumento na estabilidade e posteriormente uma diminuição para amostras contendo até $30 \%$ de $\mathrm{PbF}_{2}$.

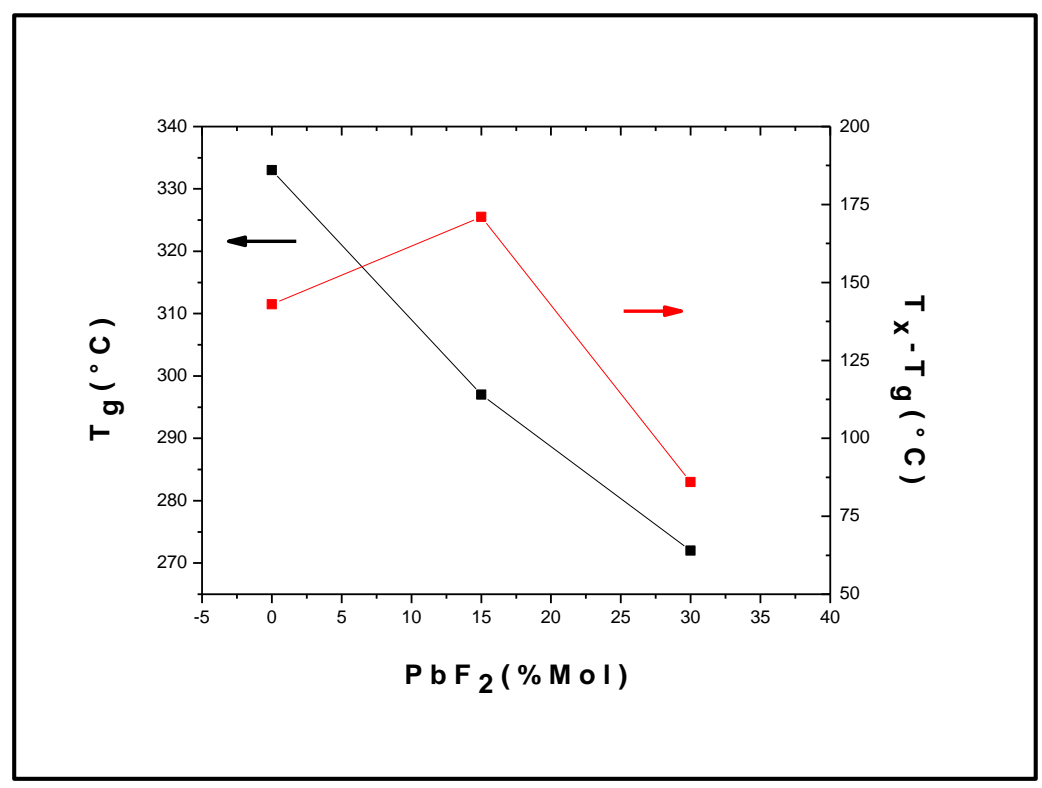

Figura 13- Variação da temperatura de transição vítrea com o aumento de $\mathrm{PbF}_{2}$ (esquerda) e estabilidade térmica dos vidros frente à cristalização (direita) para os vidros BPBG, BPBG15 e BPBG30

Em concordância com as mudanças estruturais observadas pelas técnicas espectroscópicas e termoanalíticas, as medidas de densidade e volume molar apresentaram resultados adicionais da evolução estrutural dos vidros como função da concentração de $\mathrm{PbF}_{2}$. De acordo com a figura 14, podemos observar claramente que até $30 \%$ em mol de $\mathrm{PbF}_{2}$, a densidade se mantém constante. Por outro lado, o volume molar sofre um aumento progressivo com o aumento da concentração de $\mathrm{PbF}_{2}$. Esse aumento do volume molar possivelmente está relacionado com a conversão de unidades boratos tri-coordenado para tetra-coordenados, visto que o número de coordenação destas ligações aumenta, de maneira que a rede vítrea se torna mais aberta. Outra sugestão, é que o flúor causa uma expansão na rede vítrea, no entanto, há uma saturação na quantidade de flúor para quantidades acima de $30 \%$ em mol de $\mathrm{PbF}_{2}$, começando a aparecer íons livres, facilitando a formação de $\mathrm{Pb}^{2+}$, e posteriormente a formação da fase cristalina de $\beta-\mathrm{PbF}_{2}$. 


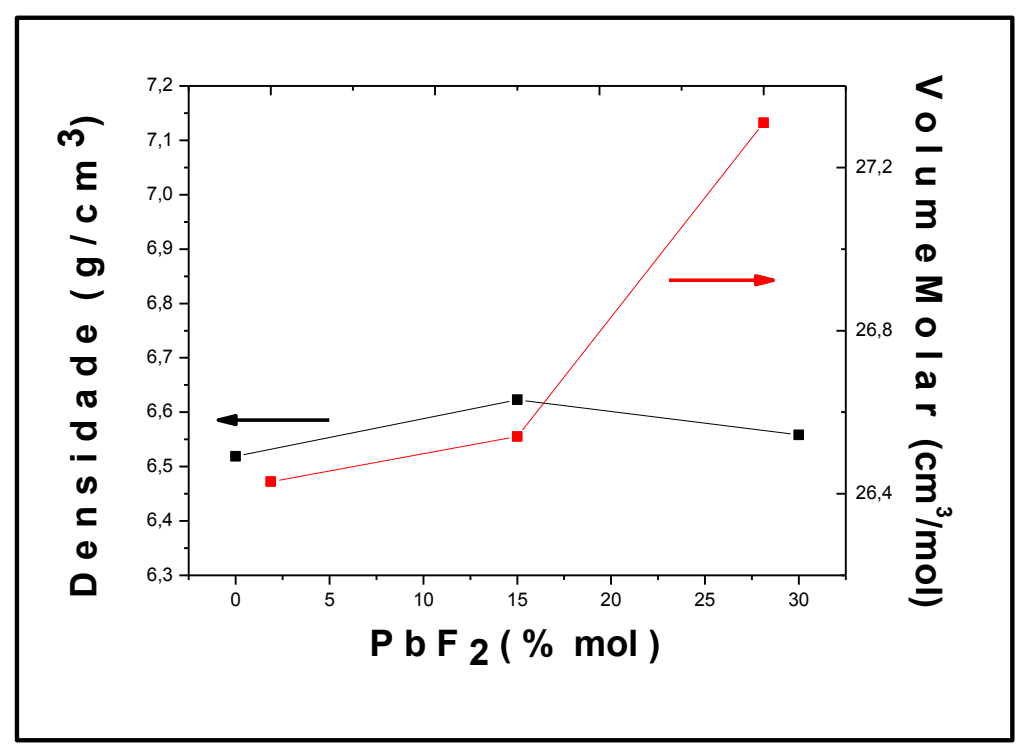

Figura 14- Densidade (esquerda) e volume molar (direita) dos vidros BPBG, BPBG15 e BPBG30

Tabela 6- Propriedades físicas dos vidros estudados. * Amostra parcialmente cristalina

\begin{tabular}{cccccc}
\hline Amostras & $\mathbf{T}_{\mathbf{g}}\left({ }^{\circ} \mathbf{C}\right)$ & $\mathbf{T}_{\mathbf{x}}\left({ }^{\circ} \mathbf{C}\right)$ & $\mathbf{T}_{\mathbf{x}}-\mathbf{T}_{\mathbf{g}}\left({ }^{\circ} \mathbf{C}\right)$ & $\boldsymbol{\rho}\left(\mathbf{g} / \mathbf{c m}^{\mathbf{3}}\right)$ & $\mathbf{V}_{\mathbf{m}}(\mathbf{c m} / \mathbf{m o l})$ \\
\hline BPBG & 333 & 476 & 143 & 6.519 & 26.43 \\
BPBG15 & 297 & 468 & 171 & 6.623 & 26.54 \\
BPBG30 & 272 & 358 & 86 & 6.558 & 27.31 \\
BPBG40 & - & - & - & - & - \\
\hline
\end{tabular}

Finalmente, a influência da substituição de $\mathrm{PbO}$ por $\mathrm{PbF}_{2}$ nas propriedades ópticas dos vidros pode ser avaliada na figura 15. Observa-se que com o aumento da concentração de $\mathrm{PbF}_{2}$, a janela de transmissão no UV é deslocado para maiores energias, ou seja, para menores comprimentos de onda. Com isso, comparamos os resultados obtidos neste trabalho com os valores relatados nas literaturas (Tabela 7) e verificamos que a adição de $\mathrm{PbF}_{2}$ contribuí significativamente para a redução no comprimento de onda de corte no UV. 


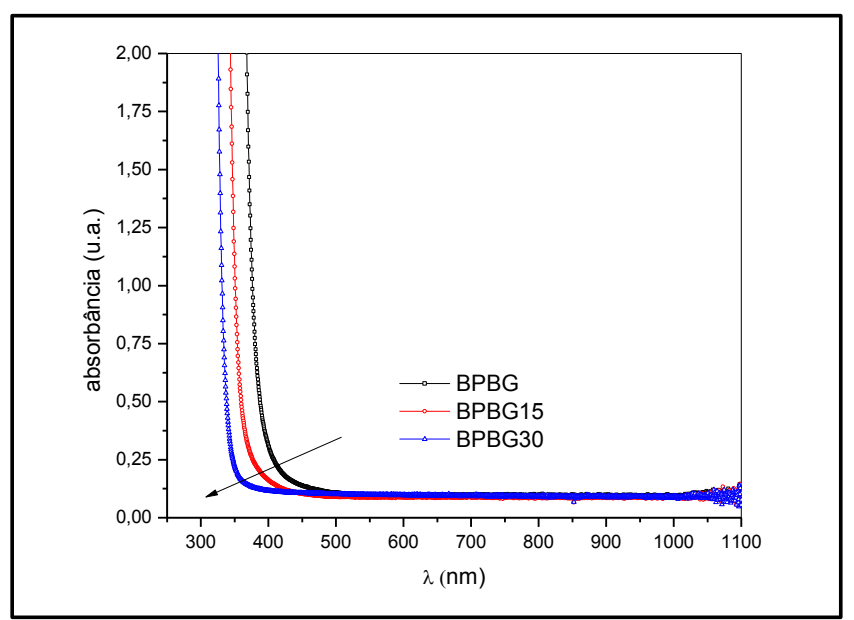

Figura 15- Espectros de absorbância na região do UV-Visível-NIR em função da concentração de $\mathrm{PbF}_{2}$

Sabe-se que, em vidros óxidos a borda de absorção óptica é determinada pela interação da radiação na região do UV com elétrons pertencentes aos íons oxigênio, cuja absorção é governada pela transição desses elétrons entre a banda de valência e a banda de condução. Neste caso, a absorção na região do UV para o vidro BPBG $\left(0 \% \mathrm{PbF}_{2}\right)$ é determinada pela excitação dos elétrons de valência presentes nas ligações $\mathrm{Pb}-\mathrm{O}-\mathrm{Pb}$, visto que, a maior concentração molar desta composição é constituída de $\mathrm{PbO}$ (53 \% mol). Com o aumento de x e redução de $\mathrm{PbO}$, a concentração dessas ligações se reduz significativamente, resultado no deslocamento da borda de absorção óptica observada.

Tabela 7- Janela de transmissão óptica dos vidros BPBG, BPBG15, BPBG30 e composições similares reportadas na literatura

\begin{tabular}{|c|c|c|c|c|c|c|}
\hline & \multicolumn{5}{|c|}{ Composição (\% mol) } & \multirow[b]{2}{*}{$\mathbf{E}_{\text {gap }(\mathrm{eV})}$} \\
\hline & $\mathbf{B}_{2} \mathbf{O}_{3}$ & PbO & $\mathrm{Bi}_{2} \mathbf{O}_{3}$ & $\mathrm{GeO}_{2}$ & $\mathrm{PbF}_{2}$ & \\
\hline BPBG & 26,66 & 53,33 & 4 & 16 & 0 & 3,35 \\
\hline BPBG15 & 26,66 & 38,33 & 4 & 16 & 15 & 3,54 \\
\hline BPBG30 & 26,66 & 23,33 & 4 & 16 & 30 & 3,77 \\
\hline $\operatorname{Ref}^{1}$ & 70 & 05 & 20 & 05 & - & 3,60 \\
\hline $\operatorname{Ref}^{1}$ & 20 & 30 & 20 & 30 & - & 3,45 \\
\hline $\operatorname{Ref}^{2}$ & 8 & 40 & 10 & 42 & - & 2,75 \\
\hline $\operatorname{Ref}^{2}$ & 8 & 40 & 35 & 17 & - & 3,12 \\
\hline $\operatorname{Ref}^{4}$ & 15 & 70 & 15 & - & - & 2,69 \\
\hline $\operatorname{Ref}^{4}$ & 70 & 15 & 15 & - & - & 3,57 \\
\hline $\operatorname{Ref}^{61}$ & 10 & 30 & 60 & - & - & 1,60 \\
\hline $\operatorname{Ref}^{61}$ & 70 & 10 & 20 & - & - & 2,84 \\
\hline $\operatorname{Ref}^{56}$ & 35 & & 50 & 15 & - & 2,88 \\
\hline
\end{tabular}




\subsection{RMN de estado sólido}

\subsubsection{RMN de alta resolução em sólidos - $\operatorname{REDOR}{ }^{11} B\left\{{ }^{19} F\right\}$ e ${ }^{11} B$ Pulso Simples (PS) - MAS}

A figura 16 apresenta os espectros de $\mathrm{RMN}$ de estado sólido do núcleo ${ }^{11} \mathrm{~B}$ sob condições de rotação em ângulo mágico para os vidros em estudo.
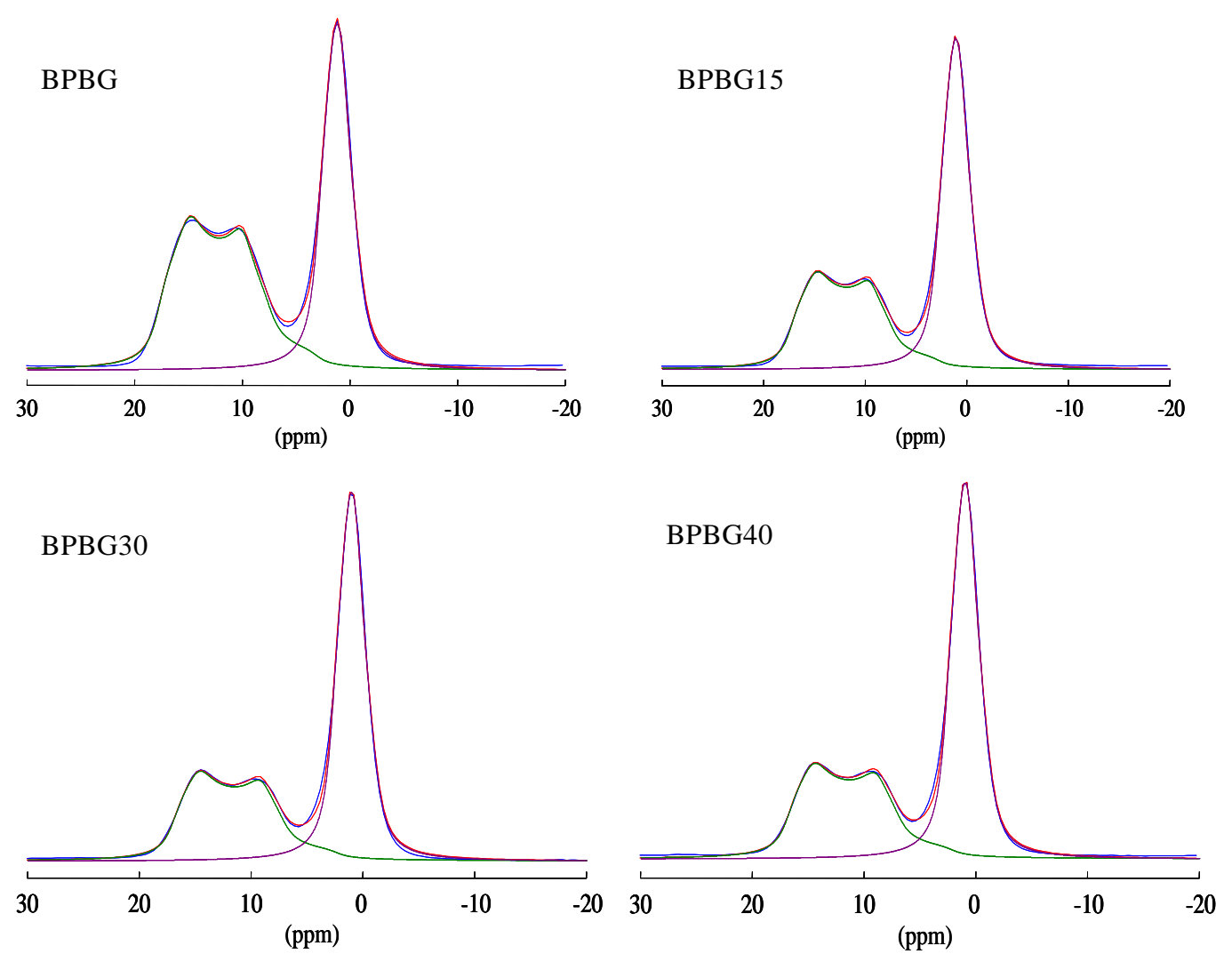

Figura 16- Espectros de RMN ${ }^{11}$ B PS - MAS das amostras BPBG, BPBG15 e BPBG30

Os espectros são influenciados pelo deslocamento químico e acoplamento quadrupolar elétrico. Uma forma de linha alargada é observada para as espécies $\mathrm{BO}_{3}$ entre 20 e $5 \mathrm{ppm}$. Essas espécies boratos experimentam um forte gradiente de campo elétrico gerado pelo ambiente dos oxigênios locais, resultando em um forte efeito de acoplamento quadrupolar de segunda ordem. Para as espécies $\mathrm{BO}_{4}$, um único sinal próximo a 1 ppm é observado. A tabela 8 resume os parâmetros obtidos a partir desses espectros usando simulações rotineiras em DMFIT [28]. 
Tabela 8- Parâmetros do ${ }^{11} \mathrm{~B}$ obtidos a partir dos espectros dos quatro vidros estudados

\begin{tabular}{ccccccc}
\hline & \multicolumn{3}{c}{ B(III) } & \multicolumn{3}{c}{ B(IV) } \\
\cline { 2 - 7 } & $\begin{array}{c}\text { Fração } \\
( \pm \mathbf{1} \%)\end{array}$ & $\begin{array}{c}\boldsymbol{\delta}_{\mathbf{C S}}^{\text {iso }} \\
( \pm \mathbf{0 . 5 p p m})\end{array}$ & $\begin{array}{c}\boldsymbol{\eta} \\
(\mathbf{0 . 0 5})\end{array}$ & $\begin{array}{c}\mathbf{C}_{\mathbf{q}} \\
( \pm \mathbf{0 . 0 5} \mathbf{M H z})\end{array}$ & $\begin{array}{c}\text { Fração } \\
( \pm \mathbf{2 \%})\end{array}$ & $\begin{array}{c}\boldsymbol{\delta}_{\mathbf{C S}}^{\text {iso }} \\
( \pm \mathbf{0 . 5 p p m})\end{array}$ \\
\hline BPBG & 54 & 18.5 & 0.32 & 2.52 & 46 & 1.2 \\
BPBG15 & 43 & 18.4 & 0.28 & 2.52 & 57 & 1.1 \\
BPBG30 & 41 & 18.2 & 0.25 & 2.54 & 59 & 1.2 \\
BPBG40 & 42 & 18.0 & 0.25 & 2.55 & 58 & 1.0 \\
\hline
\end{tabular}

Como a concentração de $\mathrm{PbF}_{2}$ é aumentada, a fração $\mathrm{N}_{4}$ das unidades estruturais $\mathrm{BO}_{4}$ aumenta significativamente, até que um valor de saturação é atingido para amostra com maior concentração de $\mathrm{PbF}_{2}$, que é parcialmente cristalina. Em comparação com os valores de $\mathrm{N}_{4}$ medidos em vidros boratos de chumbo nos sistemas com mesma razão de $\mathrm{PbO} / \mathrm{B}_{2} \mathrm{O}_{3}$ [62], os correspondentes valores encontrados nos vidros contendo $\mathrm{PbF}_{2}(\mathrm{x}=15,30$ e 40) são significativamente maiores, sugerindo que esse composto participa, pelo menos em parte, no processo de transformação da rede. A tendência observada aqui é oposta ao observada para o sistema $\mathrm{Na}_{2} \mathrm{~B}_{4} \mathrm{O}_{7}-\mathrm{Na}_{3} \mathrm{AlF}_{6}-\mathrm{TiO}_{2}$, onde os valores de $\mathrm{N}_{4}$ diminuem com o aumento da razão de $\mathrm{PbO} / \mathrm{B}_{2} \mathrm{O}_{3}$ [63]. Para esclarecer maiores detalhes dos espectros de RMN ${ }^{11} \mathrm{~B}$ PS - MAS, a figura 17 apresenta os resultados de REDOR ${ }^{11} \mathrm{~B}\left\{{ }^{19} \mathrm{~F}\right\}$. 


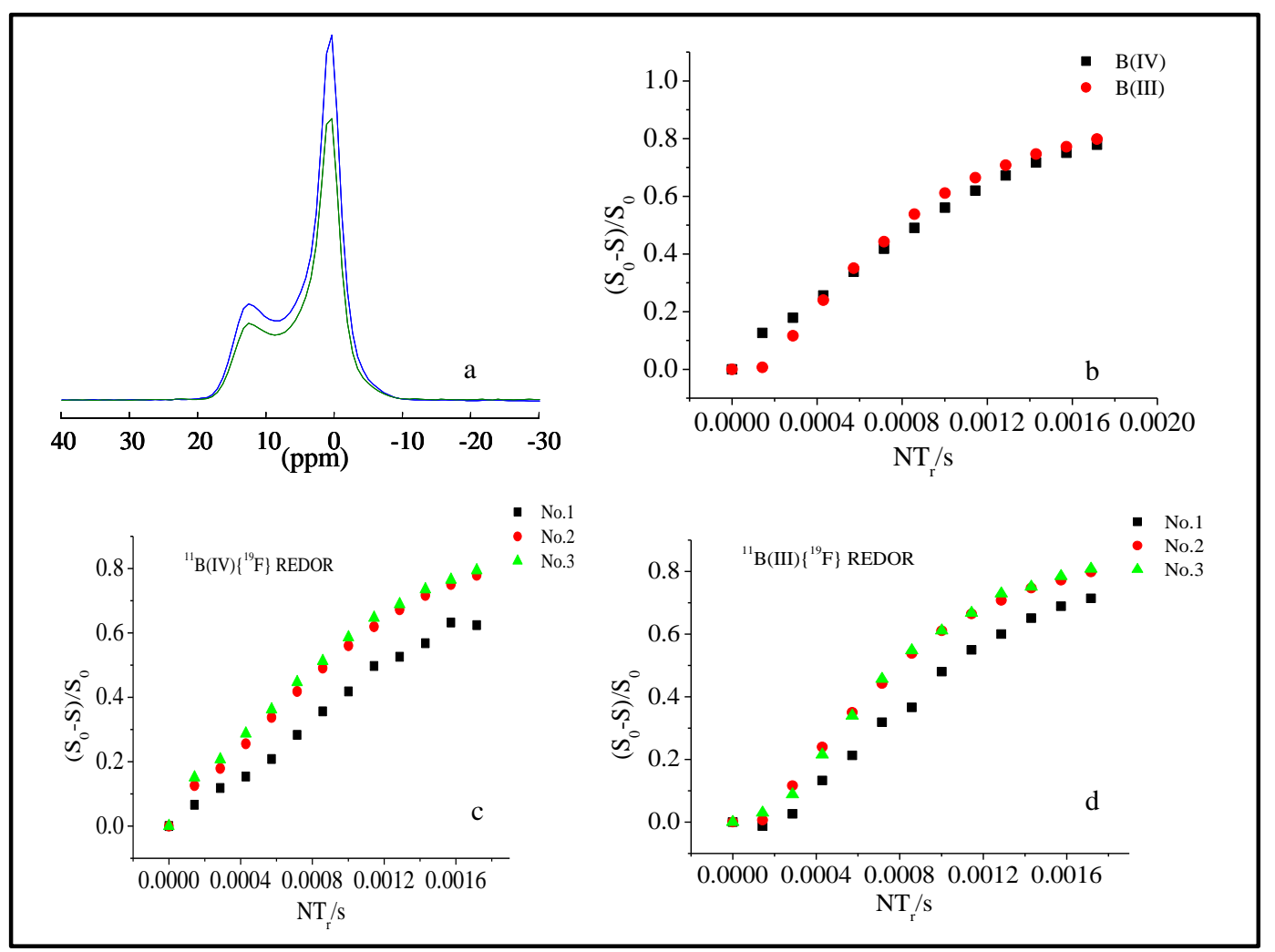

Figura 17- Dados de REDOR ${ }^{11} \mathrm{~B}\left\{{ }^{19} \mathrm{~F}\right\}$ dos vidros estudados. (a) Forma de linha do ${ }^{11} \mathrm{~B}$ para o vidro BPBG30 na ausência e na presença da defasagem dipolar (b) Curvas REDOR indicando a diferença de sinal $\Delta \mathrm{S} / \mathrm{S}_{\mathrm{o}}$ como uma função da evolução temporal dipolar de $\mathrm{NT}_{\mathrm{r}}$. (c) e (d) Curvas REDOR indicando a diferença de sinal $\Delta \mathrm{S} / \mathrm{S}_{\mathrm{o}}$ como uma função da evolução temporal dipolar de $\mathrm{NT}_{\mathrm{r}}$ para as espécies $\mathrm{BO}_{4}$ e $\mathrm{BO}_{3}$ respectivamente. 1 BPBG15, 2 BPBG30, 3 BPBG40

A parte (a) indica que ambos os sinais, das unidades $\mathrm{BO}_{3}$ e $\mathrm{BO}_{4}$ são atenuados mediante a reintrodução das interações magnéticas de dipolo-dipolo por pulsos $\pi$ aplicados no canal ${ }^{19} \mathrm{~F}$, certificando quantitativamente que ambas as espécies boratos estão em proximidade espacial com o núcleo ${ }^{19} \mathrm{~F}$. As partes (c) e (d) apresentam as curvas REDOR completas, obtidas pelo incremento sistemático do tempo de reacoplamento dipolar, ou seja, o número de ciclos do rotor vezes o período do rotor, na etapa que o reacoplamento é feito. Simulando individualmente cada pico deconvoluído na figura 16, de maneira que os mesmo parâmetros do sinal referência $S_{o}$ e o sinal defasado $S$ são utilizados para ambas as curvas, diferentes curvas REDOR foram obtidas para as duas espécies boratos. A figura $17 \mathrm{~b}$ ilustra que além do comportamento de "curto tempo" (que será discutido mais adiante), as curvas REDOR para as

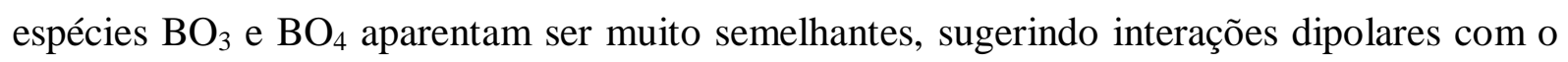
núcleo ${ }^{19} \mathrm{~F}$ similares. $\mathrm{O}$ moderado aumento da curva de REDOR indica que a maioria das espécies $\mathrm{BO}_{3}$ e $\mathrm{BO}_{4}$ não estão diretamente ligadas aos átomos de flúor. No entanto, uma inspeção minuciosa dos dados de REDOR indica que uma pequena fração de espécies $\mathrm{BO}_{4}$ 
pode apresentar ligações B-F, resultando em uma abrupta redução da amplitude do sinal para os dois primeiros dados. Em contraste, nenhuma peculiaridade é observada para espécies $\mathrm{BO}_{3}$, o que é consistente com a ausência de ligações B-F nesse ambiente particular.

\subsubsection{RMN de Alta resolução em sólidos - REDOR ${ }^{19} F\left\{{ }^{11} B\right\}$ e ${ }^{19} F$ Pulso Simples (PS) - MAS}

A figura 18 resume os dados de RMN ${ }^{19} \mathrm{~F}$ PS - MAS para todas as amostras contendo $\mathrm{PbF}_{2}(\mathrm{x}=15,30$ e $40 \% \mathrm{~mol})$.

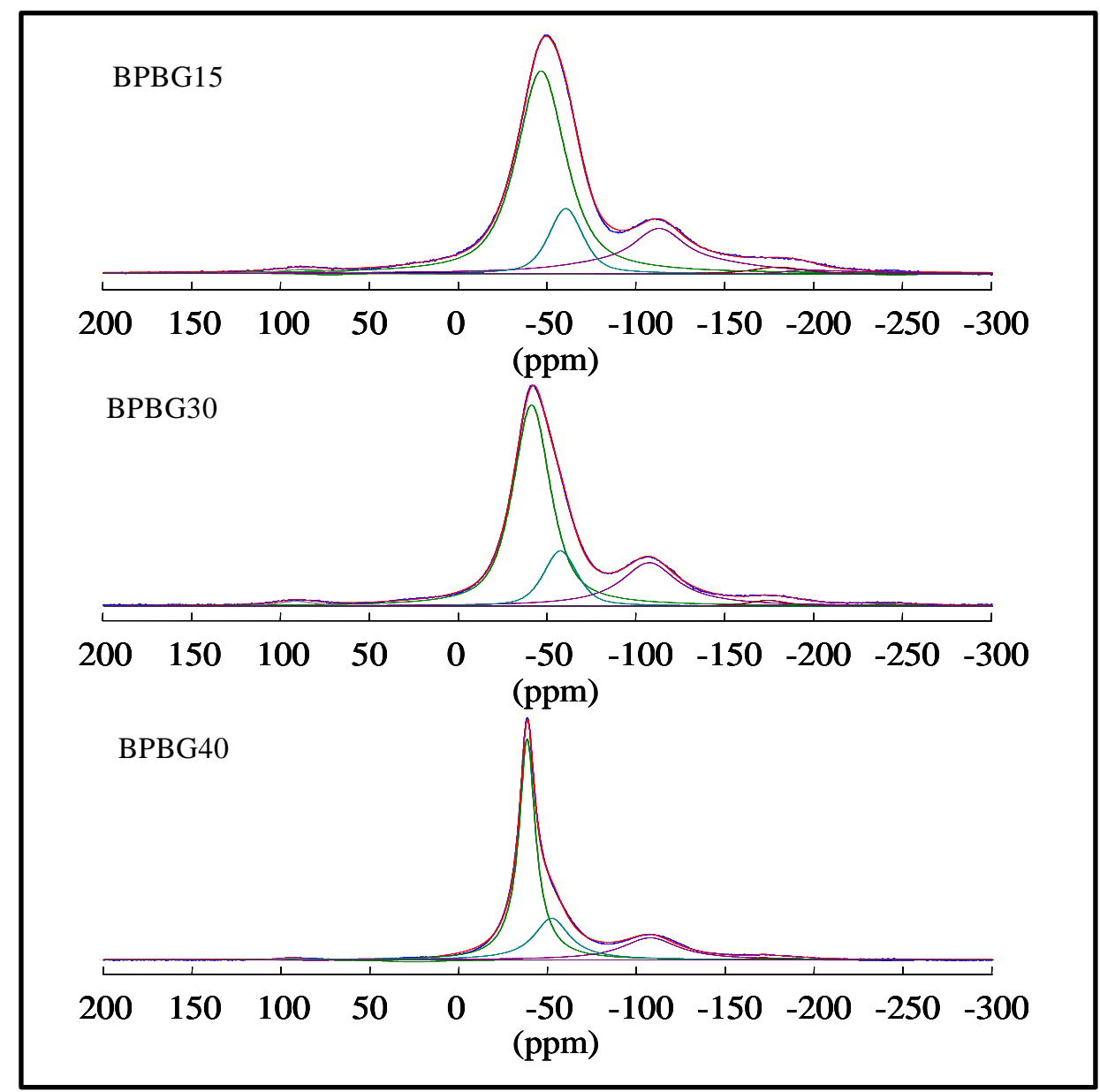

Figura 18- Espectros de RMN ${ }^{19}$ F PS - MAS dos vidros contendo $\mathrm{PbF}_{2}$ e deconvolução proposta em três novos picos

Os espectros foram deconvoluídos em três novos picos cujos valores estão sumarizados na tabela 9. O pico dominante A ao redor de $-45 \mathrm{ppm}$ esta relacionado a fase cristalina $\alpha-\mathrm{PbF}_{2}$, sugerindo a presença de flúor em um ambiente local dominado por chumbo. Para os vidros contendo 15 e $30 \%$ em mol de $\mathrm{PbF}_{2}$, a largura de banda dessa componente 
indica claramente um amplo deslocamento químico, típico de espécies fluoretos em um ambiente amorfo, enquanto que para amostra contendo $40 \% \mathrm{PbF}_{2}$, a forma e a largura de banda indica a cristalização da fase $\beta-\mathrm{PbF}_{2}$. Um segundo pico $\mathrm{B}$, distinto de $\mathrm{A}$, é identificado entre -107 a -117 ppm. Como será discutido abaixo, com base em diversos experimentos de dupla ressonância, esse pico é atribuído às ligações B-F. Em especial, na amostra parcialmente cristalizada, sugerimos a presença de um terceiro pico próximo a $-60 \mathrm{ppm}$. Atribuímos este pico, provisoriamente, a espécies de flúor que também estão presentes em um ambiente dominado por chumbo, enquanto que para amostras contendo 15 e $30 \%$ em mol de $\mathrm{PbF}_{2}$, a deconvolução sugerida na figura 18 pode parecer um tanto arbitrária (e, alternativamente, uma ampla distribuição de sítios pode ser considerada). Ao passo que uma fração significativa da concentração de flúor nestas amostras está presente na forma de $\beta$ $\mathrm{PbF}_{2}$, claramente algumas espécies fluoretos em um ambiente dominado por chumbo permanecem no estado amorfo.

Tabela 9- Deconvolução dos espectros de RMN ${ }^{19} \mathrm{~F}$ PS - MAS dos vidros contendo flúor

\begin{tabular}{lllcccc}
\hline Amostra & $\begin{array}{c}\square_{\text {iso }} \\
{[\mathbf{p p m}]}\end{array}$ & $\%$ & $\begin{array}{c}\square_{\text {iso }} \\
{[\mathbf{p p m}]}\end{array}$ & $\%$ & $\begin{array}{c}\square_{\text {iso }} \\
{[\mathbf{p p m}]}\end{array}$ & $\%$ \\
\hline BPBG15 & $-46,3$ & 67 & $-60,3$ & 14 & $-112,6$ & 19 \\
BPBG30 & $-41,0$ & 63 & $-57,2$ & 14 & $-107,1$ & 23 \\
BPBG40 & $-38,4$ & 60 & $-52,7$ & 23 & $-107,5$ & 17 \\
\hline
\end{tabular}

A figura 19 resume os resultados $\operatorname{REDOR}{ }^{19} \mathrm{~F}\left\{{ }^{11} \mathrm{~B}\right\}$, que indicam distintamente as diferentes espécies fluoretos nos vidros, experimentando forças de re-acoplamento dipolar entre os núcleos ${ }^{19} \mathrm{~F}_{-}{ }^{11} \mathrm{~B}$ drasticamente diferentes. Observe que o pico representado pela fase cristalina $\beta-\mathrm{PbF}_{2}$ na amostra 3 não é influenciado pelo reacoplamento dipolar no experimento de REDOR, enquanto que os demais sinais de flúor presentes nas amostras vítreas mostram claras evidências de reacoplamento entre os núcleos ${ }^{19} \mathrm{~F}-{ }^{11} \mathrm{~B}$. Todavia, nenhuma distinção foi feita na análise entre os picos dominantes próximos a -40 e -60 ppm, assinados como unidades $\mathrm{PbF}_{2}$. Quando se compara os espectros contendo reacoplamento dipolar por $400 \mu \mathrm{s}$ com seu análogo, ausente de reacoplamento (Figura 19, parte superior), observa-se que a componente lateral do pico em menor frequência (em torno de $-60 \mathrm{ppm}$ ) é mais atenuada que a componente lateral de alta frequência (em torno de $-30 \mathrm{ppm}$ ). Esta observação sugere uma correlação entre o deslocamento químico do ${ }^{19} \mathrm{~F}$ e a proximidade espacial das espécies fluoretos na rede borato; possivelmente a variação do deslocamento químico através dessa 
curva pode refletir diferentes números de íons $\mathrm{Pb}^{2+}$ na primeira esfera de coordenação dessas espécies fluoretos. Embora esta observação sugira regiões de $\mathrm{PbF}_{2}$ com maior ou menor presença do ${ }^{11} \mathrm{~B}$, a influência do acoplamento dipolar nas curvas de REDOR para ambas as regiões é consistente com a presença em escala atômica dos íons fluoretos na rede borato bem como ausência de segregação de fase neste domínio.

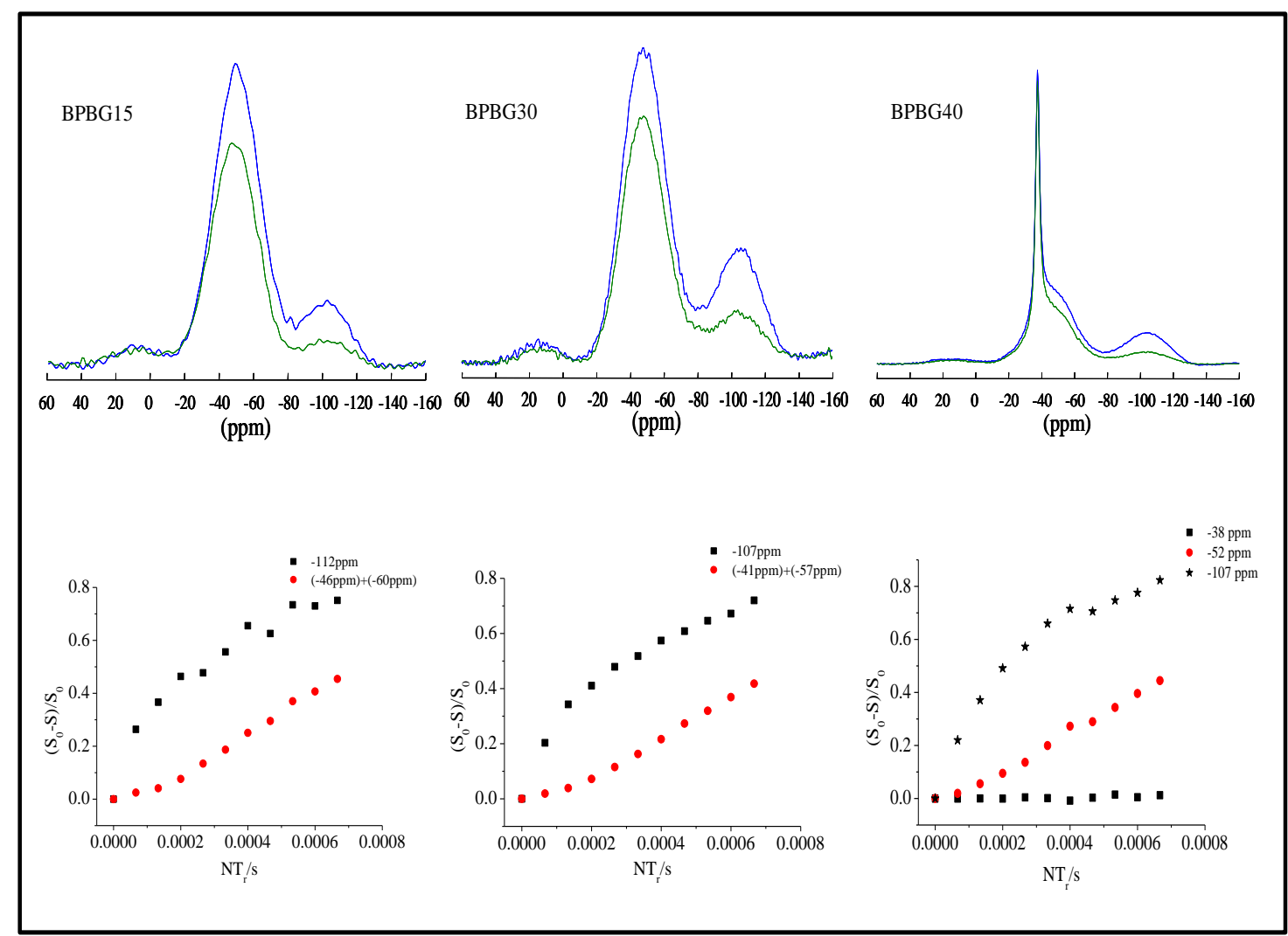

Figura 19- Dados REDOR ${ }^{19} \mathrm{~F}\left\{{ }^{11} \mathrm{~B}\right\}$ (verde) e sinal referência (azul) observados para um tempo de reacoplamento dipolar fixado em $400 \mu \mathrm{s}$ (superior). Curva REDOR para as diferentes espécies observadas nos espectros de RMN ${ }^{19} \mathrm{~F}$ PS - MAS (inferior)

\subsubsection{Polarização Cruzada ${ }^{11} B\left\{{ }^{19} F\right\}$ e Correlação em 2D da Polarização Cruzada ${ }^{19} F\left\{{ }^{11} B\right\}$}

A figura 20 apresenta os dados de RMN CPMAS ${ }^{19} \mathrm{~F}\left\{{ }^{11} \mathrm{~B}\right\}$ que exprimem a dependência do tempo de contato sobre as amostras vítreas contendo flúor. 


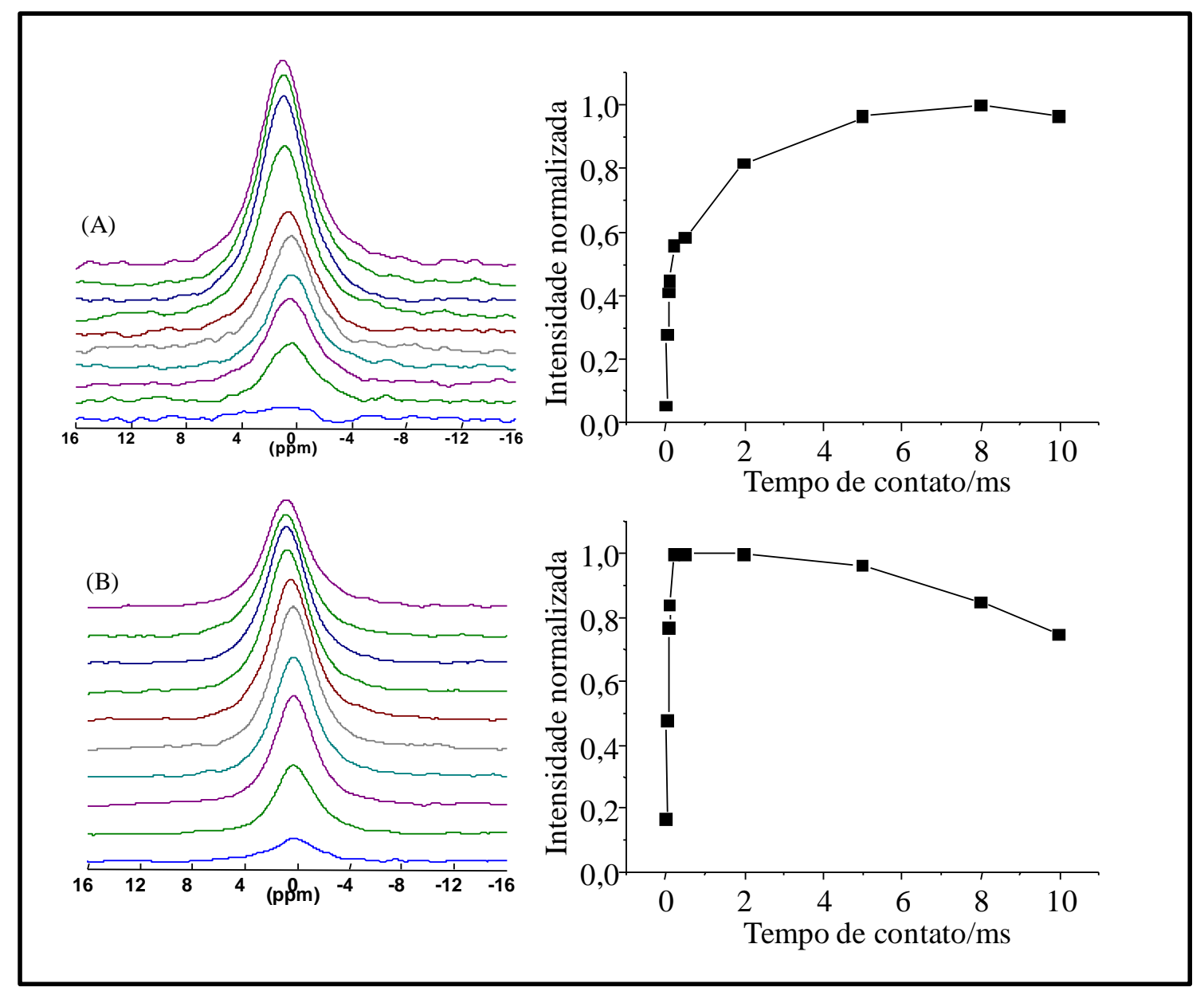

Figura 20- Dados RMN CPMAS ${ }^{19} \mathrm{~F}\left\{{ }^{11} \mathrm{~B}\right\}$ em função do tempo de contato para as amostras (a) e (b). Na ordem de amplitudes cada vez maiores os tempos de contatos são 20, 50, 80, 100, 200, 500, 2000, 5000, 8000 and $10000 \mu \mathrm{s}$

Em primeiro lugar, nas ondições de Hartmann-Hahn escolhidas, somente a ressonância das espécies $\mathrm{BO}_{4}$ pode ser detectada. Contudo, o insucesso em não observar a ressonância de espécies $\mathrm{BO}_{3}$ não significa, necessariamente, a ausência de proximidade espacial entre essas unidades boratos e fluoretos. Pode-se propor que as condições de transferência de magnetização do ${ }^{19} \mathrm{~F}$ para as unidades $\mathrm{B}(\mathrm{III})$ são distintas das condições escolhidas para as unidades B(IV). Este efeito bastante conhecido pode ser atribuído ao cruzamento de estados de spin durante o ciclo do rotor, que é criticamente influenciado pela interação nuclear quadrupolar elétrica em relação à amplitude de rádio-frequência escolhida [63]. Em contraste com o sinal das unidades $\mathrm{BO}_{3}$, o das unidades $\mathrm{BO}_{4}$ é facilmente observado em tempos de contatos muito curtos $(50 \mu \mathrm{s})$, de modo que o sinal observado abaixo dessas condições pode ser atribuído ao flúor ligado as espécies $\mathrm{BO}_{4}$. Como já visto nos resultados de REDOR ${ }^{11} \mathrm{~B}\left\{{ }^{19} \mathrm{~F}\right\}$, apenas uma pequena fração de unidades $\mathrm{BO}_{4}$ está ligada ao flúor. Nos experimentos de CPMAS, istoeste é corroborado pelo comportamento bimodal da curva de intensidade 
relativa versus o tempo de transferência de magnetização, observado na figura 20b para vidros contendo $15 \%$ mol de $\mathrm{PbF}_{2}$. Claramente, é possível observar dois intervalos, um rápido crescimento inicial para tempos de contatos $<200 \mu \mathrm{s}$ seguido de um lento processo de relaxação cruzada em altos tempos de contato, que são atribuídos às ligações cruzadas de todos os oxigênios ligados as unidades $\mathrm{BO}_{4}$ em proximidade espacial com o flúor, mas que não estão ligados a ele diretamente. Além disso, ambas as amostras vítreas apresentam uma mudança sistemática observada no deslocamento químico na região entre 0 e 1 ppm, quando o tempo de contato é elevado acima de $200 \mu$ s (figura 21).

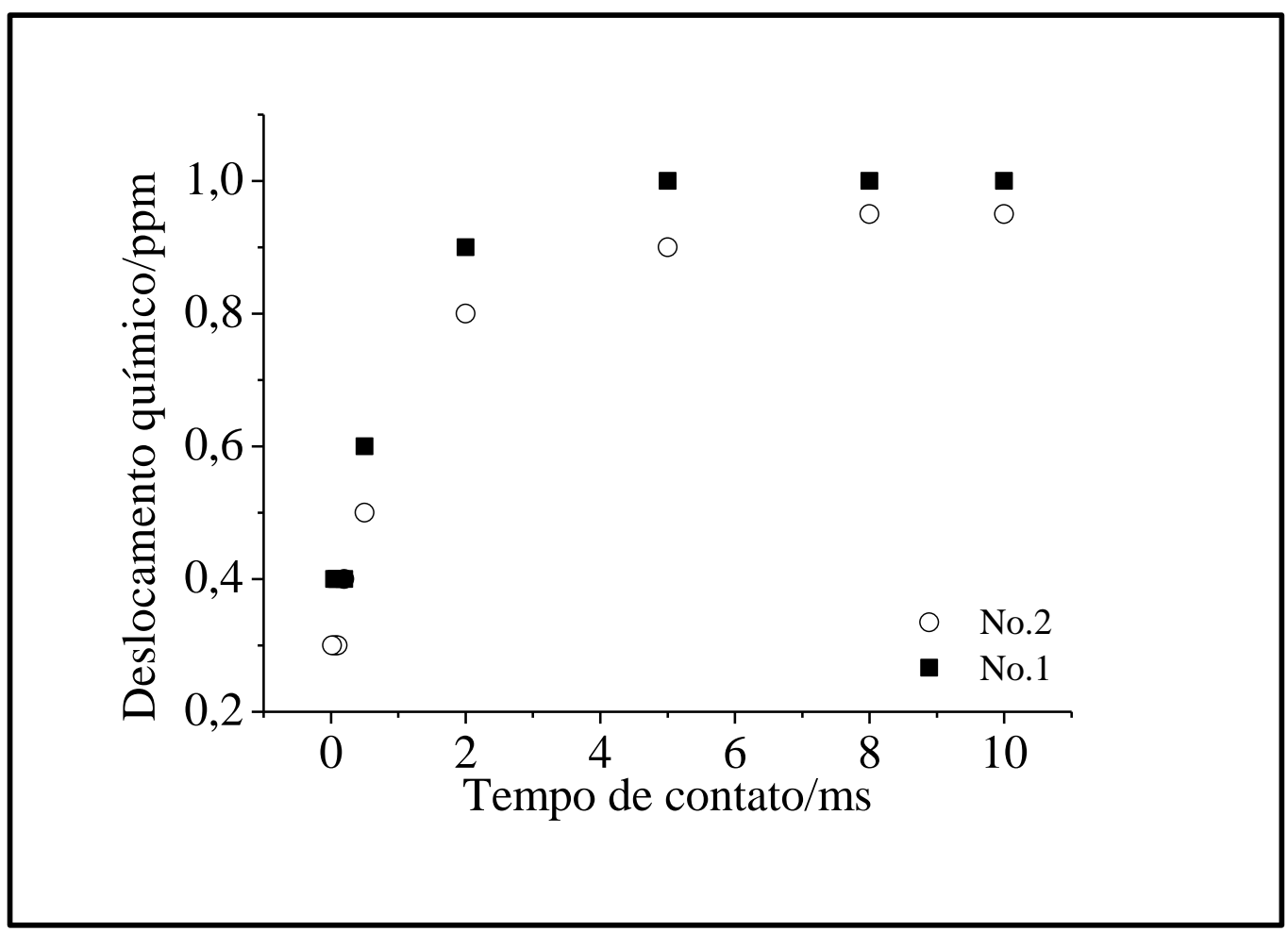

Figura 21- Desvio químico do ${ }^{11} \mathrm{~B}$ observado para as espécies $\mathrm{BO}_{4}$ nos espectros RMNCPMAS ${ }^{19} \mathrm{~F}\left\{{ }^{11} \mathrm{~B}\right\}$ como função do tempo de contato para as amostras No.1 (BPBG15) e No2 (BPBG30)

A partir desses resultados, podemos concluir que a presença do flúor nas unidades $\mathrm{BO}_{3} \mathrm{~F}^{-}$resulta em um sinal de ressonância próximo a 0,3 e $0,4 \mathrm{ppm}$, enquanto que o sinal das unidades dominantes $\mathrm{BO}_{4}{ }^{-}$é observado próximo a 1,0 ppm. Todos esses resultados indicam que - fundamentado nas espécies $\mathrm{BO}_{4}$ ligadas ao flúor - estes vidros, da mesma forma, contém significativas quantidades de espécies $\mathrm{BO}_{4}$ não ligadas ao flúor.

A figura 22 apresenta os espectros de HETCOR 2D ${ }^{19} \mathrm{~F}\left\{{ }^{11} \mathrm{~B}\right\}$ para a amostra BPBG30 observados em diferentes tempos de contato (50 e $200 \mu$ s e 5 ms). O espectro evidência, de maneira impressionante, a correlação das unidades $\mathrm{BO}_{3 / 2} \mathrm{~F}^{-}$com a ressonância do ${ }^{19} \mathrm{~F}$ próximo 
a -110 ppm, mais uma vez confirmando que este sinal pode ser atribuído a espécie flúor ligada ao boro. Resultados similares foram obtidos para um tempo de contato de $200 \mu$ s, enquanto que no tempo de contato de $5 \mathrm{~ms}$ o espetro HETCOR demonstra a participação de espécies ${ }^{19} \mathrm{~F}$ contribuindo para os sinais entre -40 e -60 ppm. Este último resultado mostra que essas espécies fluoretos também são acopladas ao boro via interação dipolar (embora com menos intensidade), consistente com os resultados de $\operatorname{REDOR}{ }^{19} \mathrm{~F}\left\{{ }^{11} \mathrm{~B}\right\}$. Resultados qualitativamente idênticos foram obtidos para o vidro com baixas concentrações de flúor (dados não apresentados).

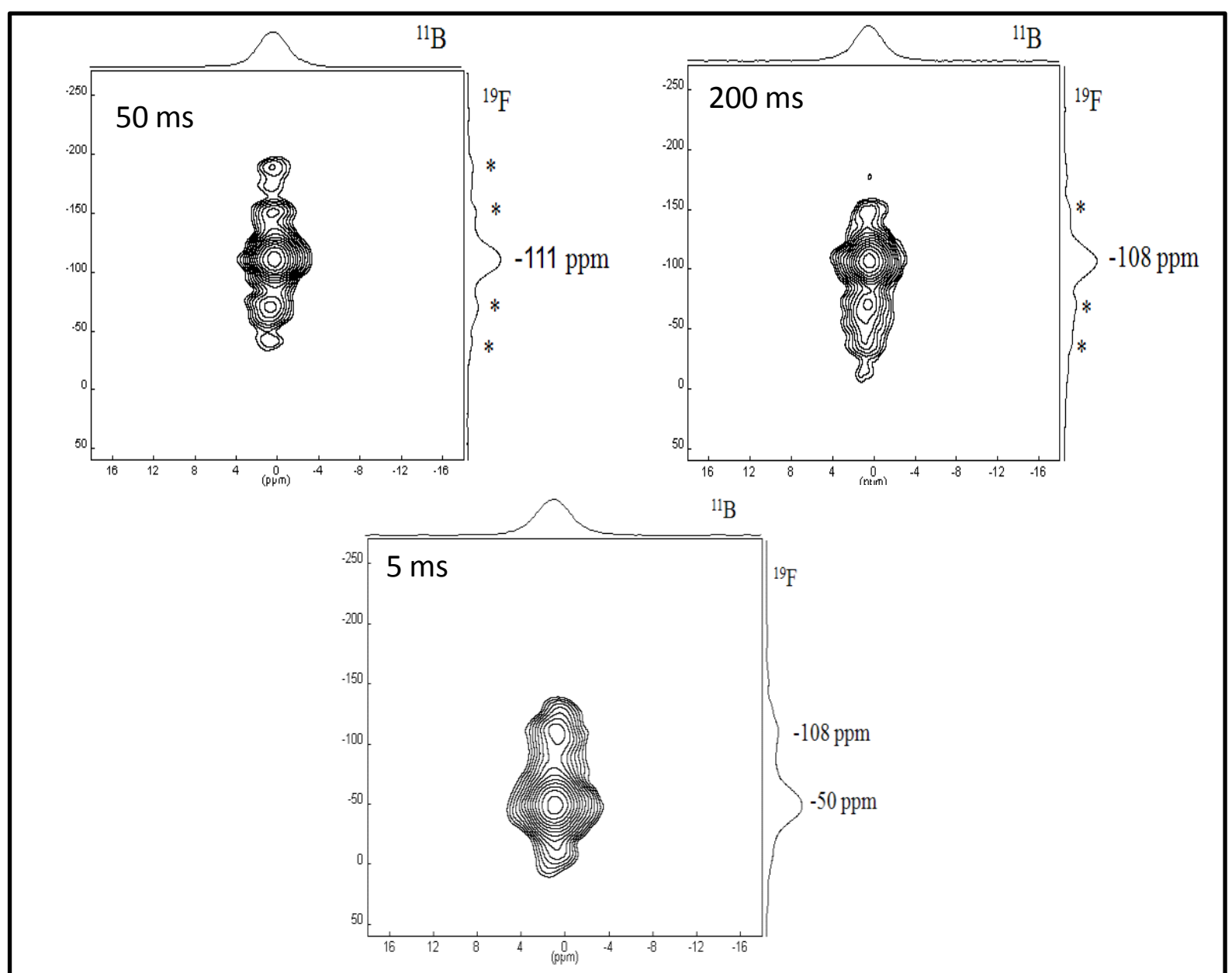

Figura 22- Dados CPMAS 2-D ${ }^{11} \mathrm{~B}\left\{{ }^{19} \mathrm{~F}\right\}$ observado para vidros BPBG30 usando tempo de contato de $50 \mu \mathrm{s}$ (esquerda), $200 \mu \mathrm{s}$ (meio), $5 \mathrm{~ms}$ (direta)

\subsubsection{Espectroscopia por decaimento de eco de spin e efeitos de agregação de íons $\mathrm{F}^{-}$}

Embora os experimentos de RMN de alta resolução tenham sido capazes de identificar diferentes ambientes para os íons flúor, novas perspectivas em sua distribuição espacial podem ser obtidas com base em experimentos sensíveis de acoplamento dipolar magnético 
homonuclear entre os núcleos ${ }^{19} \mathrm{~F}_{-}{ }^{19} \mathrm{~F}$. Neste trabalho, avaliamos este último, tanto sob condições de alta resolução, utilizando um decaimento por ecos de spin (ou eco Hahn) com rotor sincronizado, bem como pela análise do decaimento de ecos de spin em condições estatísticas, em termos do segundo momento dipolar [51]. Na figura 23 sumarizamos os resultados de decaimento de ecos de spin.

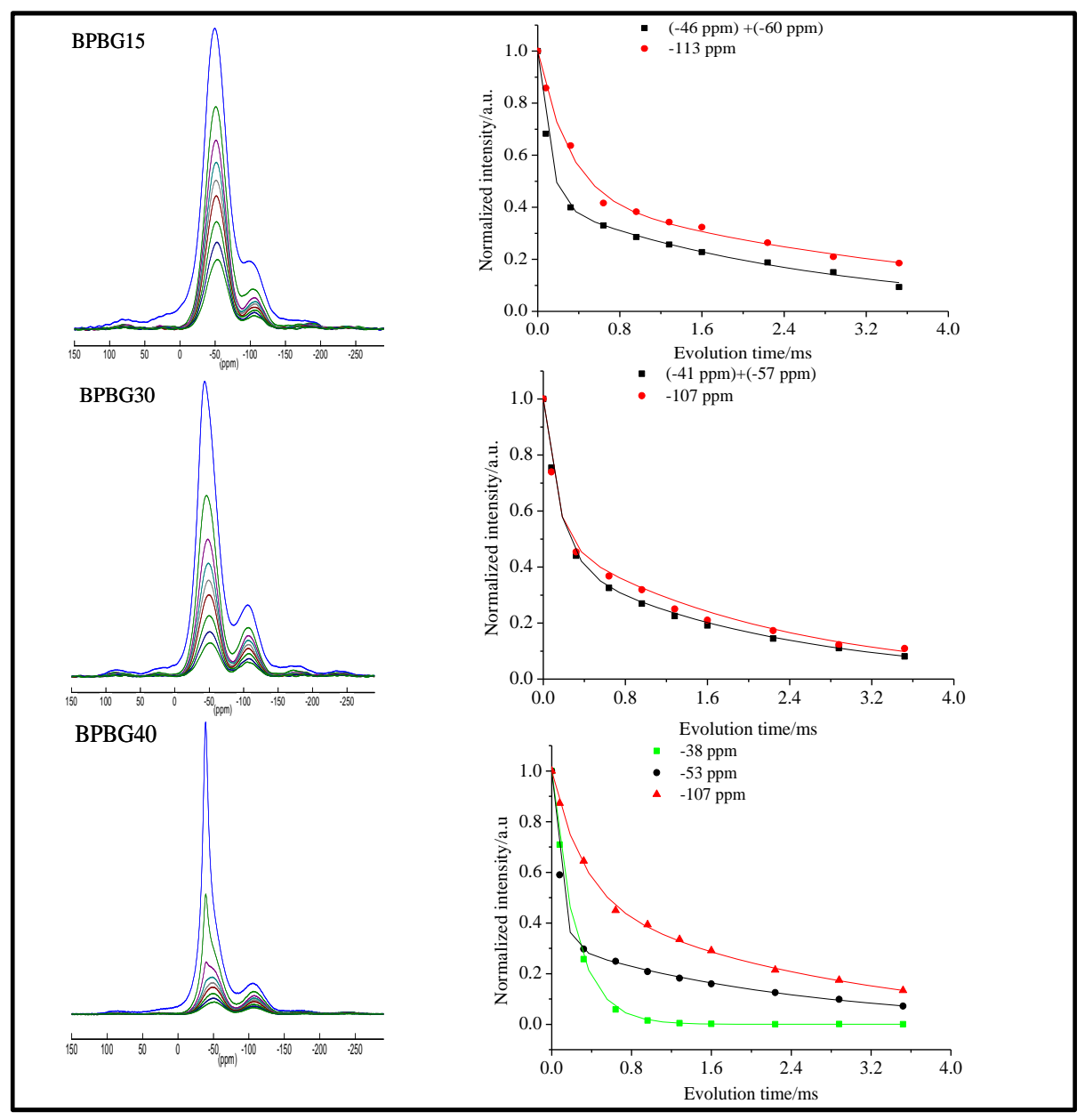

Figura 23- Amplitude do sinal ${ }^{19} \mathrm{~F}$ observado em função do tempo de acoplamento dipolar nos experimentos de ecos de spin em rotor sincronizado, para as diferentes espécies fluoretos nos vidros estudados

No caso mais simples, espera-se que tais experimentos mostrem um decaimento exponencial em função da evolução temporal, permitindo a medida do tempo de relaxação spin-spin $\left(\mathrm{T}_{2}\right)$. De acordo com Cattaneo, et al [20], em materiais rígidos tais valores de $\mathrm{T}_{2}$ são mais fortemente afetados pelas interações magnéticas homonucleares de dipolo-dipolo (aqui, acoplamento $\left.{ }^{19} \mathrm{~F}-{ }^{19} \mathrm{~F}\right)$. 
A figura 23 revela que a tendência do decaimento será bimodal para todas as espécies distintas de fluoretos resolvidas nos espectros de RMN ${ }^{19}$ F PS - MAS. Mais importante ainda, os valores correspondentes de $\mathrm{T}_{2}$ para as espécies fluoretos dominantes, próximos a -40 ppm ( e também aqueles próximos a -60 ppm) não são significativamente menores comparado àquelas espécies que contribuem para o pico próximo a $-110 \mathrm{ppm}$, sugerindo que os íons fluoretos estão bastante "misturados" com outros constituintes do vidro. Como resultado de um amplo deslocamento químico, é provável que as frequências de ressonância entre unidades de ${ }^{19} \mathrm{~F}$ distintas sejam suficientemente diferentes, de modo que a troca de spins homonucleares, termo (B) do Hamiltoniano dipolar, é efetivamente suprimida. Além disso, o termo clássico (A) do Hamiltoniano dipolar parece ser efetivamente suprimido nas rápidas condições de MAS aqui aplicadas, resultando em longos tempos de relaxação spin-spin para todas as diferentes espécies fluoretos observadas. A situação é diferente para amostra com $\mathrm{x}=$ 40, para a qual um forte acoplamento homonuclear dipolo-dipolo entre spins ${ }^{19} \mathrm{~F}$, modulado por MAS, leva a um sinal de decaimento muito mais rápido em função do acoplamento homonuclear dipolar.

Informações mais quantitativas sobre a distribuição de íons fluoretos podem ser obtidas pela espectroscopia de decaimento de ecos de spin, cujos resultados estão resumidos na figura 24 para os vidros contendo 15 e $30 \%$ em mol de $\mathrm{PbF}_{2}$. 


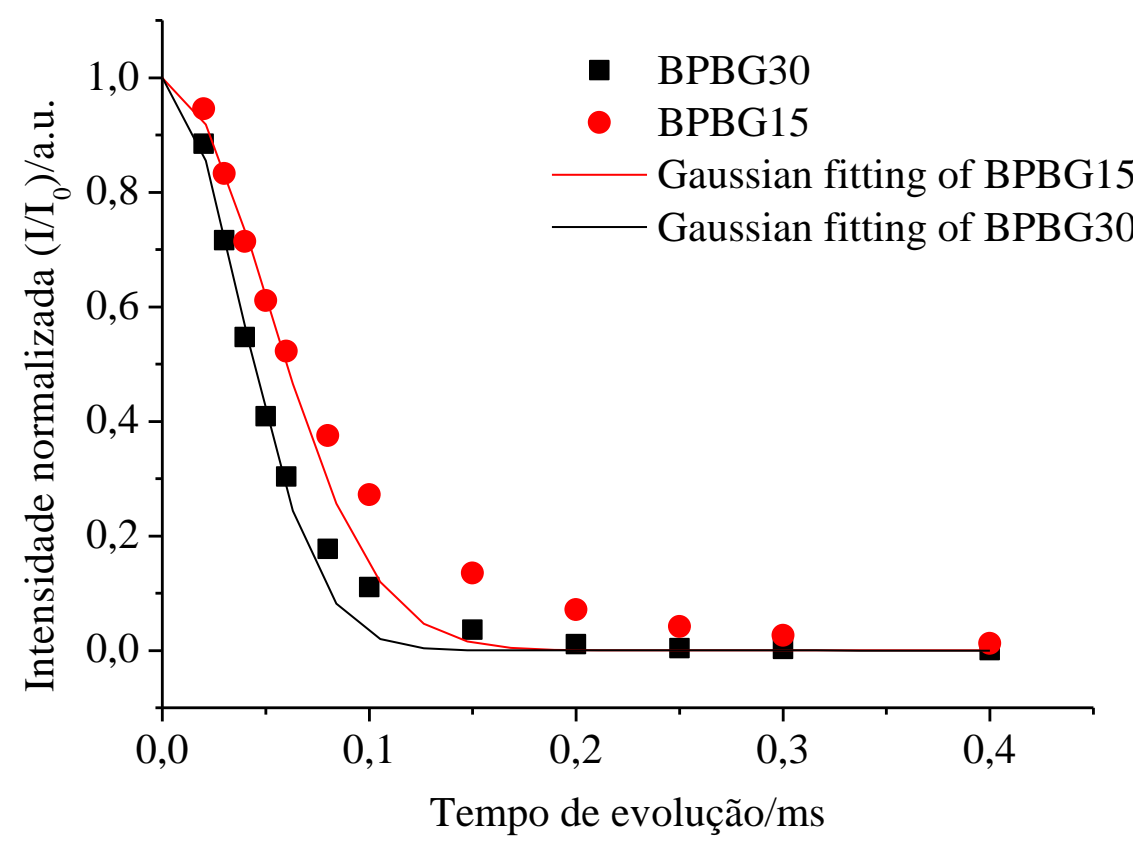

Figura 24- Amplitude ${ }^{19} \mathrm{~F}$ Hahn spin echo sob condições estáticas dos vidros BPBG15 e BPBG30 em função do tempo de acoplamento dipolar

Enquanto que em sistemas cristalinos de vários spins, espera-se que o decaimento de ecos de spin tenha forma gaussiana, como confirmado experimentalmente em vários compostos cristalinos [64], o comportamento em vidros é um pouco diferente. Os dados experimentais frequentemente mostram desvios pronunciados no decaimento da gaussiana. De acordo com [65], esses desvios indicam que uma distribuição do acoplamento magnético homonuclear de dipolo-dipolo $\left({ }^{19} \mathrm{~F}-{ }^{19} \mathrm{~F}\right)$ está presente. Como indicado na figura 24 , tais decaimentos não gaussianos são também evidentes nos presentes vidros fluoroboratos. No entanto, dentro dos limites de curtos tempos de evolução $\left(2 \mathrm{t}_{1} \leq 60 \mu \mathrm{s}\right)$ os dados podem ser ajustados de acordo com um comportamento gaussiano, e os correspondentes valores do segundo momento dipolar, obtidos a partir desses ajustes, estão listados na tabela 10. Os valores obtidos foram comparados com valores calculados para diferentes distribuições atômicos, utilizando a equação de Van Vleck (64).

Usando o pré-fator $4 / 15$ ao invés do valor $3 / 5$ para o acoplamento dipolar homonuclear, a Eq. (64) leva em conta que em materiais desordenados, onde existe uma ampla distribuição de deslocamentos químicos, o termo (B) do Hamiltoniano dipolar homonuclear é usualmente suprimido e somente a contribuição clássica do Hamiltoniano dipolar, termo A, precisa ser considerada [65]. 
Tabela 10- Valores de $\mathrm{M}_{2}\left({ }^{19} \mathrm{~F}-{ }^{19} \mathrm{~F}\right.$ ) previsto (em unidades de $10^{6} \mathrm{rad}^{2} \mathrm{~s}^{2}$ ) para diferentes cenários de íons fluoretos e comparação com os dados experimentais (erro estimado $\mp 10 \%$ )

\begin{tabular}{ccc}
\hline Cenário & BPBG15 & BPBG30 \\
\hline Agregados $\mathrm{PbF}_{2}$ amorfo & 947 & 947 \\
Distribuição espacial aleatória & 148 & 274 \\
Modelo de subdomínios de modificadores & 355 & 596 \\
Valores experimentais & 383 & 707 \\
\hline
\end{tabular}

Um cenário extremo de distribuição atômica nestes vidros, é a formação de domínios amorfos de $\mathrm{PbF}_{2}$. Neste caso, os valores de $\mathrm{M}_{2}$ serão os mesmos para ambos os vidros e próximo aos valores teóricos de $\mathrm{PbF}_{2}$ cristalino, $947 \times 10^{6} \mathrm{rad}^{2} \mathrm{~s}^{-2}$, calculados a partir da distância das ligações F-F dentro de uma rede cristalina de $\alpha-\mathrm{PbF}_{2}$. Os valores de $\mathrm{M}_{2}$ obtidos experimentalmente são significativamente menores e fortemente dependentes da composição, por essa razão a descrição deste domínio para os vidros não é aplicada. Outro cenário restritivo é uma distribuição completamente aleatória de íons fluoretos no espaço. Os valores de $\mathrm{M}_{2}$ previstos para este cenário podem ser estimados com base em um modelo simples da rede $\mathrm{PbF}_{2}$, levando em consideração a contribuição de $\mathrm{F}$ para o inventário total de ânions (oxigênio e flúor) nesses vidros. Como indicado na tabela 10 , os valores de $\mathrm{M}_{2}$ para tal cenário são bem menores que os observados experimentalmente. Portanto, há claras evidências da presença de agregados de íons fluoretos nestes vidros. Finalmente, a tabela 10 também indica os valores estimados de $\mathrm{M}_{2}$ para um cenário de subdomínios de modificadores, em que subdomínios de óxido/fluoretos consistindo somente de modificadores de rede $\mathrm{PbO}$, $\mathrm{PbF}_{2}$ e $\mathrm{Bi}_{2} \mathrm{O}_{3}$ são considerados separadamente, em que os íons fluoretos estão distribuídos aleatoriamente dentro desses subdomínios. Neste caso os átomos de oxigênios do óxido $\mathrm{Bi}_{2} \mathrm{O}_{3}$ foram incluídos no inventário de ânions, uma vez que este óxido já é conhecido como modificador regular em vidros boratos, enquanto que os átomos de oxigênios pertencentes ao elemento $\mathrm{GeO}_{2}$ não foram incluídos, consistente com os resultados experimentais de que este óxidos atua como formador de rede no sistema binário $\mathrm{B}_{2} \mathrm{O}_{3}-\mathrm{GeO}_{2}$. Como apresentado na tabela 10, este modelo, é o que melhor representa os dados experimentais obtidos. 


\section{Conclusões}

Em geral, os resultados deste estudo fornecem compreensão detalhada da estrutura dos vidros fluroboratos do sistema $26,66 \mathrm{~B}_{2} \mathrm{O}_{3}-16 \mathrm{GeO}_{2}-4 \mathrm{Bi}_{2} \mathrm{O}_{3}-(53,33-\mathrm{x}) \mathrm{PbO}-\mathrm{xPbF}$ quando $\mathrm{PbF}_{2}$ é incorporado nestas matrizes cujo principal formador vítreo é o óxido de boro $\left(\mathrm{B}_{2} \mathrm{O}_{3}\right)$. Com base em uma série de aproximações complementares de RMN-MAS dos núcleos ${ }^{19} \mathrm{~F}$ e

${ }^{11} \mathrm{~B}$, um estudo estrutural compreensivo desses vidros foi realizado. Existem claras evidências de que alguns átomos de flúor inseridos na forma de $\mathrm{PbF}_{2}$ participam da rede vítrea, resultando na formação de espécies $\mathrm{BO}_{3 / 2} \mathrm{~F}^{-}$. A partir da integração da área do sinal de ressonância próximo a -110 ppm podemos concluir que aproximadamente $20 \%$ da porção total de flúor esta presente nesta forma, assumindo que (na ausência de informação contrária) nenhuma ligação do flúor em unidades $\mathrm{BO}_{3}$ é formada. Considerando a concentração total de espécies $\mathrm{BO}_{4}$ presente nesses vidros, a análise quantitativa desses espectros mostra que $19 \%$ das unidades $\mathrm{BO}_{4}$ presentes nos vidros contendo $15 \%$ de $\mathrm{PbF}_{2}$ e $43 \%$ das unidades $\mathrm{BO}_{4}$ presentes nos vidros contendo 30 e $40 \%$ de $\mathrm{PbF}_{2}$ estão diretamente ligados aos átomos de $\mathrm{F}$, enquanto que o restante das unidades $\mathrm{BO}_{4}$ estão diretamente ligados ao oxigênio. Esses cálculos são bastante consistentes com os resultados de REDOR ${ }^{11} \mathrm{~B}\left\{{ }^{19} \mathrm{~F}\right\}$, demonstrando que, em média, as forças de acoplamento dipolar entre ${ }^{11} \mathrm{~B}-{ }^{19} \mathrm{~F}$ têm magnitude comparável para as amostras contendo 30 e $40 \%$ de $\mathrm{PbF}_{2}$, mas que são significativamente mais fracas nos vidros com concentração de $15 \%$ de $\mathrm{PbF}_{2}$ (como esperado).

A relação dos valores de $\mathrm{N}_{4}$ e os valores da $\mathrm{T}_{\mathrm{g}}$ também deve ser esclarecida. Eventualmente em vidros boratos contendo flúor livre na rede observa-se um aumento de $\mathrm{N}_{4}$, refletindo diretamente no aumento da conectividade da rede, porém, a correlação oposta é verificada neste trabalho. Esses resultados podem ser relacionados pelo fato que as unidades $\mathrm{BO}_{3 / 2} \mathrm{~F}$ em vidros oxifluoretos são do tipo não ligante e, portanto, a sua presença não aumenta a conectividade das redes boratos. Levando em consideração a concentração das unidades $\mathrm{BO}_{3 / 2} \mathrm{~F}$ e assumindo-as apenas como espécies boratos tricoordenadas, a fração $\mathrm{N}_{4}$ de todos os oxigênios ligados a espécies $\mathrm{BO}_{4}$ pode ser recalculada como $46 \%$ e $34 \%$ em vidros contendo 15 e $30 \%$ em mol de $\mathrm{PbF}_{2}$, respectivamente, o que está qualitativamente em melhor acordo com a correlação esperada $\mathrm{T}_{\mathrm{g}}$ com conectividade da rede.

Finalmente, a maioria dos íons de flúor é encontrada em um ambiente dominado por chumbo. Esta situação implica, automaticamente, em certo grau de agregação de íons de flúor, consistente com os resultados de decaimento de ecos de spin. Enquanto todos os dados de 
RMN descartam a formação de $\mathrm{PbF}_{2}$ amorfo, na forma de microdomínios, os dados de decaimento de ecos de spin são quantitativamente consistentes com um modelo em que o componente $\mathrm{PbF}_{2}$ está presente dentro de um subdomínio que inclui os componentes modificadores de rede $\mathrm{PbF}_{2}, \mathrm{PbO}_{\text {e }} \mathrm{Bi}_{2} \mathrm{O}_{3}$. Este modelo é consistente com o conceito de escala atômica de uma mistura de espécies formadoras e espécies modificadoras de rede (como sugerido pelas técnicas REDOR e dados de CP). Também é consistente com o arranjo não aleatório e com a tendência de agrupamento dos íons de flúor sugerido pelo deslocamento químico dos espectros de RMN ${ }^{19} \mathrm{~F}$ PS - MAS, indicando que a maioria dos íons de flúor são encontrados em um ambiente dominado pelo chumbo. 


\section{Referências}

1 KNOBLOCHOVA, K. et al. (2009). Raman spectra and optical properties of selected $\mathrm{Bi}_{2} \mathrm{O}_{3}-\mathrm{PbO}-\mathrm{B}_{2} \mathrm{O}_{3}-\mathrm{GeO}_{2}$ glasses. Optical Materials, Amsterdam, v. 31, n. 6 ,p. 895-898.

2 REYNOSO, V. C. S. et al. (1994). Preparation and characterization of heavy-metal oxide glasses: $\mathrm{Bi}_{2} \mathrm{O}_{3}-\mathrm{PbO}-\mathrm{B}_{2} \mathrm{O}_{3}-\mathrm{GeO}_{2}$ System. Journal of Materials Chemistry, London, v. 4, $\mathrm{n}$. 4, p. 529-532.

3 KIRK, S. E. V.; MARTIN, S. W. (1992). Preparation and characterization of high-density $\mathrm{PbO}-\mathrm{Bi}_{2} \mathrm{O}_{3}-\mathrm{B}_{2} \mathrm{O}_{3}$ Glasses. Journal of the American Ceramic Society, Malden, v. 75, n. 4, p. $1028-1031$.

4 KOTKOVA, K.; TICHA, H.; TICHY, L. (2008). Raman studies and optical properties of some $(\mathrm{PbO})_{x}\left(\mathrm{Bi}_{2} \mathrm{O}_{3}\right)_{0.2}\left(\mathrm{~B}_{2} \mathrm{O}_{3}\right)_{0.8-x}$ glasses. Journal of Raman Spectroscopy, Malden, v. 39, n. 9 , p. $1219-1226$.

5 BABU, P.; JAYASANKAR, C. K. (2001). Spectroscopy of $\operatorname{Pr}^{3+}$ ions in lithium borate and lithium fluoroborate glasses. Physica B, Amsterdam, v. 301, n. 3-4, p. 326-340.

6 KASSAB, L. R. P. et al. (2002). Spectroscopic properties of lead fluoroborate glasses codoped with $\mathrm{Er}^{3+}$ and $\mathrm{Yb}^{3+}$. Journal of the Optical Society of America B, Washington, v. 19 , n. 12, p. 2921-2926.

7 PISARSKI, W. A.; PISARSKI, J. (2006). Thermal, structural and optical properties of erbium doped oxyfluoride lead borate glasses. Glass Technology - European Journal of Glass Science and Technology Part A, v. 47, n. 6, p. 159-163.

8 PISARSKI, W. A. et al (2007). Er-Doped lead borate glasses and transparent glass ceramics for near-infrared luminescence and up-conversion applications. The Journal of Physical Chemistry B, Evanston, v. 111, n. 10, p. 2427-2430.

9 PISARSKI, W. A. et al. (2011). Rare earth-doped lead borate glasses and transparent glassceramics: structure-property relationship. Spectrochimica Acta A: Molecular and Biomolecular Spectroscopy, Amsterdam, v. 79, n. 4, p. 696-700.

10 GRESSLER, C. A.; SHELBY, J. E. (1988). Lead fluoroborate glasses. Journal of Applied Physics, Argonne, v. 64, n. 9, p. 4450-4453. 
11 GRESSLER, C. A.; SHELBY, J. E. (1989). Properties and structure of $\mathrm{PbO}-\mathrm{PbF}_{2}-\mathrm{B}_{2} \mathrm{O}_{3}$ glasses. Journal of Applied Physics, Argonne, v. 66, n. 3, p. 1127-1131.

12 M'PEKO, J. et al. (2008). Fluoride-modified electrical properties of lead borate glasses and electrochemically induced crystallization in the glassy state. Journal of Applied Physics, Argonne, v. 103, n. 4, p. 044908-(1-10).

13 TEKE, M.; CHADWICK, A.V. (1997). Ionic transport in fluoroborate glasses. Material Science Forum, Amsterdam, v. 239-241, p. 421-424, doi: 10.4028.

14 SOKOLOV, I. A. et al. (2002). Electrical properties and the structure of halogencontaining lead borate glasses: $\mathrm{I}$. The $\mathrm{PbF}_{2}-2 \mathrm{PbO} \cdot \mathrm{B}_{2} \mathrm{O}_{3}$ system. Glass Physics and Chemistry, New York, v. 28, N. 5, p. 296-302.

15 SOUZA FILHO, A. G. et al. (1999). Raman spectroscopy study of high $\mathrm{b}_{2} \mathrm{O}_{3}$ content lead fluoroborate glasses. Journal of Raman Spectroscopy, Malden, v. 30, n. 7, p. 525-529.

16 PAN, Z.; HENDERSON, D. O.; MORGAN, S. H. (1999). A raman investigation of lead haloborate glasses. Journal of Applied Physics, Argonne, v. 101, n. 3, p. 1767-1774.

17 GOPALAKRISHNAN, R. et al. (1994). X-ray photoelectron spectroscopy and ionic transport studies on lead i fluoroborate glasses. Journal of Physics D: Applied Physics, Philadelphia, v. 27, n. 12, p. 2612-2618.

18 ECKERT, H. (1992). Structural characterization of noncrystalline solids and glasses using solid state NMR. Progress in NMR Spectroscopy, Amsterdam, V. 24, n. 3, p. 159-293.

19 KLINOWSKI, J. (2005). New Techniques in Solid-State NMR. New York: Springer, $246 \mathrm{v}$.

20 CATTANEO, A. S. et al. (2008). Structural role of fluoride in the ion-conducting glass system $\mathrm{b}_{2} \mathrm{O}_{3}$-pbo-lif studied by single- and double-resonance NMR. The Journal of Physical Chemistry C, Evanston, v. 112, n. 28, p. 10462-10471.

21 GEISSBERGER, A.E.; BUCHOLTZ, F.; BRAY, P.J. (1982). ${ }^{7} \mathrm{Li},{ }^{11} \mathrm{~B}$ And ${ }^{19} \mathrm{~F}$ NMR In Amorphous Alkali Halogen Borate Solid Ionic Conductors. Journal of Non-Crystalline Solids, Amsterdam, v. 49, n. 1-3, p. 117-127.

22 AKERMAN, M. (2000). Natureza, estrutura e propriedades do vidro. CETEV. 
23 DOREMUS, R. H. (1994). Glass science. 2. ed. Toronto: Wiley.

24 DE ARAUJO, E. B. (1997). Vidro: uma breve história, técnicas de caracterização e aplicações na tecnologia. Revista Brasileira de Ensino de Física, Porto Alegre, v. 19, n. 3, 325- 329.

25 SHELBY, J. E. (2005). Introduction to glass science and technology. 2. ed. Cambridge: The Royal Society of chemistry.

26 VARSHNEYA, A. K. (1993). Fundamental of inorganic glasses. New York: Academica Press.

27 AVRAMOV, I.; ZANOTTO, E. D.; PRADO, M. O. (2003). Glass-Forming ability versus stability of silicate glasses. II. Theoretical Demonstration. Journal of Non-Crystalline Solids, Amsterdam, v. 320, n. 1-3,p. 9-20.

28 ZACHARMSEN, W. H. (1932). The atomic arrangement in glass. Ryerson Physical Laboratory, Chicago, v. 54, p 3841-3851.

29 KROGH-MOE, J. (1965). Least squares refinement of the crystal structure of potassium pentaborate. Acta Crystallographica, Chester, V. 18, n. 6, p. 1088-1089.

30 KROGH-MOE, J. (1972). The crystal structure of a sodium triborate modification, ${ }^{\beta}$ $\mathrm{Na}_{2} \mathrm{O}_{3} \mathrm{~B}_{2} \mathrm{O}_{3}$. Acta Crystallographica Section B, Chester, V. 28, n. 5, p. 1571-1576.

31 KROGH-MOE, J. (1972). The crystal structure of potassium diborate, $\mathrm{K}_{2} \mathrm{O} \cdot 2 \mathrm{~B}_{2} \mathrm{O}_{3}$. Acta Crystallographica Section B, Chester, V. 28, n. 10, p. 3089-3093.

32 KROGH-MOE, J. (1972). The crystal structure of the high-temperature modification of potassium pentaborate. Acta Crystallographica Section B, Chester, V. 28, n. 1, p. 168-172.

33. KIRK, S. E. V.; MARTIN, S.W. (1992). Preparation and characterization of high-density $\left.\mathrm{PbO}-\mathrm{Bi}_{2}\right)_{3}-\mathrm{B}_{2} \mathrm{O}_{3}-\mathrm{B}_{2} \mathrm{O}_{3}$ glasses. Journal of American Ceramic Society, Malden, v. 75, n. 4, p. 1028-1031.

34 BUENO, L. A. (2003). Vidros e Vitrocerâmicas em Sistemas Oxifluoretos. 225 f. Tese (Doutorado) - Instituto de Química de Araraquara, Universidade Estadual Paulista, Araraquara, 2003. 
35 DE SOUZA, J. E. (2010). Cristalização Induzida Eletroquimicamente em Vidros $\mathbf{B}_{2} \mathrm{O}_{3}-\mathrm{PbO}-\mathrm{PbF}_{2}$ Abaixo da Temperatura de Transição Vítrea. $166 \mathrm{f}$. Dissertação

(Mestrado) - Instituto de Física de São Carlos, Universidade de São Paulo, São Carlos, 2010.

36 WANG, Y. (1989). x-ray photoelectron spectroscopy study of lead fluoroborate glasses. Journal of Materials Science Latters, New York, V. 8, N. 10, p. 421-423.

37 CHOWDARI, B.V.R.; RONG, Z. (1995). Study of the fluorinated lithium borate glasses. Solid State Ionics, Amsterdam, v. 78, n. 1-2, p. 133-142.

38 DOWEIDAR, H.; EL-DAMRAWI, G.; ABDELGHANY, M. (2012). Structure and properties of $\mathrm{CaF}_{2}-\mathrm{B}_{2} \mathrm{O}_{3}$ glasses. Journal of Materials Science, New York, v. 47, n. 9, p. 4028-4035.

39 SHELBY J.E.; BAKER L.D. (1998). Alkali fluoroborate glasses. Physics and Chemistry of Glasses - European Journal of Glass Science and Technology Part B, v. 39, n. 1, p. 2328.

40 SOUTO, S. et al. (1999). Density and ultrasonic velocities in fast ionic conducting borate glasses. Materials Science and Engineering, Amsterdam, v. 64, n. 1, p. 33-38.

41 BORISOV, A. S.; HAZENDONK, P.; HAYES, P. G. (2010). Solid-State nuclear magnetic resonance spectroscopy: a review of modern techniques and applications for inorganic polymers. Journal of Inorganic and Organometallic Polymers, New York, v. 20, n. 2, p. 183-212.

42 MARICQ, M. M.; WAUGH, J. S. (1979). NMR in rotating solids. The Journal of Chemical Physics, Argonne, v. 70, n. 7, p. 3300-3316.

43 U. HAEBERLEN, U.; WAUGH, I. S. (1968). Coherent averaging effects in magnetic resonance. Physical Review, New York, v. 175, n. 2, p. 175-190.

44 DUER, M. J. (2002). Solid-State NMR Spectroscopy: Principles and Applications. Cambridge.

45 AMOUREUX, J. P.; FERNANDEZ, C. (1998). Triple, quintuple and higher order multiple quantum mas nmr of quadrupolar nuclei. Solid State Nuclear Magnetic Resonance, Amsterdam, v. 10, n. 4, p. 211-223.

46 GULLION, T. (1998). Introduction to rotational-echo, double-resonance NMR. Concepts in Magnetic Resonance, v. 10, n. 5, p. 277-289. 
47 DETERS, H. (2008). Structural examination of yttrium aluminoborate laser glasses. Diploma Thesis in Chemistry, Institut für Physikalische Chemie Westfälische WilhelmsUniversität Münster.

48 NAITO, A. et al. (1994). Inter- and Intra-Molecular Contributions of Neighboring Dipolar Pairs to the Precise Determination of Interatomic Distances in a Simple $\left[{ }^{13} \mathrm{C},{ }^{15} \mathrm{~N}\right]-$ Peptide by ${ }^{13} \mathrm{C},{ }^{15} \mathrm{~N}-$ REDOR NMR Spectroscopy. Chemical Physics Letters, Amsterdam, v. 229, n. 5, p. 506-5 11 .

49 WIILLEN, L.; ZIICHNER, L.; MILLER-WARMUTH, W.; ECKERT, H. (1996).

${ }^{11} \mathrm{~B}\left\{{ }^{27} \mathrm{Al}\right\}$ and ${ }^{27} \mathrm{~A} 1\left\{{ }^{11} \mathrm{~B}\right\}$ Double resonance experiments on a glassy sodium aluminoborate. Solid State Nuclear Magnetic Resonance, Amsterdam, v. 6, n. 3, p. 203-212.

50 HAHN, E. L. (1950). Spin Echoes. Physical Review, New York, v. 80, N. 4, p. 580-594.

51 LATHROP, D.; ECKERT, H. (1989). Structural models for non-oxide chalcogenide glasses. atomic distribution and local order in the system phosphorus-selenium studied by $31 \mathrm{p}$ dipolar nmr spectroscopy. Journal of the American Chemical Society, Philadelphia, v. 111, n. 10 , p. $3536-3541$.

52 GULLION, T. SCHAEFER, J. (1969). Rotational-Echo double-resonance NMR. Journal of Magnetic Resonance, Amsterdam, v. 81. n. 1, p. 196-200.

53 MEERA, B.N. et al. (1990). Raman study of lead borate glasses. Journal of NonCrystalhne Solids, Amsterdam, v. 126, n. 3, p. 224-230.

54 PISARSKI, W.A. et al. (2006). Europium-doped lead fluoroborate glasses: structural, thermal and optical investigations. Journal of Molecular Structure, Amsterdam, v. 792793, p. 207-211.

55 LINES, M.E. (1987). Absolute raman intensities in glasses I. Theory. Journal of NonCrystalline Solids, Amsterdam, v. 89, n. 1-2, p. 143-162.

56 FAN, H. et al. (2010). Infrared, Raman and XPS Spectroscopic Studies of $\mathrm{Bi}_{2} \mathrm{O}_{3}-\mathrm{B}_{2} \mathrm{O}_{3}-$ $\mathrm{GeO}_{2}$ Glasses. Solid State Sciences, Amsterdam, v. 12, n. 4, p. 541-545.

57 MIHAILOVA, B.; GOSPODINOV, M.; KONSTANTINOV, L. (1999). Raman spectroscopy study of sillenites. i. comparison between $\mathrm{bi}_{12}(\mathrm{si}, \mathrm{mn}) \mathrm{o}_{20}$ single crystals. Journal of Physics and Chemistry of Solids, Amsterdam, v. 60,n. 11, p. 1821-1827. 
58 KHARLAMOV, A. A.; ALMEIDA, R. M.; HEO, J. (1996). Vibrational spectra and structure of heavy metal oxide glasses. Journal of Non-Crystalline Solids, Amsterdam, v. 202, n. 3, p. 233-240.

59 BAIA, L. et al. (2001). Raman and ir spectroscopy studies of manganese doped $\mathrm{GeO}_{2-}$ $\mathrm{Bi}_{2} \mathrm{O}_{3}$ glasses. Journal of Molecular Structure, Amsterdam, v. 599, n. 1-3, p. 9-13.

60 KAMITSOS, E. I. et al. (1996). Raman and infrared structural investigation of $\mathrm{xRb}_{2} \mathrm{O}(1-$ $\mathrm{x}) \mathrm{GeO}_{2}$ glasses. The Journal of Physical Chemistry, Evanston, v. 100, n. 28, p. 1175511765 .

61 SHARMA, G. et al. (2006). Effects of gamma irradiation on optical and structural Properties of $\mathrm{PbO}-\mathrm{Bi}_{2} \mathrm{O}_{3}-\mathrm{B}_{2} \mathrm{O}_{3}$ glasses. Radiation Physics and Chemistry, Amsterdam, v. 75, n. 9, p. 959-966.

62 MARTIN, M. et al. (2011). Aspects of the photoelastic response in lead borate glasses. Journal of Non-Crystalline Solids, Amsterdam, v. 357, n. 1, p. 2120-2125.

63 VEGA, A. J. (1992). CP/MAS of Quadrupolar S = 3/2 Nuclei. Solid State Nuclear Magnetic Resonance, Amsterdam, v. 1, n. 1, p. 17-32.

64 LATHROP, D. et al. (1992). Dipolar ${ }^{31}$ P NMR Spectroscopy of Crystalline Inorganic Phosphorus Compounds. Solid State Nuclear Mugnetic Resonance, Amsterdam, v. 1, n. 2, p. 73-83.

65 FRANKE, D. et al. (1991). Structural Models for Covalent Non-Oxidic Glasses. Atomic Distribution and Local Order in Glassy CdGePz Studied by ${ }^{31} \mathrm{P}$ and ${ }^{113} \mathrm{Cd}$ MAS and SpinEcho and ${ }^{31} \mathrm{P}^{113} \mathrm{Cd}$ Spin-Echo Double Resonance NMR Spectroscopy. Journal of the American Chemical Society, Philadelphia, v. 113, n. 13, p. 4822- 4830. 